\title{
Molekularzytogenetische Charakterisierung von Plattenepithelkarzinomen des Kopf-Hals-Bereiches
}

\section{HABILITATIONSSCHRIFT}

zur Erlangung der Lehrbefähigung für das Fach

\section{Hals-Nasen-Ohrenheilkunde}

\author{
vorgelegt dem Fakultätsrat der Medizinischen Fakultät Charité \\ der Humboldt-Universität zu Berlin
}

von

Frau Dr. med. Ulrike Bockmühl

geboren am 05.07.1963 in Berlin

Präsident: $\quad$ Prof. Dr. Dr. h.c. H. Meyer

Dekan: $\quad$ Prof. Dr. med. M. Dietel

eingereicht am 20. Oktober 1998

Gutachter:

1. Prof. Dr. M. Dietel

2. Prof. Dr. H. Glanz

3. Prof. Dr. J. Werner 


\section{INHALTSVERZEICHNIS}

1. EINLEITUNG 4

1.1. Epidemiologie von Kopf-Hals-Karzinomen 4

1.2. Molekulargenetische Basis der Karzinogenese 5

1.3. Molekulargenetische und -zytogenetische Befunde bei 6

Plattenepithelkarzinomen des Kopf-Hals-Bereiches

2. FRAGESTELLUNG 9

3. MATERIAL UND METHODEN 10

$\begin{array}{ll}\text { 3.1. Tumormaterial } & 10\end{array}$

3.2. Vergleichende Genomische Hybridisierung (CGH) 10

3.3. Verlust der Heterozygotie (LOH) 20

3.4. Immunhistochemische Untersuchungen 22

3.5. Etablierung von Zellinien 22

3.6. Statistische Auswertung 23

4. ERGEBNISSE 24

4.1. Genetische Charakterisierung der Plattenepithelkarzinome des 24 Kopf-Hals-Bereiches als Tumorentität

4.2. Vergleich Primärtumor und korrespondierende Zellinie 30

4.3. Vergleich Primärtumor und Lymphknotenmetastase 34

4.4. Vergleich metastasierender und nicht metastasierender Karzinome 37

4.5. Vergleich von Karzinomen unterschiedlicher Differenzierung $\quad 40$

4.6. Vergleich Primärtumor und Zweitkarzinom 42

4.7. Überlebensstatistik 45 
5. DISKUSSION 51

5.1. Charakteristische genetische Alterationen der Tumorentität 52

5.2. Genetische Unterschiede zwischen Tumorsubgruppen 55

$\begin{array}{lll}\text { 5.3. Klonalitätsbestimmung } & 60\end{array}$

6. ZUSAMMENFASSUNG 64

$\begin{array}{lll}\text { 7. LITERATURVERZEICHNIS } & 67\end{array}$

8. ABKÜRZUNGSVERZEICHNIS 75

9. TABELLARISCHER ANHANG 76 


\section{EINLEITUNG}

\subsection{Epidemiologie der Kopf-Hals-Karzinome}

Maligne Tumoren des Kopf-Hals-Bereiches stehen an 6. Stelle der Häufigkeit aller Krebserkrankungen. Die International Agency for Research on Cancer (IARC) gibt die Anzahl von Neuerkrankungen an malignen Tumoren in der Bundesrepublik Deutschland für 1990 mit 315584 Fällen an. Darunter beträgt die Häufigkeit der Kopf-Hals-Karzinome bei Männern ca. 8\% und bei Frauen ca. 1,5\%. Die Mortalität dieser Malignome ist für 1990 mit ca. 5\% bei der männlichen bzw. 1\% bei der weiblichen deutschen Bevölkerung angegeben (Black et al. 1997). Im Vergleich zu 1985 ist geschlechtsunabhängig sowohl die Inzidenz als auch die Mortalität an Pharynxkarzinomen angestiegen gegenüber unveränderten Daten für Larynxkarzinome (http://www-dep.iarc.fr). Altersgipfel für Neuerkrankungen an Mundhöhlen- und Kehlkopfkarzinomen liegen in der 6 . Dekade, für Pharynxmalignome im 7. Lebensjahrzehnt (Jahnke 1995; Rudert 1995). Hochsignifikante ätiologische Faktoren sind Nikotin- und Alkoholabusus.

Die malignen Tumoren des oberen Aerodigestivtraktes sind zu ca. 95\% Plattenepithelkarzinome. Trotz der grundsätzlich ähnlichen Morphologie ist ihr biologisches Verhalten im Einzelfall stark unterschiedlich. Die Prognose unterscheidet sich schon abhängig vom Sitz des Primärtumors. So liegt die 5Jahres-Überlebensrate z.B. bei Oropharynxkarzinomen in Abhängigkeit vom Tumorstadium zwischen 15 und 60\% (Rudert 1995; Schantz et al., 1997) gegenüber 65 und 100\% bei glottischen Larynxkarzinomen (Jahnke 1995; Sessions et al., 1997). Metastasierung und Prognose können aber auch bei gleicher Lokalisation und gleichem Stadium des Primärtumors sehr differieren. Darüberhinaus wird bei diesen Malignomen ein unterschiedliches Ansprechen auf Radio- und/oder Chemotherapie beobachted (Frommhold 1995; Schalhorn 1995). Und nicht zuletzt lassen sich bei bis zu 10\% der Patienten syn- oder metachrone Zweitkarzinome feststellen (Gluckman et al., 1980; Bedi et al., 1996). Trotz verbesserter Diagnose- und Therapiestrategien konnte die Prognose der KopfHals-Karzinome in der letzten Dekade nicht wesentlich verbessert werden. 


\subsection{Molekulargenetische Basis der Karzinogenese}

Bereits 1890 beobachtete von Hansemann, daß Tumorzellen sehr häufig atypische Mitosen aufweisen und assoziierte dieses Phänomen mit der Karzinogenese (von Hansemann 1890). Boveri war es dann, der als erster chromosomale Veränderungen im Rahmen der Tumorentstehung vermutete und 1914 eine "Chromosomentheorie über den Ursprung des Krebses" veröffentlichte (Boveri 1914). Nachdem 1956 die Darstellung menschlicher Chromosomen gelang (Tjio \& Levan 1956), fanden Nowell \& Hungerford 1960 die erste spezifische Aberration für einen neoplastischen Prozeß, das Philadelphia-Chromosom bei der chronischen myeloischen Leukämie (Nowell \& Hungerford 1960). 1969 konnten Huebner und Todaro zeigen, daß die Aktivierung spezifischer Gene zu einer malignen Zelltransformation führen kann und bezeichneten sie als Onkogene (Huebner \& Todaro 1969). Das Klonalitätsprinzip, d.h. das sich jeder Tumor aus nur einer Vorläuferzelle entwickelt, wurde erstmals 1976 von Nowell postuliert (Nowell 1976).

Nach heutigem Wissen geht man davon aus, daß die maligne Transformation über eine Akkumulation mehrerer genetischer Veränderungen erfolgt. Dieser Stufenprozeß wird durch Defekte in speziellen Genen, den Proto-Onkogenen und den Tumorsuppressorgenen (TSG) wie auch den DNA-Reparatur-Genen ausgelöst. Proto-Onkogene kodieren Proteine, die die Zellteilung und das Wachstum unterstützen, TSG verschlüsseln solche, die es unterdrücken. Beide Genklassen sind normale Bestandteile im menschlichen Genom, und ihr Zusammenwirken im Zellzyklus ist ausgewogen. Infolge genetischer Alterationen können jedoch TSG inaktiviert und Proto-Onkogene zu karzinogenen Onkogenen verändert werden, was dann letztlich zu einer unkontrollierten Zellproliferation führen kann. Ein Proto-Onkogen wird aktiviert, wenn es durch eine Punktmutation, eine Translokation oder Inversion von chromosomalen Abschnitten oder eine Amplifikation eine neue bzw. zusätzliche Funktion erhält, die zur Transformation gesunder Zellen führt (Rabbitts 1994). Für die Initiation der Tumorentstehung ist die somatische Mutation in einem Allel des ProtoOnkogens ausreichend, d.h. sie wirkt dominant. Die Inaktivierung von TSG hingegen erfolgt über einen Funktionsverlust beider Allele, z.B. durch den Verlust eines Allels und die gleichzeitige Mutation bzw. Methylierung in der 
komplementären Sequenz. Damit wirken TSG rezessiv. Lokalisation und Isolierung dieser Gene sind sowohl für die Aufklärung der Ätiologie als auch der Progression von malignen Tumoren unerläßlich und eröffnen neue Wege in der Diagnostik sowie hinsichtlich einer spezifischen Tumortherapie.

\subsection{Molekulargenetische und -zytogenetische Befunde bei Plattenepithelkarzinomen des Kopf-Hals-Bereiches}

Die Karyotypen von Kopf-Hals-Karzinomen sind oft außerordentlich komplex und zeigen sowohl sehr viele strukturelle als auch numerische Aberrationen. Ein Verlust genetischen Materials wurde bei dieser Tumorentität häufig für die Chromosomen 3p, 5q, 8p, 9p, 18q und 21q beschrieben, während ein DNAGewinn bei 3q, 5p, 7p, 8q und 11q13 feststellt wurde (Carey et al., 1993; Jin et al., 1993; Jin et al., 1995; Mertens et al., 1997; van Dyke et al., 1994). Häufige Bruchpunkte als Ausgangspunkt struktureller Aberrationen wurden bei den chromosomalen Banden 1p22, 3p11-q11, 5q13, 8q10, 11q13 und 15q10 gefunden (Jin et al., 1993; Jin et al., 1995; Mertens et al., 1997). In ca. der Hälfte der Fälle zeigte sich dabei die Ausbildung sog. Isochromosomen (Jin et al., 1993; Jin et al., 1995). Für die Bruchpunkte bei 1p22, 3p21, 8p11 und distal 14q wurde eine Assoziation mit einer geringeren Radiosensitivität der Kopf-Hals-Karzinome festgestellt. Rearrangements der chromosomalen Bande 11q13 traten oft als sog. homogeneously stained regions (hsr) auf (Jin et al., 1993; Jin et al., 1995; Mertens et al., 1997). Åkervall et al. (1995) fanden, daß Patienten, deren Tumoren Veränderungen bei 11q13 aufwiesen, ein signifikant schlechteres Überleben hatten. Interessanterweise konnten in diesem Bereich die Onkogene INT2, HST1 sowie Cyclin D1 lokalisiert werden. Als prognostisch ungünstiger wurden weiterhin der Verlust von Chromosom 18q und Tumoren mit komplexen Karyotypen gegenüber Karzinomen mit rein numerischen oder einfachen strukturellen Aberrationen beschrieben (Jin et al., 1995).

Aufgrund des schlechten Zuganges $\mathrm{zu}$ teilungsfähigen Zellen ist die zytogenetische Diagnostik solider Tumoren wesentlich erschwert. Zudem setzen sich epitheliale Tumoren meist aus vielen Klonen zusammen, deren unterschiedliches Wachstumsverhalten die Zellkultur bestimmt und damit die 
praktische Wertigkeit der zytogenetischen Charakterisierung einschränkt. Im Vergleich dazu bieten inzwischen molekulargenetische und -zytogenetische Methoden bessere Möglichkeiten, das Tumorgenom zu untersuchen.

Mit Hilfe der Analyse des Heterozygotieverlustes ("loss of heterozygosity", LOH) lassen sich im Genom von Tumorzellen Regionen markieren, die einen Allelverlust aufweisen und damit potentiell auf die Lokalisation von TSG hinweisen. Der LOH läßt sich über die Analyse polymorpher genetischer Marker feststellen. Bei Kopf-Hals-Karzinomen wurden so vor allem Allelverluste auf den Chromosomen 3p, 5q, 9p, 9q, 11p, 13q, 17q und 18q festgestellt (Ah-See et al., 1994; Bockmühl et al., 1996a; Field et al., 1995a; Ishwad et al., 1995; Nawroz et al., 1994; Scully \& Field 1997). Li et al. (1994) zeigten, daß das Auftreten von mehr als zwei Allelverlusten für Marker auf 3p, 8p, 13q und 17p mit einer signifikant schlechteren Prognose korrelierte. Weitere Untersuchungen ergaben, daß Allelverluste auf 9p mit der Inaktivierung des TSG p16 zusammenhängen und bereits in präkanzerösen plattenepithelialen Veränderungen auftreten (van der Riet et al., 1994; Reed et al., 1996). Auf der Basis der LOH-Analyse konnten dann, wie für das kolorektale Karzinom (Fearon \& Vogelstein 1990), bestimmte genetische Veränderungen verschiedenen Stadien der Tumorentwicklung von Kopf-Hals-Karzinomen zugeordnet werden (Califano et al., 1995; Sidransky 1997). Nach diesem Tumorprogressionsmodell beginnt die maligne Transformation der normalen Mukosa mit 9p-Deletionen. In Dysplasien finden sich dann bereits zusätzliche DNA-Verluste auf $3 p$ und $17 p$, in Carcinomata in situ weiterhin 11q-, 13q- und 14q-Verlusten, gefolgt von Deletionen auf 6p, 4q und $8 p$ bei invasiven Plattenepithelkarzinomen. Es wird von Sidransky (1997) jedoch auch betont, daß weniger die genaue Reihenfolge der Veränderungen als vielmehr deren Akkumulation mit ca. 6-10 unabhängigen genetischen Defekten die maligne Progression bestimmt.

Welche Onkogene bzw. TSG im einzelnen an der Genese und Progression von Kopf-Hals-Karzinomen beteiligt sind, ist auch weiterhin unklar. Von den bisher bekannten Proto-Onkogenen wurden Cyclin D1 sowie der epidermale Wachstumsfaktor-Rezeptor, EGF-R, und der transformierende Wachstumsfaktor alpha, TGF- $\alpha$ bei Kopf-Hals-Karzinomen häufiger amplifiziert gefunden (Sidransky 1997). Kandidaten unter den TSG sind das p16- sowie das p53-Gen 
(Sidransky 1997). Brennan et al. (1995) stellten bei Patienten mit Nikotin- und Alkoholabusus signifikant häufiger p53-Mutationen fest, und Koch et al. (1996) fanden eine Korrelation des mutierten p53-Gens mit einer schlechten Prognose.

Die Korrelation eines einzelnen genetischen Markers, wie z.B. einer Mutation im p53-TSG oder eines Allelverlustes, mit der Prognose von Neoplasien hat oft zu widersprüchlichen Aussagen geführt. Der Nachweis mehrerer Aberrationen als Ausdruck einer genetischen Instabilität ist deshalb vermutlich besser geeignet, die Malignität eines Tumors abzuschätzen. 


\section{FRAGESTELLUNG}

Wissenschaftlicher Ansatz der vorliegenden Arbeit ist die Hypothese, daß bestimmte Veränderungen im Genotyp von Kopf-Hals-Karzinomen verbesserte Aussagen über ihr jeweiliges biologisches Verhalten ermöglichen und somit eine Erweiterung der auf dem Phänotyp aufbauenden Diagnose darstellen könnten.

Im einzelnen werden dazu folgende Fragestellungen bearbeitet:

- Läßt sich den Plattenepithelkarzinomen des Kopf-Hals-Bereiches ein spezifisches Muster chromosomaler Alterationen zuordnen?

- Zeigen sich Unterschiede im Genotyp bei Plattenepithelkarzinomen des KopfHals-Bereiches in Abhängigkeit von der Lokalisation des Primärtumors (Mundhöhle/Oropharynx/Hypopharynx/Larynx)?

- Läßt sich insbesondere mittels der CGH ein "genetisches Tumorgrading" durchführen?

Haben dabei bestimmte chromosomale Veränderungen ein stärkeres Gewicht oder sind unterschiedliche Veränderungen gleichgewichtig, aber dafür die Anzahl der Alterationen prognostisch relevant?

- Lassen sich zwischen metastasierenden und nicht-metastasierenden Plattenepithelkarzinomen spezifische genetische Unterschiede feststellen?

- Gibt es signifikante Unterschiede zwischen den genetischen Mustern von Primärtumoren und korrespondierenden Metastasen?

- Zeigen Mehrfachtumoren eines Patienten ähnliche chromosomale Veränderungen, und inwieweit läßt sich ein Zweittumor anhand seines Aberrationsmusters eindeutig von einer Metastase abgrenzen? 


\section{MATERIAL UND METHODEN}

\subsection{Tumormaterial}

In der vorliegenden Arbeit wurden 100 primäre Plattenepithelkarzinome des Kopf-Hals-Bereiches, in 25 Fällen synchrone oder metachrone Lymphknotenmetastasen, in zwei Fällen pulmonale Metastasen und in 10 Fällen Zweitkarzinome untersucht. Alle Patienten wurden primär im Zeitraum zwischen 1994 und 1998 in der HNO-Klinik der Charité operiert. Die klinischpathologischen Daten des Kollektivs sind in Tabelle $1 \mathrm{im}$ Anhang zusammengestellt. Die histologische Diagnose wurde am HE-Schnitt im Institut für Pathologie der Charité gestellt. Das Grading erfolgte nach dem System von Anneroth et al. (1987), das Staging wurde entsprechend den geltenden UICCKriterien durchgeführt.

Das mittlere Alter der Patienten lag sowohl für Frauen als auch für Männer bei 56,7 Jahren. Der Beobachtungszeitraum betrug längstens 48 Monate. Neunundzwanzig Patienten waren innerhalb dieser Zeit am Tumorleiden verstorben, davon 15 am Lokalrezidiv und 14 an einer Metastasierung.

Die Daten über die Zweitkarzinome sind in Tabelle 2 im Anhang aufgelistet. In 7 Fällen wurden synchrone, in 3 Fällen metachrone Karzinome untersucht.

Die Tumorgewebsproben wurden mit Ausnahme mehrerer Zweitkarzinomfälle direkt aus den Operationspräparaten gewonnen. Innerhalb einer Stunde postoperativ erfolgte der Zuschnitt des Tumormaterials, wobei ein Teil in Flüssigstickstoff tiefgefroren und ein weiterer Teil für die Zellkultur asserviert wurde. Die Entnahme von Frischmaterial und die weitere pathologische Aufarbeitung erfolgten durch denselben Pathologen. Dadurch wurde gewährleistet, daß die konventionelle Aufarbeitung und insbesondere die Stadieneinteilung nicht beeinträchtigt war.

\subsection{Vergleichende Genomische Hybridisierung (CGH)}

Die Vergleichende Genomische Hybridisierung (engl. "Comparative Genomic Hybridization", CGH) ist eine 1992 erstmals beschriebene molekularzytogenetische Methode, die es erlaubt, in einem Experiment einen 
Überblick über die gesamten chromosomalen und subchromosomalen Veränderungen eines Tumorgenoms zu erlangen (Kallioniemi et al., 1992). Die CGH beruht auf der Fluoreszenz-in-situ-Hybridisierung (FISH). Es werden die zu untersuchende Tumor-DNA und daneben normale DNA eines gesunden Probanden extrahiert, mit unterschiedlichen Fluoreszenzfarbstoffen markiert und dann zu gleichen Teilen auf normale Metaphasenchromosomen, die aus Blutlymphozyten eines ebenfalls gesunden Probanden gewonnen werden, hybridisiert. Tumor- und Normal-DNA konkurrieren dabei um homologe Bindungsstellen auf den Chromosomen. Überwiegt im Tumor eine DNASequenz, so bindet diese häufiger an die entsprechende chromosomale DNA, hat der Tumor hingegen DNA verloren, so bindet mehr Normal-DNA. Die genetischen Aberrationen eines Tumorgenoms werden somit als DNA-Gewinn (Überrepräsentierung, Amplifikation) oder DNA-Verlust (Deletion) erkennbar. Dies hat biologische Bedeutung, da eine Amplifikation auf die Aktivierung eines Proto-Onkogens, eine Deletion hingegen auf die Inaktivierung eines TSG hinweisen können. Um diese DNA-Veränderungen quantifizieren zu können, erfolgt die Auswertung nicht visuell sondern nach Aufnahme mit einer CCDKamera über ein Computersystem mit einem Programm zur digitalen Bildanalyse der Fluoreszenzbilder.

Die CGH wurde in Anlehnung an die Protokolle von Kallioniemi et al. (1992; 1994b) sowie du Manoir et al. (1993) durchgeführt. Die Einzelheiten unserer Protokolle sind publiziert (Bockmühl et al., 1996b; Petersen et al., 1996; Roth et al., 1997) und über unsere Internetseite (http://amba.charite.de/cgh) abrufbar. Die CGH umfaßt folgende Schritte: a) DNA-Extraktion, b) Metaphasen-Präparation,

c) DNA-Markierung, d) Hybridisierung, e) DNA-Nachweis, f) digitale Bildverarbeitung und -auswertung.

\section{DNA-Extraktion}

Die bei $-80^{\circ} \mathrm{C}$ asservierten Proben wurden mit einem Gefriermikrotom (Frigocut 2800-E, Reichert-Jung) geschnitten. Erster und letzter Schnitt wurden in Haematoxylin-Eosin gefärbt und mikroskopisch auf den Prozentsatz an Tumorzellen untersucht. Tumoren mit weniger als 80\% Karzinomgewebe wurden nicht in die Studie einbezogen. Die restlichen 20 Gefrierschnitte (Schnittdicke: $30 \mu \mathrm{m})$ wurden jeweils in $2 \mathrm{ml}$ Eppendorf-Röhrchen mit $900 \mu 1$ Digestionspuffer, 
bestehend aus 30mM Trispuffer $(\mathrm{pH} \mathrm{8,5)}+1 \mathrm{mM}$ Ethylendiamintetraessigsäure $($ EDTA, ph 8,0$)+0,5 \%$ Tween $20+$ Proteinase $\mathrm{K}(1 \mathrm{mg} / \mathrm{ml})$, aufgenommen und über Nacht bei $50^{\circ} \mathrm{C}$ inkubiert. Nach DNA-Extraktion mit Phenol/Chloroform/Isoamylalkohol folgte die Fällung in Ethanol nach Standardprotokoll (Sambrook et al. 1989). Die Pellets wurden dann in Aqua bidest gelöst und ihre Konzentration mit einem Photometer bei $280 \mathrm{~nm}$ bestimmt. Bei den Fällen 196, 198, 200, 203 und 204 wurde die Tumor-DNA aus dem Paraffinblock nach Standardprotokoll extrahiert (Wright \& Manos 1990).

Die Normal-DNA wurde durch Blutentnahme von gesunden Spendern gewonnen. Nach Abtrennung der Leukozyten erfolgte die DNA-Extraktion wie oben beschrieben.

\section{Metaphasen-Präparation}

Die Präparation der Metaphasen erfolgte aus Blutlymphozyten gesunder Probanden, die in einer Kurzzeitkultur durch Phythämagglutinin zur Proliferation angeregt wurden. Nach Arretierung in der Metaphase mittels Colcemid erfolgte die Aufreinigung der Lymphozytenkerne über mehrere Waschschritte und das Auftropfen der Kerne auf gereinigte Objektträger (Verma \& Babu 1994). Kurz vor der eigentlichen Hybridisierung wurden die Objektträger mit den Metaphasenchromosomen in $70 \%$ igem Formamid/2xSSC $(\mathrm{pH} 7,5)$ bei $78^{\circ} \mathrm{C}$ für 60-90 Sekunden denaturiert und danach jeweils 3 Minuten in einer eiskalten aufsteigenden Alkoholreihe dehydriert.

\section{DNA-Markierung}

Die Markierung der DNA erfolgte über eine Nick-Translation, wobei die TumorDNA mit Biotin-16-dUTP (Boehringer, Mannheim, FRG), die NormalgewebsDNA mit Digoxigenin-11-dUTP (Boehringer, Mannheim, FRG) nach Standardprotokoll (Sambrook et al. 1989) markiert wurden. Die Größe der entstandenen Fragmente wurde mittels eines 2\%igen Agarosegels überprüft. Nach Erreichen der optimalen Länge von 300 bis 700 Basenpaaren wurde die Reaktion

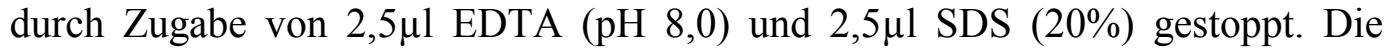
Markierungseffizienz wurde in regelmäßigen Abständen mit einem einfachen Dot Blot und anschließender Farbreaktion überprüft. 


\section{Hybridisierung}

Die Fällung von jeweils $5 \mu \mathrm{g}$ markierter Tumor- und Normalgewebs-DNA, $20 \mu \mathrm{g}$ Cot1-DNA (Gibco BRL, Life Technologies, Paisly, UK) und $1 \mu$ g HeringsspermaDNA erfolgte in 3-fachem Volumen absolutem Ethanol und 0,3M Natriumacetat bei $-80^{\circ} \mathrm{C}$ für ca. 30 Minuten. Nach Zentrifugation bei $+4^{\circ} \mathrm{C}$ und $14000 \mathrm{rpm}$ für 30 Minuten, Dekantieren des Überstandes und Trocknen des Pellets wurde dieses für 30 Minuten bei $37^{\circ} \mathrm{C}$ in $5 \mu 1$ deionisiertem Formamid gelöst. Danach wurden $10 \mu 1$ Mastermix (20\% Dextransulfat/4xSSC) zugegeben und das Gemisch für 5 Minuten bei $77^{\circ} \mathrm{C}$ denaturiert. Anschließend erfolgte das "preannealing" (Hybridisierung repetitiver Sequenzen) bei $37^{\circ} \mathrm{C}$ für 1 bis 2 Stunden.

Zwölf $\mu$ l einer Probe wurden jeweils auf einen der vorbereiteten Objektträger aufgetragen, durch ein 18 x 18mm Deckglas bedeckt und mit Fixogum luftdicht sowie blasenfrei abgeschlossen. Die Hybridisierung erfolgte bei konstant $37^{\circ} \mathrm{C}$ für 3 Tage (Kallioniemi et al., 1994).

Die Tumor-DNA wurde überwiegend geschlechtsneutral hybridisiert, d.h. bei einem Tumor von einem männlichen Patienten wurde die DNA mit männlicher Referenz-DNA und männlichen Metaphasenchromosomen präpariert bzw. bei weiblicher Tumor-DNA mit XX-Normal-DNA und XXMetaphasenchromosomen.

\section{DNA-Nachweis}

Die Detektion erfolgte durch eine Bindung von Fluorescein-Avidin (FITC) an die Biotin-markierte Tumor-DNA und Anti-Digoxigenin-Rhodamin (TRITC) an die mit Digoxigenin markierte Normalgewebs-DNA. Zur Identifizierung der Chromosomen wurden diese mit 4,6-Diamino-2-Phenylindol-Dihydrochlorid (DAPI) gefärbt (Verma \& Babu 1994).

Nach der Hybridisierung erfolgten zunächst 3 Waschschritte für jeweils 3 Minuten mit Formamid/2xSSC $(1: 1, \mathrm{pH} 7,0)$ bei $37^{\circ} \mathrm{C}$, anschließend wiederum dreimal jeweils 3 Minuten mit $0,1 \times S S C$ bei $60^{\circ} \mathrm{C}$. Danach wurden die Präparate kurz in $4 \times \mathrm{xSC} / 0,2 \%$ Tween 20 getaucht und dann mit $3 \% \mathrm{BSA}$ in $4 \mathrm{xSSC} / 0,2 \%$ Tween20 für 20 Minuten in einer feuchten Kammer bei $37^{\circ} \mathrm{C}$ inkubiert (BlockingSchritt). Nach einem erneuten kurzen Waschschritt mit 4xSSC/0,2\% Tween20 wurden pro Objektträger FITC (Vector Laboratories, Burlingame, CA) 1:200 und 
TRITC (Boehringer, Mannheim, FRG) $1: 100$ in $3 \%$ BSA in $4 x S S C / 0,2 \%$ Tween20 aufgetragen, mit einem Deckgläschen bedeckt und für 30 Minuten abgedunkelt in einer feuchten Kammer bei $37^{\circ} \mathrm{C}$ inkubiert. Danach wurden die Objektträger wiederum dreimal jeweils 3 Minuten in $4 x \mathrm{SSC} / 0,2 \%$ Tween 20 bei $45^{\circ} \mathrm{C}$ gewaschen bevor sie mit DAPI $(0,2 \mathrm{mg} / \mathrm{ml}, 1: 5000)$ für 5 Minuten bei Raumtemperatur gegengefärbt wurden. Abschließend wurden die Präparate mit Aqua dest. gespült und mit Antifading (DABCO) eingedeckt.

\section{Digitale Bildverarbeitung und-auswertung}

Die Bildaquirierung wurde an einem Zeiss Axiophot Epifluoreszenzmikroskop (Plan NEOFLUAR Ölobjektiv x63, N.A. 1.25, Zeiss, Oberkochen, FRG) durchgeführt. Es wurden folgende Filter verwendet: DAPI - Zeiss Filter-Set 02 Ausführung G365, Beamsplitter FT 395, Emission LP 42; FITC - Zeiss Filter-Set 10, Ausführung BP 450-490, Beamsplitter FT 510, Emission BP 515-565; TRITC - Chroma Filter-Set plus Ausführung Zeiss-Filter-Set 15, Ausführung BP 546/12, Beamsplitter FT 565, Emission BP 570-650. Pro Fall wurden 10 bis 15 Metaphasen ausgewählt. Von jeder Metaphase wurden drei monochrome Bilder (entsprechend den Fluorochromen) aufgenommen. Die Bildaufnahme erfolgte über eine mit einem Mikroskop verbundene CCD-Kamera (Photometrics, Tucson, AZ). Die FITC-, TRITC- und DAPI-Fluoreszenzsignale wurden jeweils separat als 8-bit Graustufenbilder (256 Graustufen) digital kodiert und im TIFF-Format abgespeichert. Die digitale Bildauswertung erfolgte anhand einer CGH-Software, die auf der Grundlage des AMBA-Systems und des Karyotypisierungsmoduls KARYOTYP (IBSB GmbH, Berlin, FRG) entwickelt und auf einem Pentium PC unter Windows implementiert wurde (Roth et al., 1997). Die drei Fluoreszenzbilder einer Metaphase und der erste Schritt der Bildauswertung sind beispielhaft in Abbildung 1 veranschaulicht.

Aus der Übereinanderlagerung des FITC- und TRITC-Bildes, der Normierung der Fluoreszenzintensitäten und dem Vergleich der korrespondierenden Bildpunkte resultiert das sog. RATIO-Bild. Es gibt die DNA-Veränderungen anhand von Fehlfarben wieder. Ein DNA-Gewinn (Überrepräsentierung, Amplifikation) im Tumor gegenüber dem Normalgewebe ist grün und ein DNA-Verlust (Deletion) rot gefärbt, während ein Gleichgewicht beider Genome blau dargestellt ist. 

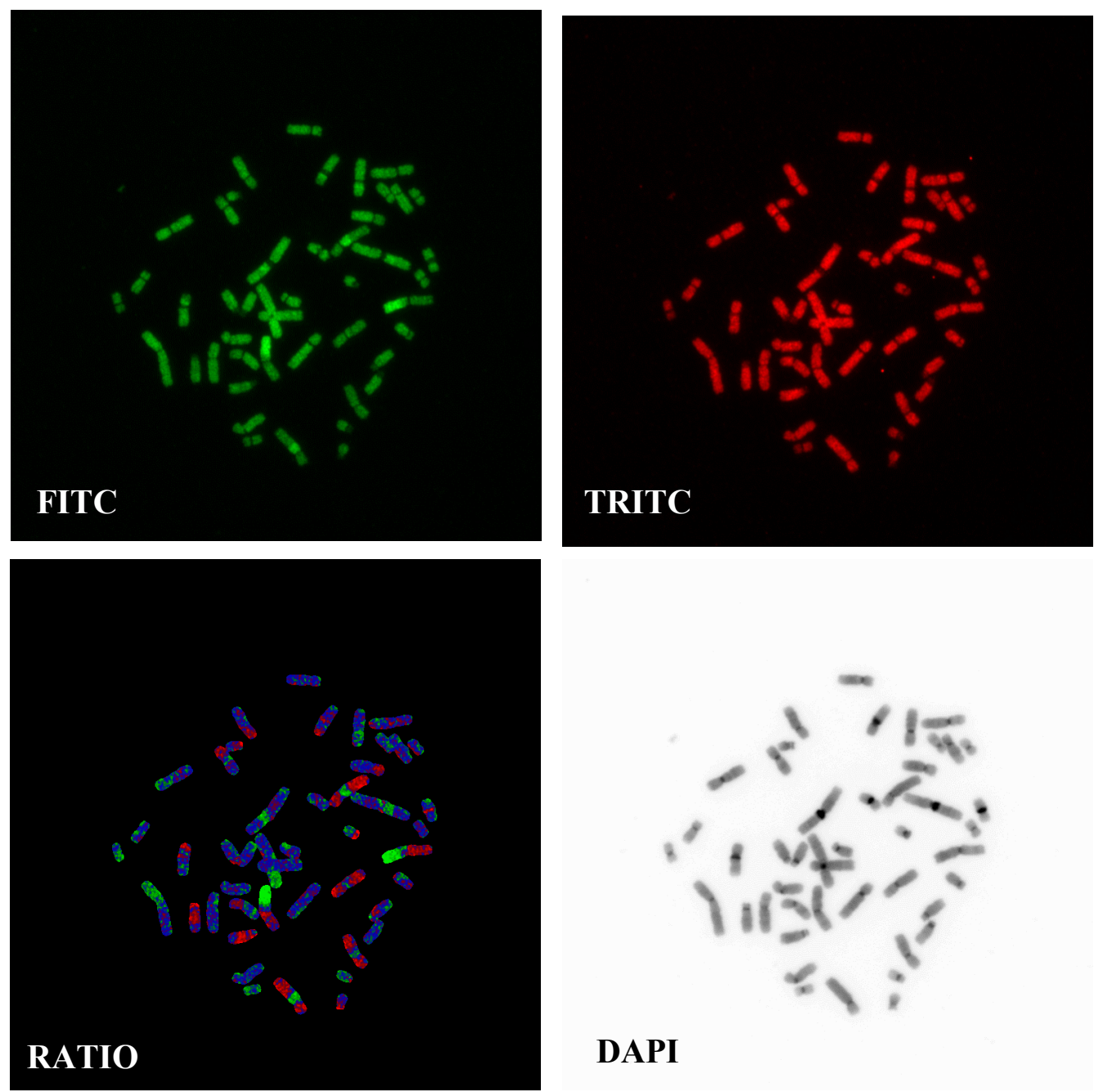

Abbildung 1: Erster Schritt der Bildverarbeitung.

Nach Identifizierung der Chromosomen anhand des DAPI-Bildes werden die Chromosomen jeder Metaphase in ein Karyogramm sortiert. Pro Fall werden dann die Karyogramme von mindestens 10 Metaphasen $\mathrm{zu}$ einem SummenKaryogramm gemittelt. Dadurch können zufällige Fehler und Rauscheffekte minimiert werden. Neben den Chromosomen-Ideogrammen sind die DNAVeränderungen als Profile angegeben. Die mittlere der drei Linien verdeutlicht das Gleichgewicht zwischen Tumor- und Normal-DNA, während die linke bzw. rechte Linie dem theoretischen Wert für eine Mono- bzw. Trisomie in 50\% der Tumorzellen eines diploiden Tumors entsprechen. Die Sensitivität der Methode läßt die Detektion von Deletionen bis zu 10 Megabasen und Amplifikationen bis 2 Megabasen Größe zu. Um die typischen DNA-Veränderungen einer Tumorentität darzustellen, können die Summen-Karyogramme mehrerer Fälle zu 
einem sog. Super-Karyogramm zusammengefaßt werden (Bockmühl et al., 1996c). Diese Auswertungsschritte sind in der nachfolgenden Abbildung 2 wiedergegeben.

\section{Karyogramm}

Analyse einer Metaphase eines Tumors

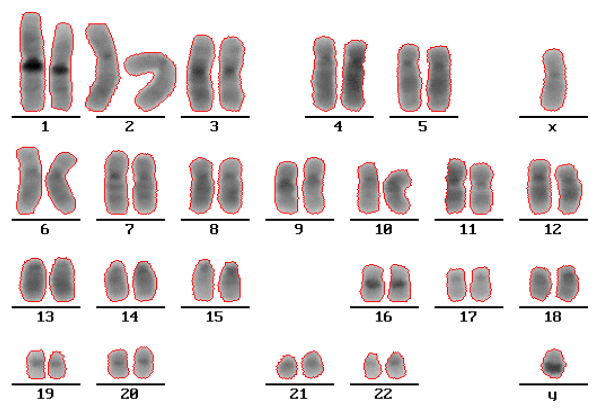

DAPI-Bild

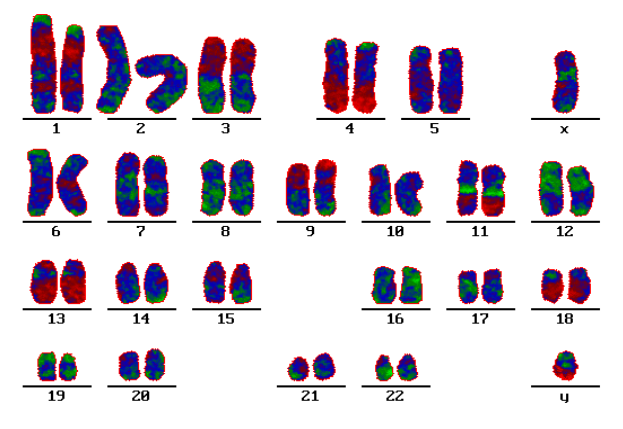

RATIO-Bild

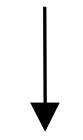

Summen-Karyogramm

Analyse von 10 Metaphasen eines Tumors

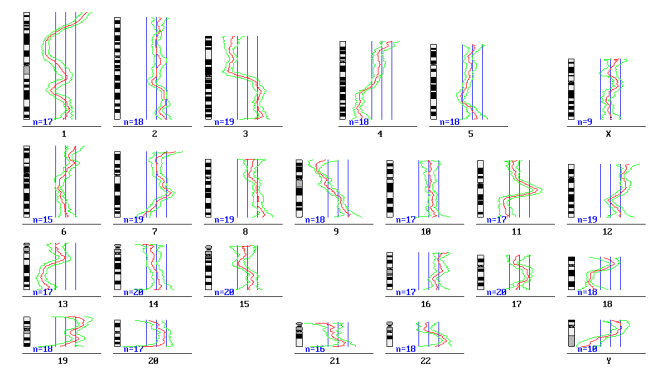

RATIO-Profil mit 95\%-Konfidenz-Intervall
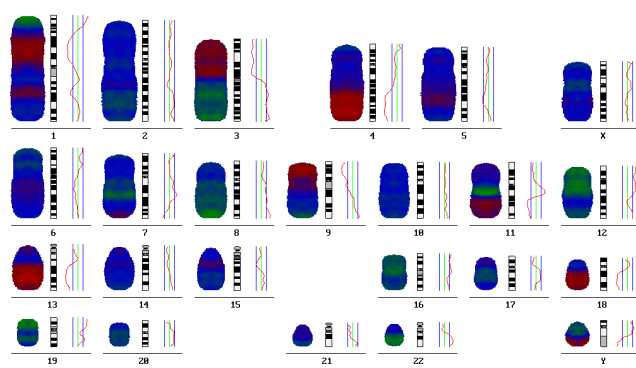

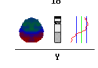

RATIO-Chromosomen und -Profile

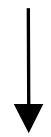

\section{Super-Karyogramm}

Analyse von 19 Tumoren einer Entität

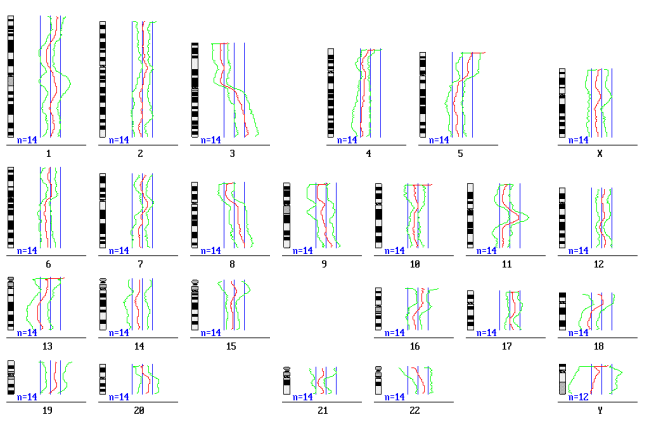

RATIO-Profil mit 95\%-Konfidenz-Intervall

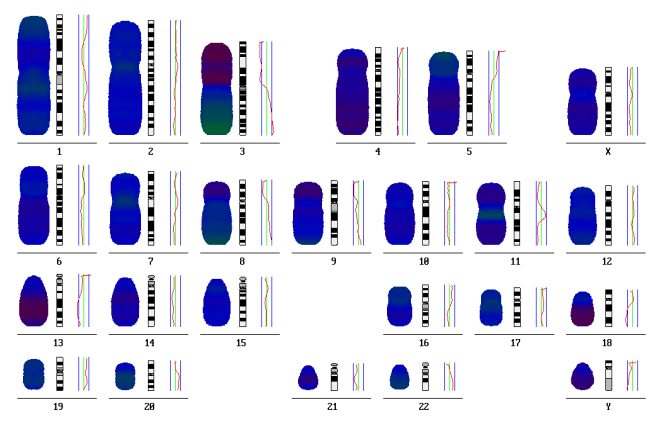

RATIO-Chromosomen und -Profile 
Der statistische Vergleich von Tumorgruppen kann durch die Berechnung von sog. Differenzhistogrammen erfolgen. Diese beruht auf der Erstellung von Histogrammen für die jeweilige Gruppe. Dazu werden von jedem Einzelfall die Imbalancen in den RATIO-Profilen mit dem Student-t-Test auf 95\%ige und/oder 99\%ige Signifikanz geprüft (Abbildung 3A). Das CGH-Histogramm der Tumorgruppe repräsentiert dann die Anzahl der Fälle, die an einer gegebenen chromosomalen Region eine signifikante Veränderung aufweisen, normiert über die Gesamtzahl der Fälle dieser Tumorgruppe. Daraus ergibt sich die Verteilung der Imbalanzen in Form einer Inzidenzkurve $\mathrm{zu}$ beiden Seiten der Chromosomenideogramme, wobei Ausschläge links Deletionen und rechts Amplifikationen entsprechen (Abbildung 3B). Die Inzidenz läßt sich dann anhand von Hilfslinien ablesen; der Maximalwert von 100\% wird erreicht, wenn alle Tumoren an einer bestimmten chromosomalen Region die gleiche Alteration aufweisen. Aus den Histogrammen zweier zu vergleichender Tumorgruppen kann dann das Differenzhistogramm errechnet werden, in dem die Unterschiede über einen Chi-Quadrat-Test auf ihre Signifikanz geprüft werden (Abbildung 3C).

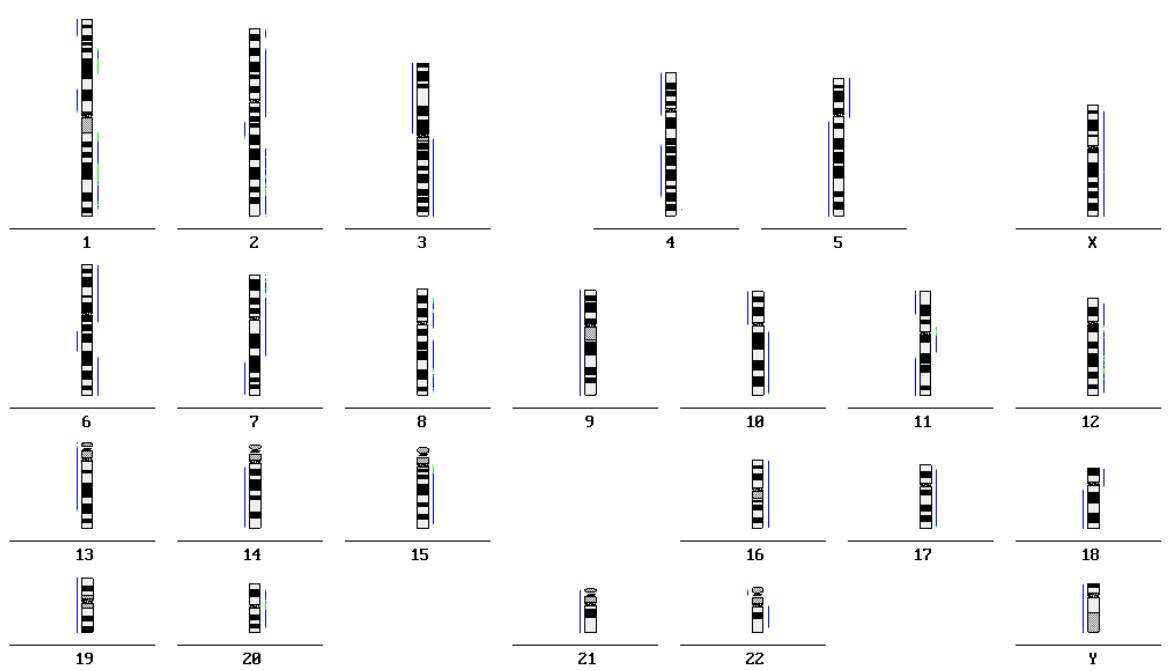

Abbildung 3A:Imbalancen eines Einzelfalls in Form einer Strichdarstellung (blaue Striche $=99 \%$, grüne Striche $=95 \%$ Signifikanz im Student-t-Test). 


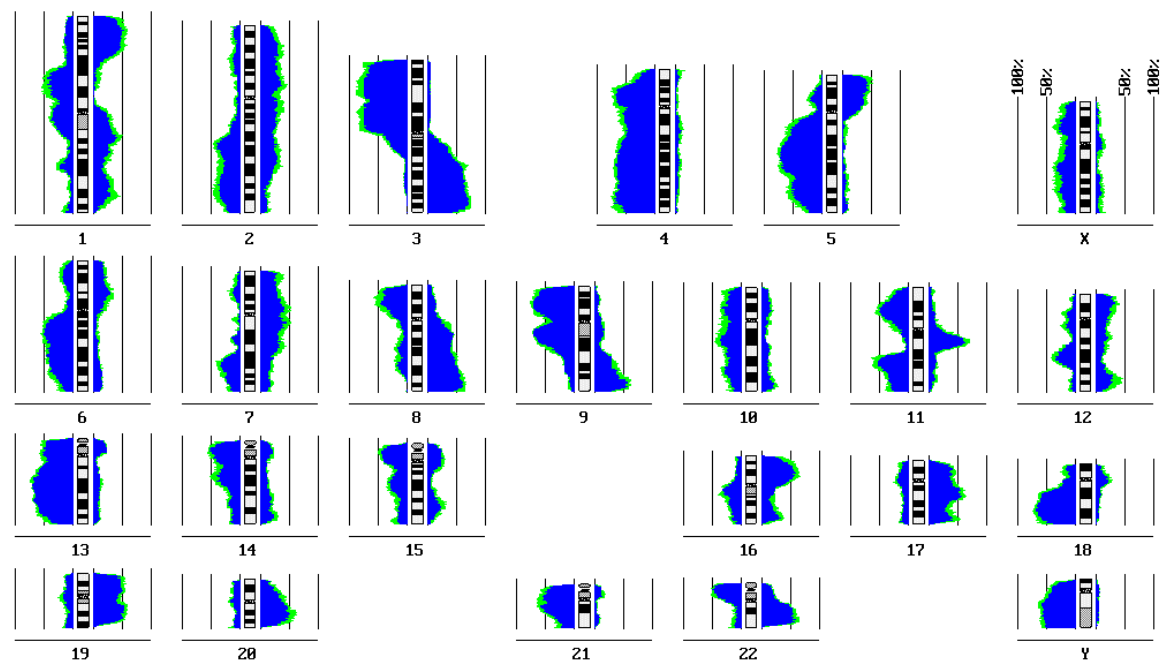

Abbildung 3B:Histogramm einer Tumorgruppe (blaue Bereiche $=99 \%$, grün $=95 \%$ signifikante Imbalancen).

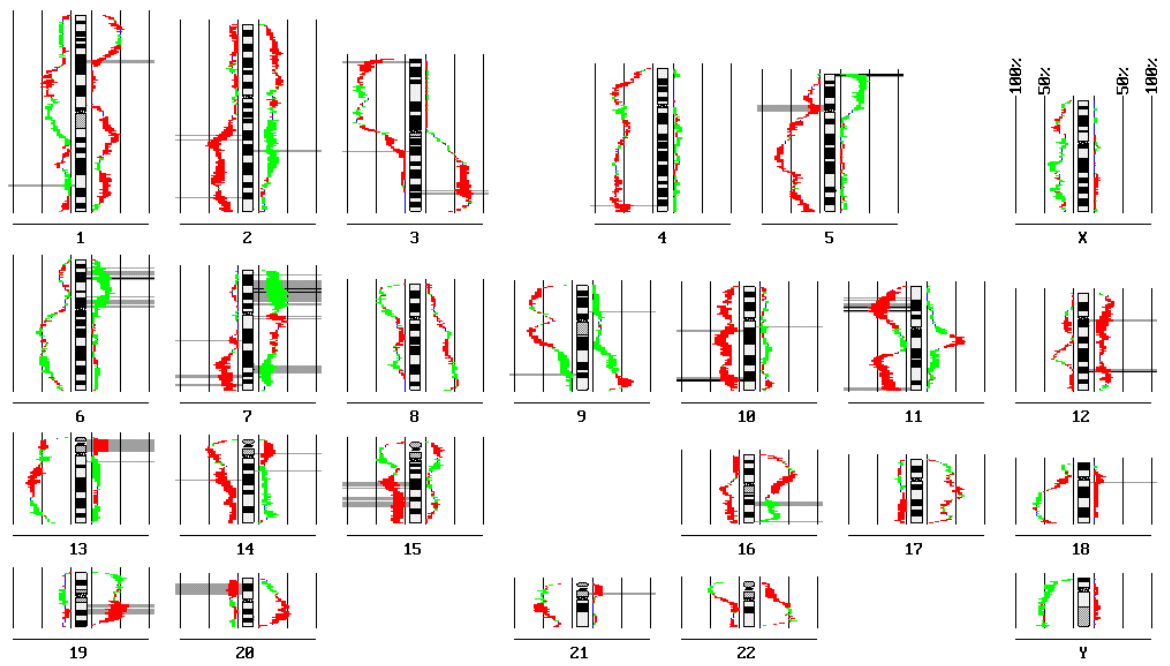

Abbildung 3C:Differenzhistogramm zum Vergleich zweier Tumorgruppen, grün bzw. rot dargestellt. Signifikante Unterschiede sind durch graue Balken markiert (hellgrau $=95 \%$, dunkelgrau $=99 \%$ Signifikanz im Chi-Quadrat-Test). 
Der Vergleich von Primärtumor und Lymphknotenmetastase bzw. Zweitkarzinom erfolgte anhand der Summen-Karyogramme sowie der RATIO-Profile für jedes Chromosom. Die Alterationen eines Tumorpaares wurden dabei in einer Strichdarstellung (siehe auch Abbildung 3A) miteinander verglichen, wobei diese aus den Profilen mit Hilfe des Student-t-Testes ermittelt wurden. Die Abbildung 4 zeigt beispielhaft an einem Chromosom den Auswertungsmodus. Als übereinstimmende Veränderungen wurden die mit roten Pfeilen gekennzeichneten Regionen, als differierende Alterationen die schwarz markierten Bereiche gewertet. Die Anzahl der jeweils unterschiedlichen bzw. gemeinsamen genetischen Veränderungen zweier Tumoren wurden dann im Verhältnis zur Gesamtzahl der Alterationen in Prozent angegeben.

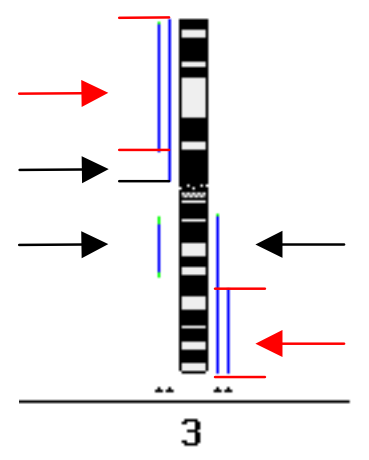

\author{
Abbildung 4: \\ Der Vergleich des Chromosoms 3 zweier \\ Tumoren zeigt 2 übereinstimmende (rote \\ Pfeile) und 3 differierende Alterationen \\ (schwarze Pfeile).
}

\title{
Validitätsprüfung
}

Zur methodischen Kontrolle der Hybridisierungen wurden in Abständen a) Normal-DNA gegen Normal-DNA und b) Tumoren mehrfach hybridisiert.

Mit der CGH können keine balancierten Translokationen oder Inversionen erkannt werden, so daß ein zytogenetischer Vergleich, wenn möglich, durchgeführt werden sollte. Da weiterhin das Auflösungsvermögen der CGH zu gering ist, um auch sehr kleine genetische Veränderungen detektieren zu können, muß sie durch andere Methoden wie z.B. den Nachweis von Heterozygotieverlusten (LOH, siehe unten) ergänzt werden. 


\subsection{Verlust der Heterozygotie ( $\mathrm{LOH})$}

Mit der Analyse des Heterozygotieverlustes (engl. "loss of heterozygosity", LOH) lassen sich Allelverluste in sehr kleinen DNA-Sequenzen (sog. Mikrosatelliten) feststellen. Diese Methode beruht auf der Grundlage, daß ein Individuum für einen Genort verschiedene Nukleotidsequenzen besitzen kann, was als "Heterozygotie" bezeichnet wird. Diese unterschiedlichen Allele lassen sich z.B. in einer Elektrophorese durch 2 Banden sichtbar machen. Sind die DNASequenzen der homologen Chromosomen für einen Genlocus identisch, so liegt eine "Homozygotie" vor, d.h. es wäre nur eine Bande darstellbar. Die "Heterooder Homozygotie" für einen bestimmten Genlocus ist im Normalfall in allen Zellen eines Individuums gleich. Vergleicht man jedoch Tumor- mit Normalgewebe desselben Patienten, so können Unterschiede auftreten, d.h. im Rahmen der Tumorgenese kann die Nukleotidsequenz so verändert sein, daß es zu einem Allelverlust (LOH) kommt. Dieser läßt sich mit Hilfe polymorpher Mikrosatelliten-Marker nachweisen, vorausgesetzt der Patient ist für den eingesetzten Marker heterozygot.

\section{DNA-Extraktion}

Die DNA-Extraktion von Tumor- und Normalgewebs-DNA erfolgte wie bereits für die CGH beschrieben, wobei für die LOH-Analyse die Normal-DNA jeweils von demselben Patienten zu isolieren war. Sie wurde vorrangig aus Gewebe der Unterkieferspeicheldrüse, das im Rahmen der Präparation der Neck dissection gewonnen wurde, extrahiert.

\section{Polymerasekettenreaktion (PCR)}

Die PCR wurde zur Amplifikation von DNA-Sequenzen im Bereich von Mikrosatelliten-Polymorphismen auf den Chromosomen 8p, 10q, 13q und 21q eingesetzt. Diese Chromosomenarme wurden vor allem ausgewählt, um die Ergebnisse der $\mathrm{CGH}$ zu überprüfen. Die Nukleotidsequenzen der Primerpaare D10S569, D10S541, D10S185, D10S169, D13S232，D13S788，D13S887, D13S796, D13S285, D21S1253, D21S1257, D13S1260, D13S1889, D21S1896, D21S1908, D21S1910, D21S1914 wurden der Généthon genetic map entnommen und von MWG-Biotech (Ebersberg, FRG) synthetisiert. Jeweils ein Primer des 
Paares war mit IRD41 Infrarot Farbstoff markiert. Die PCR wurde in einem Volumen von $30 \mu 1$ mit 100ng genomischer DNA $+15 \mathrm{pmol}$ von jedem Primer + $200 \mu \mathrm{mol}$ dNTPs + 0,8U Taq-DNA-Polymerase (Böhringer, Mannheim, FRG) sowie 10-fach konzentrierter PCR-Reaktionspuffer (Böhringer, Mannheim, FRG), bestehend aus 20mM Tris-HCL + 1,5mM $\mathrm{MgCl}_{2}+500 \mathrm{mM}$ KCL $(\mathrm{pH} 8,3)$, durchgeführt. Es wurde der Thermocycler "Omni Gene" (MWG Biotech, Ebersberg, FRG) verwendet. Die DNA Proben wurden für 5 Minuten denaturiert und dann über 35 Zyklen amplifiziert (Zyklus: 1min $95^{\circ} \mathrm{C}$, 30s bei Annaeling Temperatur und $30 \mathrm{~s}$ bei $72^{\circ} \mathrm{C}$ ) gefolgt von einem abschließenden Extensionsschritt von 5 Minuten bei $72^{\circ} \mathrm{C}$. Die Größe der PCR Produkte wurde mittels eines 1,5\%igen Agarosegels überprüft.

Die Nukleotidsequenzen der Marker für 8p23 (D8S264, D8S1788, D8S1824, D8S1781, D81806, D8S1798, D8S262) wurden der Literatur entnommen (Dib et al., 1996) und von RESEARCH GENETICS (Huntsville, AL) hergestellt, wobei jeweils ein Primer mit $\left[{ }^{32} \mathrm{P}\right]$ ATP markiert war. PCR, PAGE sowie die radioaktive Detektion wurden nach Ishwad et al. (1996) unter Leitung von Frau Professor Gollin am Institut für Humangenetik der Universität Pittsburgh durchgeführt.

\section{Polyacrylamidgelelektrophorese (PAGE)}

Die Auftrennung der Allele erfolgte in einem 6\%igen, denaturierenden PAGE (Biozym, Hess/Oldendorf, FRG) in vertikaler Elektrophorese über einen Licor Sequencer (MWG Biotech, Ebersberg, FRG). Die Ergebnisse wurden auf ZipDisketten gespeichert und offline mittels eines Computer-Programmes auf der Basis der AMBA-Software ausgewertet (http://amba.charite.de/cgh).

\section{Auswertung}

Verglichen wurde das Bandenmuster des Tumorgewebes mit dem des normalen Gewebes. Sind im Normalgewebe die Amplifikationsprodukte des mütterlichen und väterlichen Allels verschieden groß, so stellen sich 2 Banden dar (Heterozygotie). Im Falle gleich großer Allele ist nur eine Bande sichtbar, es besteht Homozygotie. Dementsprechend kann der Tumor entweder hetererozygot (het.), homozygot (nicht informativ, n.i.) sein oder einen LOH aufweisen. Ein $\mathrm{LOH}$ wurde gewertet, wenn die Intensität eines Allels der Tumorprobe weniger als 50\% der Intensität der Bande des Normalgewebes aufwies. 


\subsection{Immunhistochemische Untersuchungen}

Mit Hilfe der Immunhistochemie wurden 38 primäre Kopf-Hals-Karzinome auf die Proteinexpression der TSG p16 und Rb sowie des Proto-Onkogens Cyclin D1 getestet. Dazu wurden die monoklonalen Maus-Antikörper DCS-50 gegen p16, 1F8 gegen pRb und DCS-6 gegen Cyclin D1 verwendet (Neomarkers, Fremont, CA). Methodisch wurde in Anlehnung an Lukas et al. (1995), Bartek et al. (1992) und Lukas et al. (1994) vorgegangen. Von den Tumoren wurden jeweils $5 \mu \mathrm{m}$ dicke Gefrierschnitte angefertigt und für ca. 10 Minuten in einem eiskalten Aceton-Methanol-Gemisch (1:1) fixiert. Die endogene Peroxidase wurde mit einer $1 \%$ igen $\mathrm{H}_{2} \mathrm{O}_{2}$ /Methanol-Lösung blockiert. Nach Waschen mit PBS-Puffer ( $\mathrm{pH} 7,6)$ wurden die Inkubationsschritte jeweils in einer feuchten Kammer wie folgt ausgeführt: 20 Minuten mit normalem Pferdeserum (1:50) bei Raumtemperatur; über Nacht mit dem entsprechenden primären Antikörper $(1: 100)$ bei $4^{\circ} \mathrm{C} ; 45$ Minuten mit dem biotinylierten zweiten Antikörper (AntiMaus, 1:200) bei Raumtemperatur; 30 Minuten mit dem Avidin-Biotin-Komplex (Vector, Burlingame, CA). Abschließend wurde die Reaktion mit Diaminobenzidin entwickelt. Es wurden interne Positivkontrollen verwendet.

\subsection{Etablierung von Zellinien}

Die Anlage von Zellkulturen diente zum einen dem Vergleich der CGHErgebnisse mit der klassischen Zytogenetik und zum anderen, um anhand der Zellinien detailiertere molekulargenetische und -biologische Untersuchungen durchführen zu können.

Das frische Tumorgewebe wurde mit einem sterilen Skalpell so weit wie möglich zerkleinert und bei Raumtemperatur für 20 Minuten in einer Antibiotikalösung, bestehend aus Penicillin (100U/ml), Streptomycin $(100 \mu \mathrm{g} / \mathrm{ml})$, Neomycin $(100 \mu \mathrm{g} / \mathrm{ml})$ und Bacitracin $(50 \mathrm{U} / \mathrm{ml})$, inkubiert. Anschließend wurden die Gewebsbröckchen zur enzymatischen Aufspaltung in Dispase/KollagenaseLösung aufgenommen. Nach 40 -minütiger Inkubation bei $37^{\circ} \mathrm{C}$ wurde das Tumormaterial 2 mal mit L-15 Medium (Boehringer, Mannheim, FRG) abzentrifugiert. Die gewaschenen Gewebsbröckchen wurden schließlich in L-15 
Medium und 10\% fetalem Kälberserum resuspendiert und in $25 \mathrm{ml}$ Kulturflaschen ausgesät.

Die Zellkulturen wurden 2 mal wöchentlich mit frischem Medium versorgt und wenn erforderlich zur Eliminierung von Fibroblasten partiell trypsiniert. Eine Zellinie wurde als etabliert gewertet, wenn sie mehr als 20 Passagen durchlaufen hatte. Bei steigender Anzahl an Mitosen wurden die Kulturflaschen zur

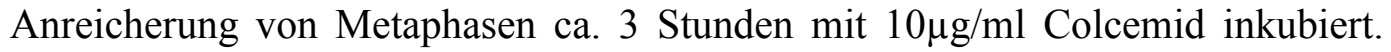
Danach wurde das Medium durch eine vorgewärmte Trypsin-EDTA-Lösung (1:250) ersetzt, um die Zellen voneinander und vom Boden des Gefäßes zu lösen. Die suspendierten Zellen wurden abzentrifugiert und anschließend mit 0,55\%iger KCl-Lösung hypotonisiert. Die Fixierung erfolgte mit einem Methanol-EisessigGemisch im Verhältnis 3:1. Nach vier bis fünf Waschschritten mit jeweils frischer Fixierungslösung wurde die Suspension auf entfettete Objektträger aufgetropft.

Zur Karyotypisierung wurde die Giemsa-Bänderung (G-banding) der Chromosomen benutzt, die nach Standardprotokoll durchgeführt wurde (Verma \& Babu 1994; Mitelman 1995). Die chromosomalen Aberrationen wurden von Frau PD Dr. G. Thiel am Institut für Medizinische Genetik der Charité entsprechend der internationalen Nomenklatur klassifiziert (ISCN 1995).

\subsection{Statistische Auswertung}

Die statistische Auswertung bezüglich des Student-t-Testes, der Kaplan-MeierKurven und der Cox-Regression erfolgte mit Hilfe des SPSS-Software-Paketes (SPSS Inc.). In die Analyse gingen die klinisch-pathologischen Parameter ein, und es wurden bei allen Tumoren die Einzelveränderungen für jedes Chromosom ausgezählt. 


\section{ERGEBNISSE}

\subsection{Charakterisierung der Plattenepithelkarzinome des Kopf-Hals- Bereiches als Tumorentität}

$C G H$

Die Abbildung 5 zeigt das Histogramm über alle genetischen Alterationen in 100 Plattenepithelkarzinomen des Kopf-Hals-Bereiches. Die blauen Inzidenzbereiche geben den Prozentsatz der chromosomalen Veränderungen an, die mit einer Signifikanz von 99\% auftreten, der grüne Saum kennzeichnet die Inzidenz mit 95\%iger Signifikanz. Links der Chromosomenideogramme sind DNA-Verluste, rechts DNA-Überrepräsentierungen dargestellt. Die Zentromerbereiche sind aufgrund der Interferenz mit kompetitiven DNA-Sequenzen von der Auswertung ausgeschlossen.

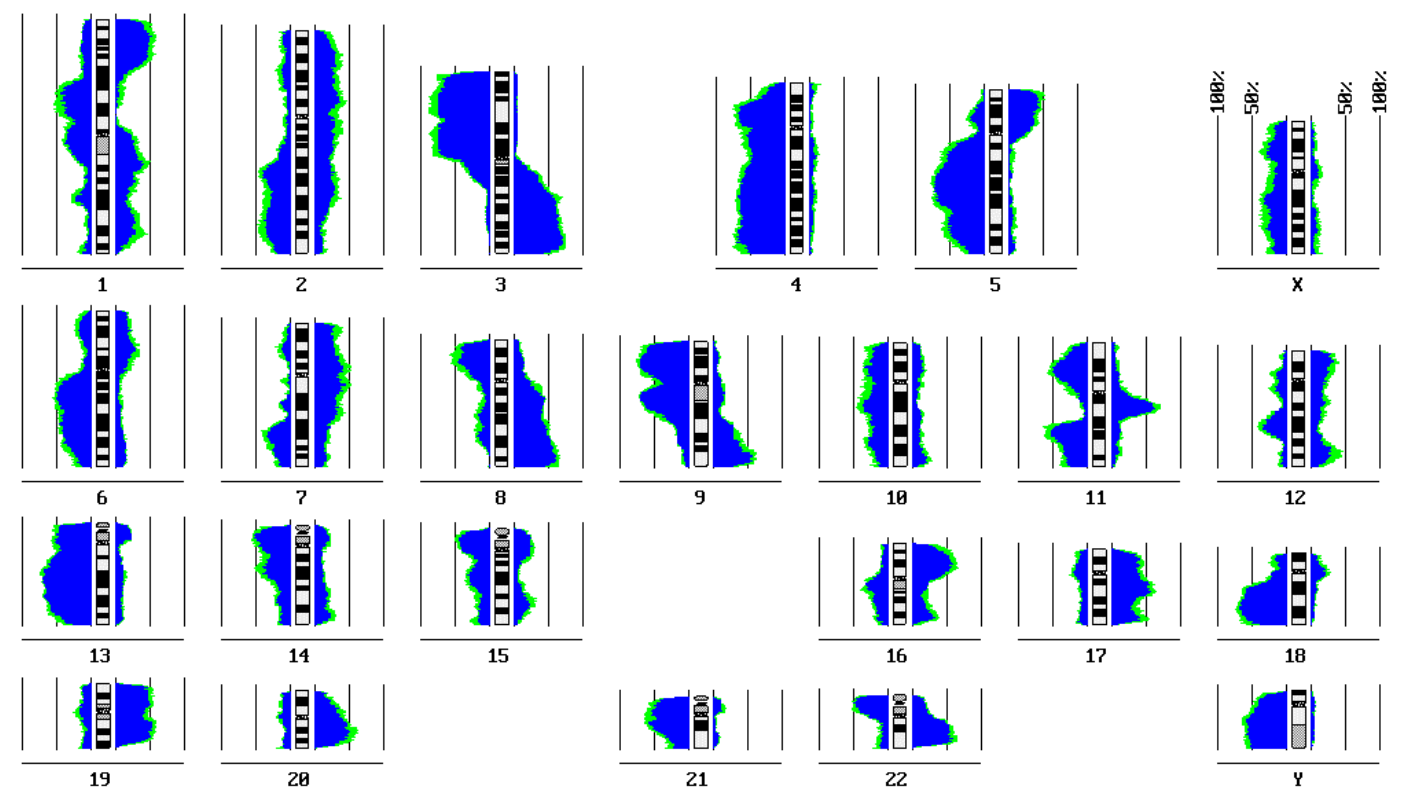

Abbildung 5: Histogramm über alle genetischen Alterationen in 100 Kopf-HalsKarzinomen.

In $>50 \%$ der Fälle zeigten die untersuchten Tumoren Deletionen der Chromosomen 3p, 4p/q, 5q, 6q, 8p, 9p, 11p/q, 13q, 18q und 21q. Als häufigste Alteration konnten bei 91 Tumoren Deletionen auf Chromosom $3 p$ festgestellt 
werden. In 55 Fällen war der gesamte Chromosomarm deletiert, während 36 Tumoren nur partielle Deletionen aufwiesen. Die zweithäufigste Deletion betraf $9 \mathrm{p}$ in 79 von 100 Fällen, gefolgt von 5q-, 13q- und 18q-Verlusten in $77 \%$ bzw. jeweils 72\% der Fälle. Gipfel der Inzidenzkurve markierten die Regionen 1p22, 3p12-p14, 3p21-p23, 4p13-p15.1, 5q15-q22, 6q14-q16, 7q31, 8p21, 9p21-p22, 11p13-p14, 11q32-q33, 12q21, 14q21 und 21q21.

Die häufigsten DNA-Überrepräsentierungen fanden sich im Bereich von 1p, 3q, 5p, 8q, 9q, 11q13, 16p, 17q, 19, 20q und 22q mit Inzidenzpeaks bei 5p15, 8q24, 9q34, 11q13, 17q21 und 20q12-q13.1. High-copy-Amplifikationen zeigten sich häufig auf 3q26-qter, 11q13, 8q24 und 9q34. Amplifikationen des 3q-Armes waren in 31 und Überrepräsentierungen des 5p-Armes in 17 Fällen mit Deletionen des korrespondierenden Chromsomarmes kombiniert, was auf das Vorliegen von sog. Isochromosomen $3 q$ bzw. $5 p$ hindeutet.

Hinsichtlich der Lokalisation der Primärtumoren zeigten sich keine signifikanten Unterschiede im Muster der chromosomalen Veränderungen, was auf die jeweils kleinen Gruppen zurückzuführen sein kann. Der Vergleich von Mundhöhlen-, Oro- und Hypopharynxkarzinomen einerseits mit den Larynxkarzinomen (supraglottische, glottische und subglottische Karzinome) andererseits ergab, daß die Pharynxkarzinome etwas häufiger Amplifikationen im Bereich der Chromosomenarme 1q, 2p, 3q und 7q sowie eine Deletion von 11q aufwiesen.

Die Anzahl der Alterationen variierte unter den Tumoren zwischen 3 und 29 Einzelveränderungen, mit einem Mittelwert von 18. In 84 Fällen zeigten sich mehr Deletionen als Amplifikationen. Die DNA-Verluste schwankten pro Tumor zwischen 1 und 20 (Mittelwert = 11). Amplifikationen variierten zwischen 1 und 14 (Mittelwert $=7)$.

\section{$\mathrm{LOH}$}

Zur Überprüfung der CGH-Ergebnisse wurden die DNA-Verluste der Chromosomenarme 10q, 13q und 21q mittels polymorpher genetischer Marker auf Heterozygotieverluste (LOH) getestet. Die Daten der Einzelfälle sind tabellarisch im Anhang aufgeführt.

Das Chromosom 10q betreffend wurden 48 Primärkarzinome und 10 Lymphknotenmetastasen untersucht. Bis auf einen Primärtumor waren alle Fälle 
für mindestens einen der 4 Marker heterozygot (siehe Tabelle 3 im Anhang). Bei 16 der 47 informativen primären Karzinome (34\%) gelang der Nachweis von Allelverlusten für mindestens einen Marker. Innerhalb der Gruppe der 10 Lymphknotenmetastasen zeigten 6 Fälle mindestens einen LOH (60\%). Vier Metastasen wiesen im Vergleich zum Primärtumor zusätzliche Allelverluste auf wie in Abbildung 6 verdeutlicht. Während der primäre Tumor 67 (T) für die Marker D10S569, D10S541 und D10S169 heterozygot ist, zeigt die Metastase (Lk) jeweils einen LOH; demgegenüber weisen Primärtumor und Lymphknotenmetastase des Falles 27 ein identisches Allelmuster mit LOH bei den Markern D10S561 und D10S185 auf. In den 3 anderen Fällen fand sich der zusätzliche LOH in den Metastasen jeweils bei dem distal gelegenen Marker D10S169 (10q25-26).
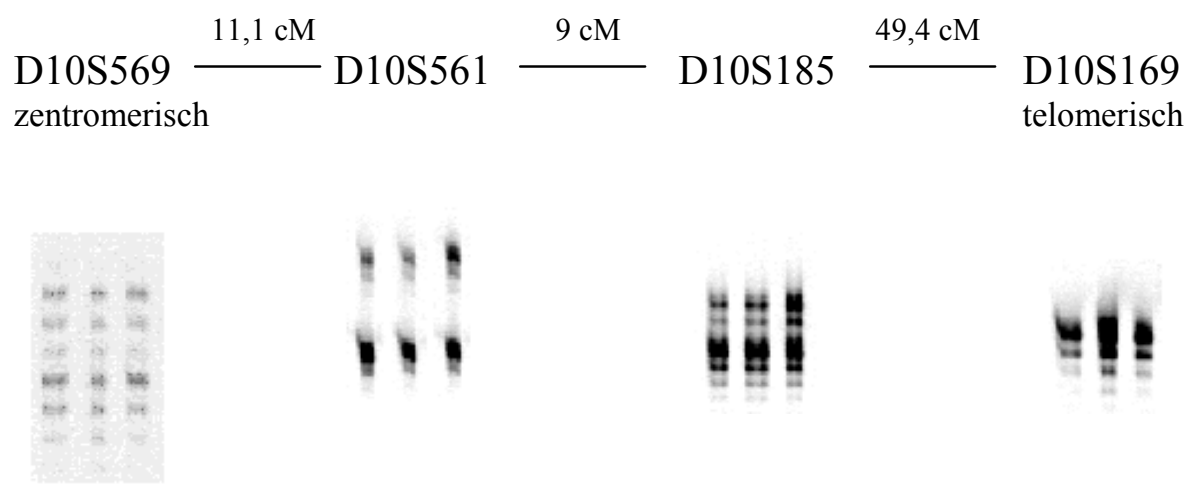

Fall 27

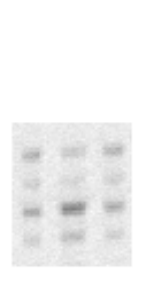

T Lk N

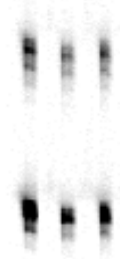

T Lk N

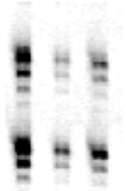

T Lk N

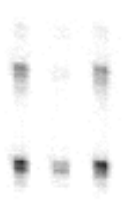

T Lk N

Abbildung 6: 10q-LOH-Beispiele, Vergleich des Allelmusters zwischen Primärtumor (T) $\mathrm{N}=$ Normalgewebe. 
Der Vergleich von CGH- und LOH-Ergebnissen zeigte für die Primärtumoren eine Übereinstimmung in $87,5 \%$ (d.h. in 42 von 48 Fällen) und für die Lymphknotenmetastasen in allen Fällen.

Heterozygotieverluste auf 13q wurden bei 36 primären Kopf-Hals-Karzinomen mittels 5 polymorpher genetischer Marker untersucht. Alle Tumoren waren für mindestens einen Marker heterozygot (siehe Tabelle 4 im Anhang). In 47\% der Fälle, d.h. in 17 von 19 Karzinomen, wurde mindestens ein LOH nachgewiesen. Für die Region 13q14, in der das Rb TSG lokalisiert ist, traten Allelverluste nur in $25,8 \%$ auf, während distal davon bei 13q32-qter in 44\% LOH feststellbar waren. Die Übereinstimmung der LOH-Daten mit den CGH-Ergebnissen betrug ebenfalls $87,5 \%$.

Neunundzwanzig Primärtumoren und 2 Zellinien wurden auf Allelverluste des Chromosomenarmes 21q getestet. Alle Fälle waren für mindestens einen der 8 Primer heterozygot (siehe Tabelle 5 im Anhang). In 18 der 29 Karzinome (62\%) war wenigstens ein LOH nachweisbar. Beide Zellinien zeigten Allelversluste ohne daß die Primärtumoren $\mathrm{LOH}$ aufwiesen. Die $\mathrm{LOH}$ waren so verteilt, daß die Marker D21S1914, D21S1896, D21S1908, D21S1910 und D21S1889 jeweils eine minimale Verlustregion repräsentieren. Die CGH-LOH-Übereinstimmung betrug $94 \%$.

Im Rahmen einer gemeinsamen Studie mit der Universität Pittsburgh wurden Heterozygotieverluste im Bereich von 8 p23 in 50 primären Kopf-HalsKarzinomen, 17 Lymphknotenmetastasen und einer Zellinie untersucht. Diese Region wurde ausgewählt, da sie bei Mundhöhlenkarzinomen als häufig deletiert gefunden wurde. Alle Fälle waren für mindestens einen von 7 Markern heterozygot. Allelverluste wurden in $45 \%$ der Primärtumoren festgestellt. Wiederum zeigte die Zellinie LOH, die im korrespondierenden Karzinom nicht nachweisbar waren ebenso wie in 3 Fällen zusätzliche Allelverluste im Lymphknoten auftraten. In 14 Fällen stimmte das Allelmuster von Primärtumor und Lymphknoten überein. Der Vergleich von CGH- und LOH-Ergebnissen zeigte für die Primärtumoren eine Übereinstimmung in 78,6\%. 


\section{Immunhistochemie}

Die immunhistochemischen Ergebnisse der Einzelfälle sind in Tabelle $4 \mathrm{im}$ Anhang zusammengefaßt.

Nur bei 5 der 38 Tumoren ließ sich eine nukleäre p16-Färbung nachweisen (Abbildung 7A), während 33 Karzinome (87\%) keine Reaktion mit dem Antikörper DCS-50 zeigten. In allen Fällen waren die Fibroblasten und Lymphozyten als interne Kontrolle positiv, und die positive Reaktion blieb aus, wenn die Schnitte mit unspezifischem Maus-Serum inkubiert wurden. In 84\% stimmten die Ergebnisse der Immunhistochemie für p16 mit den CGH-Daten überein, d.h. alle Malignome mit einem durch die CGH festgestellten 9p-Verlust auch negativ für das p16-Protein waren.

Alle untersuchten Kopf-Hals-Karzinome zeigten eine Reaktion mit dem spezifischen Antikörper DCS-6 gegen Cyclin D1, die zwischen den Zellkernen teilweise ungleichmäßig ausgeprägt war. In $47 \%$ der Fälle war die nukleäre Färbung schwach, während die Zellkerne in 29\% mittelgradig und in 24\% stark gefärbt waren (Abbildung 7B). Alle mittel bis stark positiven Karzinome wiesen in der $\mathrm{CGH}$ eine Überrepräsentierung der Region $11 \mathrm{q} 13$ auf. Von den untersuchten Patienten waren 11 am Tumorleiden verstorben. In 6 dieser Fälle (26a, 27a, 55a, 60a, 62a, 69a) zeigten die Malignome eine starke Expression des Cyclin D1-Proteins.

Mit dem spezifischen Antikörper 1F8 konnte pRb in 36 von 38 Tumoren (95\%) immunhistochemisch nachgewiesen werden (Abbildung 7C). Lediglich 2 Karzinome zeigten keine nukleäre Färbung. Bei den pRb positiven Tumoren war in $15 \%$ der Fälle ein heterogenes Expressionsmuster feststellbar, d.h. neben den positiven fanden sich gleichzeitig $\mathrm{pRb}$ negative Zellkerne. Es bestand keine Korrelation zwischen dem pRb Expressionsmuster und Allelverlusten bei 13q14 bzw. durch die CGH festgestellten Deletionen auf Chromosom 13q. Bis auf einen $\mathrm{pRb}$ negativen Tumor, der auch für p16 negativ war, zeigte sich eine reziproke Expression von $\mathrm{pRb}$ und $\mathrm{p} 16$. 


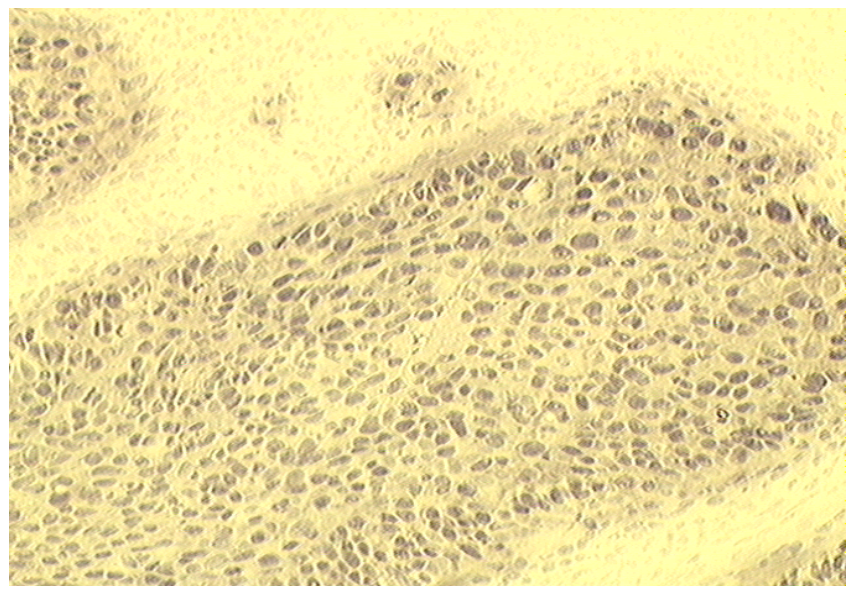

Abbildung 7A:Immunhistochemisch positive Proteinexpression des TSG p16; keine HE-Gegenfärbung. Vergrößerung x50.

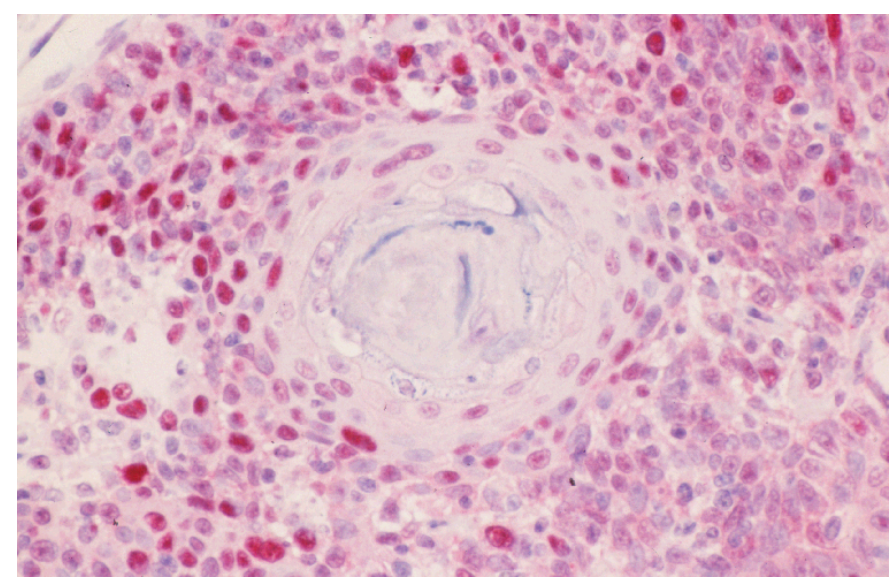

Abbildung 7B:Immunhistochemisch mittel- bis stark positive Proteinexpression von Cyclin D1. HE-Gegenfärbung. Vergrößerung x100.

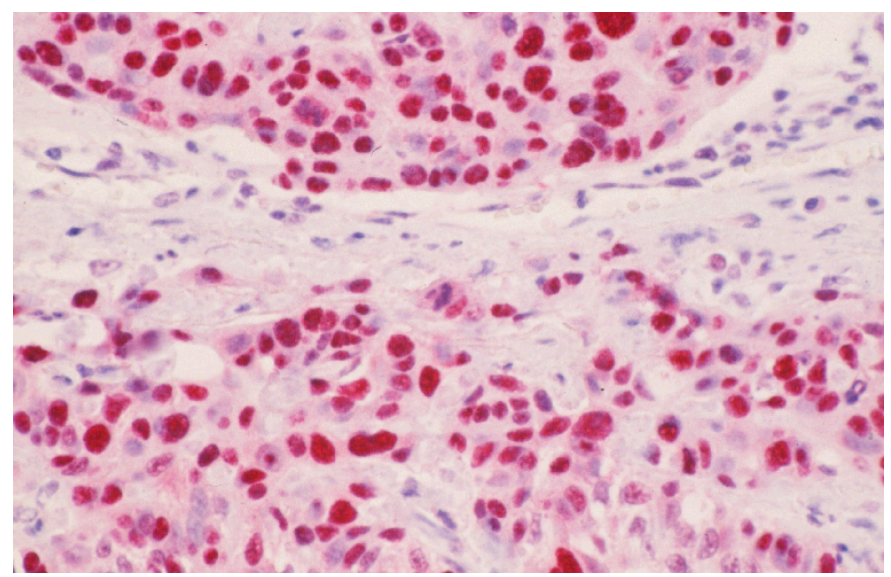

Abbildung 7C:Immunhistochemischer Nachweis der Proteinexpression des TSG Rb. HE-Gegenfärbung. Vergrößerung x100. 


\subsection{Vergleich Primärtumor und korrespondierende Zellinie}

Von 3 primären Plattenepithelkarzinomen (von insgesamt 69 angelegten Primärkulturen) konnten Zellinien etabliert werden; zum Primärtumor 29a die Zellinie D6, zu 44a die D36 und zum Tumor 133a die D40.

Die Zellinien zeigten insgesamt mehr genetische Imbalancen als die Primärtumoren, wobei jeweils die für die Plattenepithelkarzinome des Kopf-HalsBereiches charakteristischen Veränderungen (Deletionen auf 3p, 4q, 8p, 9p, 13q und 18q sowie die Amplifikationen auf 3q, 5p, 8q, 9q und 11q13) übereinstimmten. Ein Beispiel dafür, daß die Zellinie genetisch dem Primärtumor entspricht und zwar in $90 \%$ der Alterationen, zeigt die Abbildung 8.
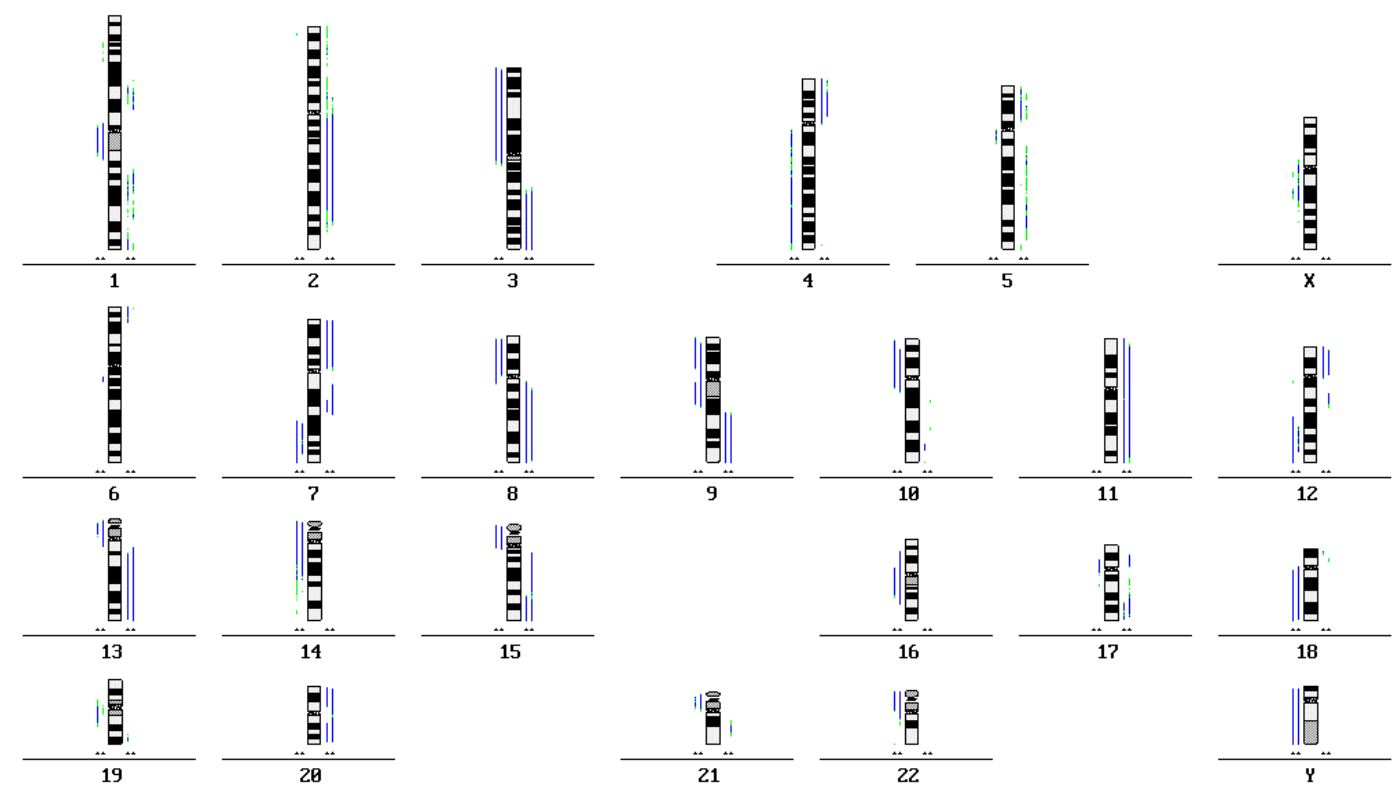

Abbildung 8: Vergleich des Primärtumors 133a und der korrespondierenden Zellinie D40p4. Die Striche am Chromosomideogramm repräsentieren innen die Alterationen im Primärtumor und außen diejenigen der Zellinie, wobei links jeweils die Deletionen und rechts die Amplifikationen dargestellt sind. 
Die zwischen Primärtumor (pt) und Zellinie (z) unterschiedlichen Veränderungen sind in der nachfolgenden Tabelle 7 aufgelistet.

\begin{tabular}{|c|c|c|}
\hline Zellinie & DNA-Verluste & DNA-Überrepräsentierungen \\
\hline D6p9 & $10 \mathrm{p}(\mathrm{z})$ & $\begin{array}{l}3 q 21-q \operatorname{ter}(\mathrm{z}), 5 \mathrm{p}(\mathrm{z}), 5 \mathrm{q} 31 \text {-qter } \\
(\mathrm{z}), 8 \mathrm{q}(\mathrm{z}), 9 \mathrm{q} 21-33(\mathrm{z}), 20 \mathrm{q}(\mathrm{z})\end{array}$ \\
\hline D36-1p26 & $\begin{array}{l}8 p(z), 9 p(z), 18 q 11-12(p t), 21 q \\
(z)\end{array}$ & $\begin{array}{l}1 \mathrm{p} 32-\operatorname{pter}(\mathrm{z}), 8 \mathrm{q} 13-21(\mathrm{pt}), \\
9 \mathrm{q} 13-21(\mathrm{z}), 15 \mathrm{q} 22-25(\mathrm{z}), 16(\mathrm{z}) \\
17(\mathrm{z}), 19 \mathrm{q}(\mathrm{z}), 20(\mathrm{z})\end{array}$ \\
\hline D36-2p23 & $\begin{array}{l}1 \mathrm{p} 22-31(\mathrm{z}), 2 \mathrm{q} 33-\mathrm{qter}(\mathrm{z}), 3 \mathrm{q} 12- \\
24(\mathrm{z}), 6 \mathrm{q} 11-22(\mathrm{z}), 7 \mathrm{q} 21-31(\mathrm{z}) \\
8 \mathrm{p}(\mathrm{z}), 8 \mathrm{q} 11-23(\mathrm{z}), 9 \mathrm{p}(\mathrm{z}) \\
12 \mathrm{q} 13-22(\mathrm{z}), 21 \mathrm{q}(\mathrm{z})\end{array}$ & $\begin{array}{l}3 q 22-27(z), 7 p(z), 8 q 13-23(p t), \\
9 q 13-21(z), 10 q 23-q t e r(z), \\
15 q 22-25(z), 16(z), 17(z), 19 p \\
(z), 20(z), 22 q(z),\end{array}$ \\
\hline D40p4 & $4 q(z)$ & $2 q 11-32(z)$ \\
\hline
\end{tabular}

In einem Fall (Primärtumor $=44 a$ ) gelang es, zwei sowohl morphologisch wie molekularzytogenetisch unterschiedliche Klone anzuzüchten (Zellinien D36-1 und D36-2). Die Abbildung 9 zeigt die Unterschiede in der Morphologie. 


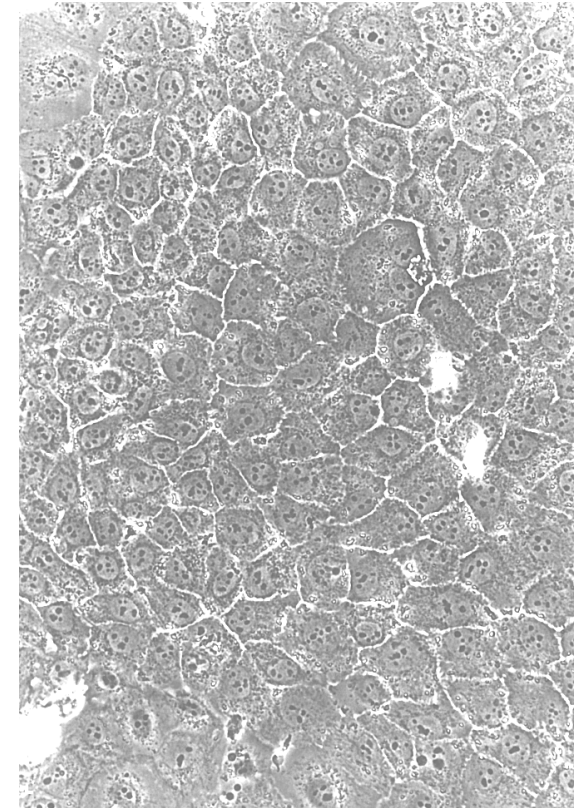

A

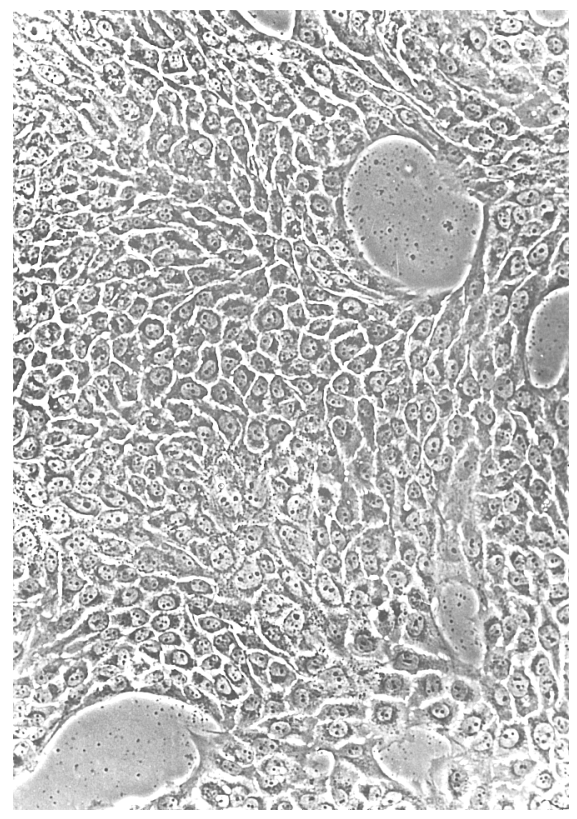

B

Abbildung 9: Vergleich der Morpholgie zwischen den Zellinien D36-1 und -2. (A) D36-1p26 ist großzellig, annähernd plattenepithelial differenziert mit wenig Mitosen wächst. (B) D36-2p23 zeichnet sich durch ein kleinzelliges, undifferenziertes, stark polymorphes Wachstum mit vielen atypischen Mitosen aus. Vergrößerung x200.

Der Morphologie entsprechend ließen sich in den Zellinien untereinander als auch im Vergleich zum Primärtumor molekularzytogenetische Unterschiede feststellen. Die Abbildung 10 verdeutlicht, daß die Übereinstimmung nur in $60 \%$ aller Veränderungen besteht.

Der Primärtumor wie auch beide Zellinien weisen gemeinsame Deletionen bei 2p23-pter, 3p, 4q, 6p22-pter, 6q23-q24, 10p, 10q11-q21, 13q11-q21, 15q11-q15, 18q12-qter und Amplifikationen bei 2q14.3-q22, 3q26-qter, 5p, 8q24, 9q22-qter, 11q12-q23, 14q24-qter auf. In den Zellinien zeigen sich darüberhinaus gemeinsame Deletionen auf 8p, 9p, 21q und Amplifikationen auf 15q22-q25, 16, 17 sowie 20. Die Differenzen zwischen beiden Zellinien und/oder dem Primärtumor betreffen vor allem die Chromosomen 1p, 2q, 3, 6q, 7, 8q, 10q, 12q, 19 und 22q (siehe Tabelle oben). 

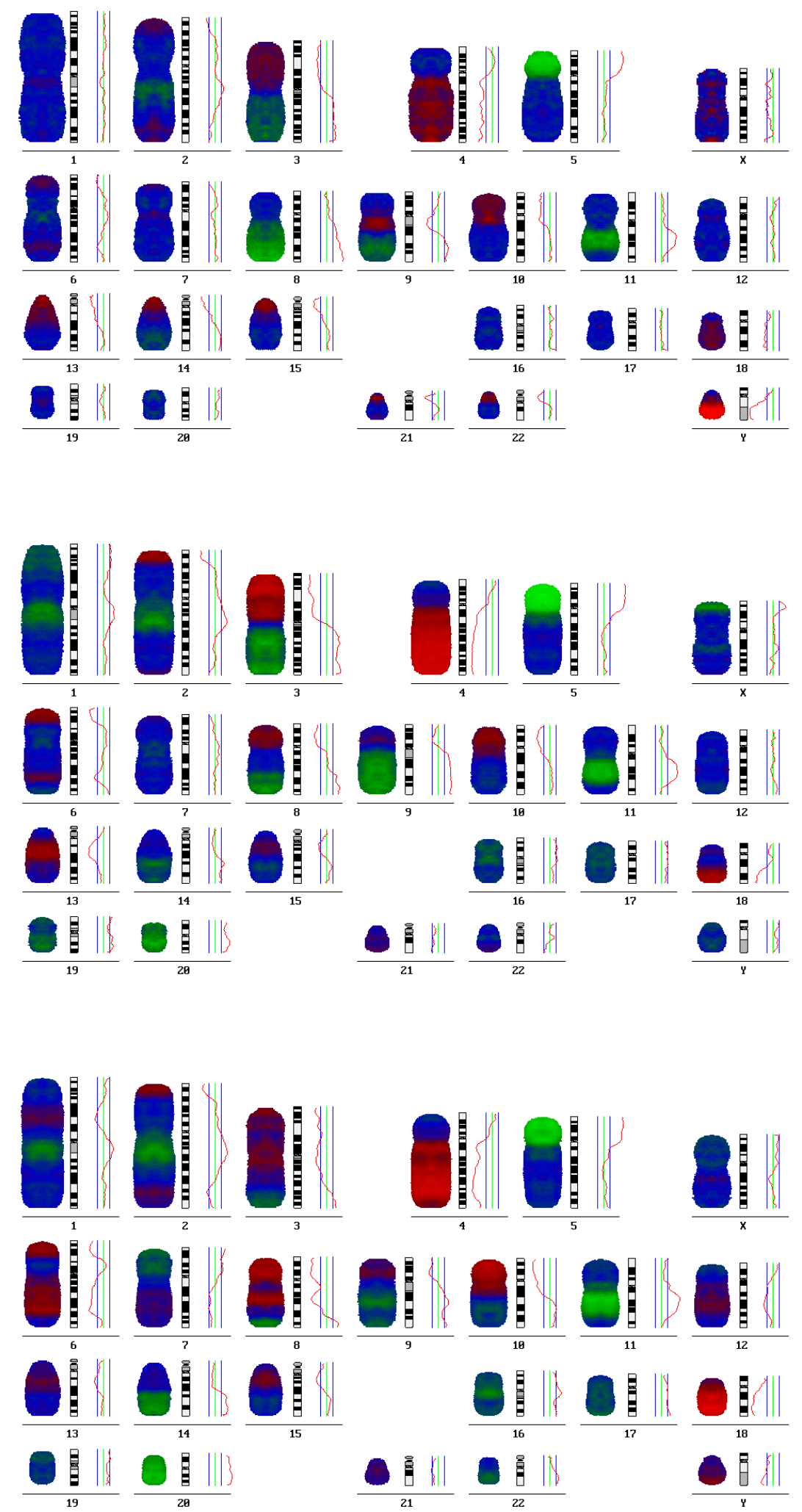

Abbildung 10: Vergleich der Summen-Karyogramme des Primärtumors 44a (oben) mit den Zellinien D36-1p26 (Mitte) und D36-2p23 (unten). 
Die Karyotypen der Zellinien D36-1 und -2 (wie nachfolgend aufgelistet) stimmen im wesentlichen mit den CGH-Veränderungen überein (z.B. Deletionen von Chromosom 4q, 6q, 18q oder die Amplifikation von Chromosom 20 und das 5qIsochromosom). Einzelne in der CGH unterschiedliche Alterationen lassen auf die Zusammensetzung der Markerchromosomen schließen wie z.B. die Amplifikation auf 11q.

$$
\begin{array}{ll}
\text { D-36-1 } & 41-43, \quad \mathrm{XY}, \operatorname{add}(2)(\mathrm{q} 36), \mathrm{i}(3)(\mathrm{q} 10),-4, \operatorname{del}(4)(\mathrm{q} 21),+\mathrm{i}(5)(10) \times 2, \\
& \operatorname{del}(6)(\mathrm{q} 23 \mathrm{q} 25), \operatorname{add}(7)(\mathrm{p} 22),-8,+\operatorname{der}(9) \mathrm{t}(9 ; ? ; 10)(\mathrm{p} 24 ; ? ; \mathrm{q} 11),-11,-13, \\
& -15,-18,+19,+5-8 \operatorname{mar}[\mathrm{cp} 7] / 80, \operatorname{idem} 2[\mathrm{cp} 4] \\
\text { D-36-2 } & 74-77, \quad \mathrm{XXY},-\mathrm{Y}, \operatorname{add}(2)(\mathrm{q} 36),-4,-4, \operatorname{del}(4)(\mathrm{q} 21) \times 2,+\mathrm{i}(5)(\mathrm{p} 10) \times 3, \\
& \operatorname{del}(6)(\mathrm{q} 23 \mathrm{q} 25) \times 2, \operatorname{add}(7)(\mathrm{p} 22),-8,-8,+\operatorname{der}(9) \mathrm{t}(9 ; ? ; 10)(\mathrm{p} 24 ; ? ; \mathrm{q} 11) \times 2, \\
& -11,-11,-13,-13,-15,-15,-18,-18,+20,+20,+6-8 \operatorname{mar}[\mathrm{cp} 5]
\end{array}
$$

\subsection{Vergleich Primärtumor und Lymphknotenmetastase}

Von 25 Primärtumoren wurden 23 synchrone und 4 metachrone cervicale Lymphknotenmetastasen sowie in 2 Fällen pulmonale Metastasen mittels der CGH untersucht. Der Vergleich zwischen den Primärtumoren und ihren Metastasen ergab, daß die chromosomalen Alterationen im Mittel in 62,5\% vollständig übereinstimmten. In 3 Fällen lag der Prozentsatz der identischen Veränderungen knapp unter 50\% (zwischen 45\%-49\%), und nur in einem Fall bestand in lediglich 27,3\% Übereinstimmung. Demgegenüber zeigten 4 Fälle in 85\% identische Veränderungen. Alle anderen 17 Tumorpaare lagen in der prozentualen Übereinstimmung ihrer Alterationen zwischen 50\% und 85\%.

Die klonale Zuordnung von Primärtumor und Metastase wurde vorgenommen, wenn das CGH-Muster der Alterationen in möglichst mehr als 50\%, aber wenigstens $>40 \%$ der charakteristischen Alterationen übereinstimmte und/oder gleiche spezifische Amplifikationen auftraten. Bis auf einen Fall war somit die Klonalität nachweisbar.

Die Abbildung 11 zeigt als Beispiel die Summen-Karyogramme eines primären glottischen Larynxkarzinoms (pT4 pN2 M0 G2) mit einer synchronen und einer metachronen cervicalen Lymphknotenmetastase. Die metachrone Metastase entstand 1 Jahr nach operativer Therapie und adjuvanter Radiatio. 

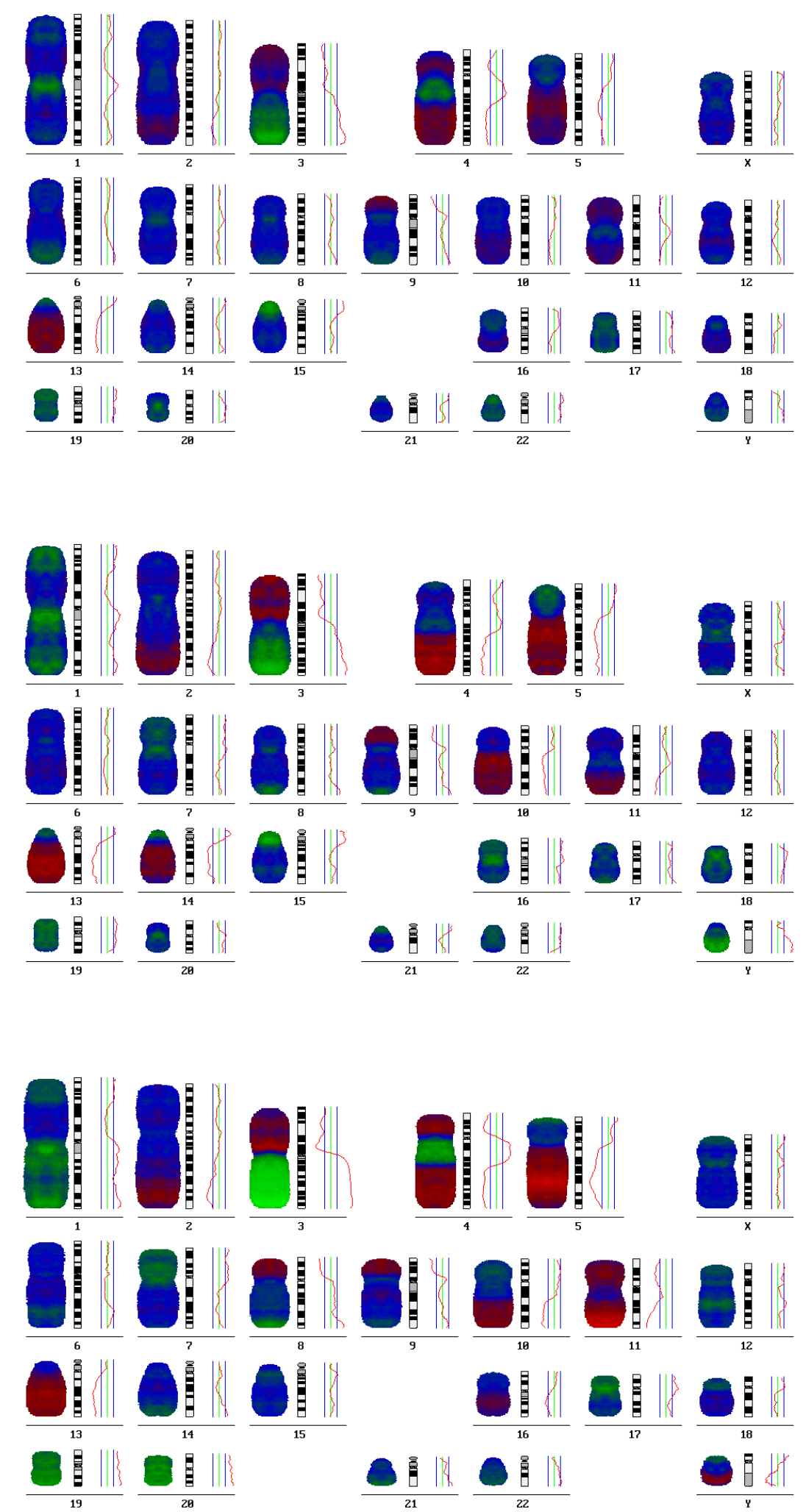

Abbildung 11:Vergleich der Summen-Karyogramme des Primärtumors 37a (oben) mit einer synchronen (Mitte) und einer metachronen (unten) Lymphknotenmetastase. 
Das im wesentlichen gleiche Muster von Veränderungen im Bereich der Chromosomen 2, 3, 4q, 5q, 9p, 10q, 13q, 19, und 22q verdeutlicht den klonalen Zusammenhang der 3 Tumoren. Im Vergleich zum Primärtumor weisen die Metastasen jedoch insgesamt mehr Alterationen auf, und einzelne Veränderungen wie im Bereich der Chromosomen 1, 4, 7p, 8, 10q, 11, 14, 19 und 20 variieren. Darin spiegeln sich mögliche Mechanismen der klonalen Entwicklung von KopfHals-Karzinomen wieder. So könnten z.B. das zusätzliche Auftreten von Überrepräsentierungen oder das Entstehen einer high-copy-Amplifikation aus einer einfachen Überrepräsentierung wie bei 1q, 4q, 7p, 12q, 19 und 20 Regionen möglicher Proto-Onkogene markieren. Die Ausdehnung interstitieller Deletionen auf Verluste des gesamten Chromosomarmes wie bei $3 p$ oder $5 q$ läßt diese Veränderungen als Auslöser in der Entwicklung großer chromosomaler Imbalancen vermuten. Die erst in den Metastasen klar hervortretende Deletion von $10 \mathrm{q}$ ist charakteristisch für den metastasierenden Klon. Ein weiteres Beispiel dieses Phänomens entspricht den Ergebnissen der LOH-Analyse für das Chromosom 10q (siehe oben) und wird auch am Beispiel des CGH-Profils für den Fall 67 deutlich (Abbildung 12).

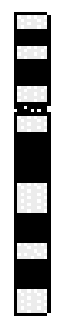

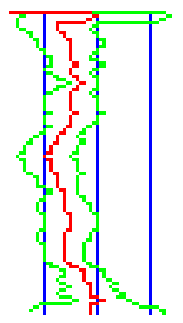

$\mathrm{T}$

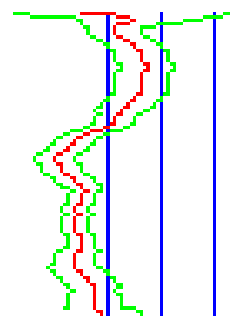

LK
Abbildung 12:

CGH-Profil des Falles 67.

$\mathrm{T}=$ Primärtumor,

Lk=Lymphknotenmetastase.

Anhand des 99\% Konfidenzintervalls zeigt sich in der Lymphknotenmetastase eindeutig der Verlust fast des gesamten 10q-Armes, während die Deletion im Primärtumor subtiler und nur bei 10q21 gelegen ist.

Um die Primärtumoren und ihre korrespondierenden Lymphknotenmetastasen in Bezug auf alle chromosomalen Veränderungen vergleichen zu können, wurde aus beiden Gruppen ein Differenzhistogramm berechnet. Das Ergebnis ist in Abbildung 13 dargestellt. 


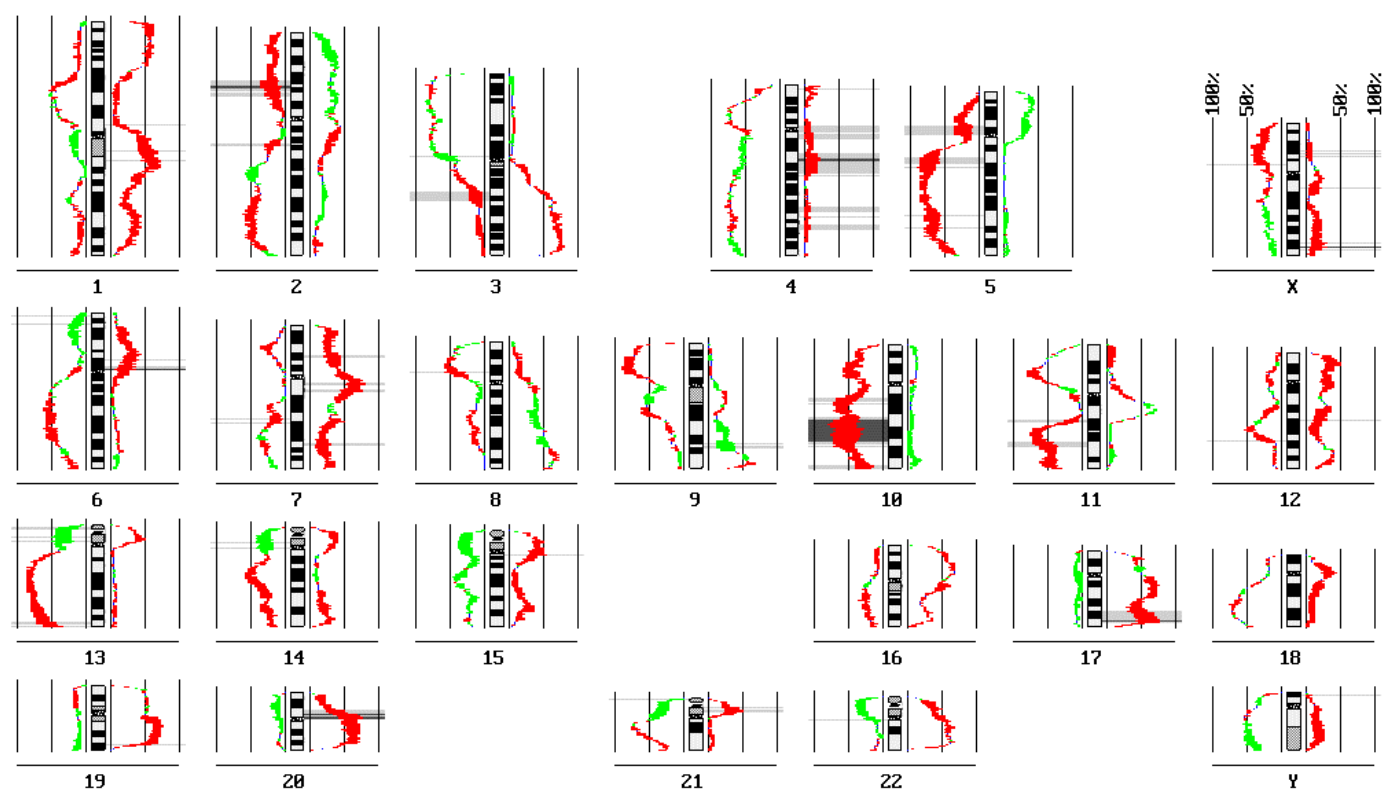

Abbildung 13: Differenzhistogramm zwischen 25 Primärtumoren und ihren synchronen Lymphknotenmetastasen.

Die roten Bereiche verdeutlichen ein Überwiegen der Alterationen in den Lymphknotenmetastasen. Die grünen Bereiche zeigen Veränderungen, die häufiger bei den Primärtumoren auftreten. Die grau markierten Areale kennzeichnen statistisch signifikante Unterschiede zwischen beiden Gruppen im Chi-Quadrattest (dunkelgrau $=99 \%$, hellgrau $=95 \%$ Signifikanz). Hervorstechend sind wiederum die in den Metastasen hoch signifikant häufiger nachweisbaren DNA-Verluste auf Chromosom 10q.

\subsection{Vergleich metastasierender und nicht metastasierender Karzinome}

Siebenunddreißig nicht metastasierende (pN0) primäre Kopf-Hals-Tumoren wurden 63 metastasierenden $(\mathrm{pN}+)$ Karzinomen gegenübergestellt. Zunächst wurde geprüft, ob es Unterschiede in der Anzahl der chromosomalen Aberrationen gibt. Mit Hilfe des Student-t-Testes ließen sich beide Gruppen sowohl in der Anzahl aller Alterationen $(p=0,001)$ als auch in der Anzahl der Deletionen $(p=0,0001)$ signifikant voneinander unterscheiden. Die $p N+$ Tumoren wiesen im Mittel 20,9 Veränderungen auf gegenüber durchschnittlich 15,8 
Aberrationen bei den pN0 Karzinomen. Die Anzahl der Deletionen betreffend, lag der Mittelwert in der pN+ Gruppe bei 12,6 und im pN0 Kollektiv bei 8,7.

Zur Identifizierung spezifischer, den metastasierenden Phänotyp charakterisierender chromosomaler Veränderungen wurden beide Gruppen durch die Berechnung eines Differenzhistogramms miteinander verglichen. Das Ergebnis ist in der Abbildung 14 dargestellt.

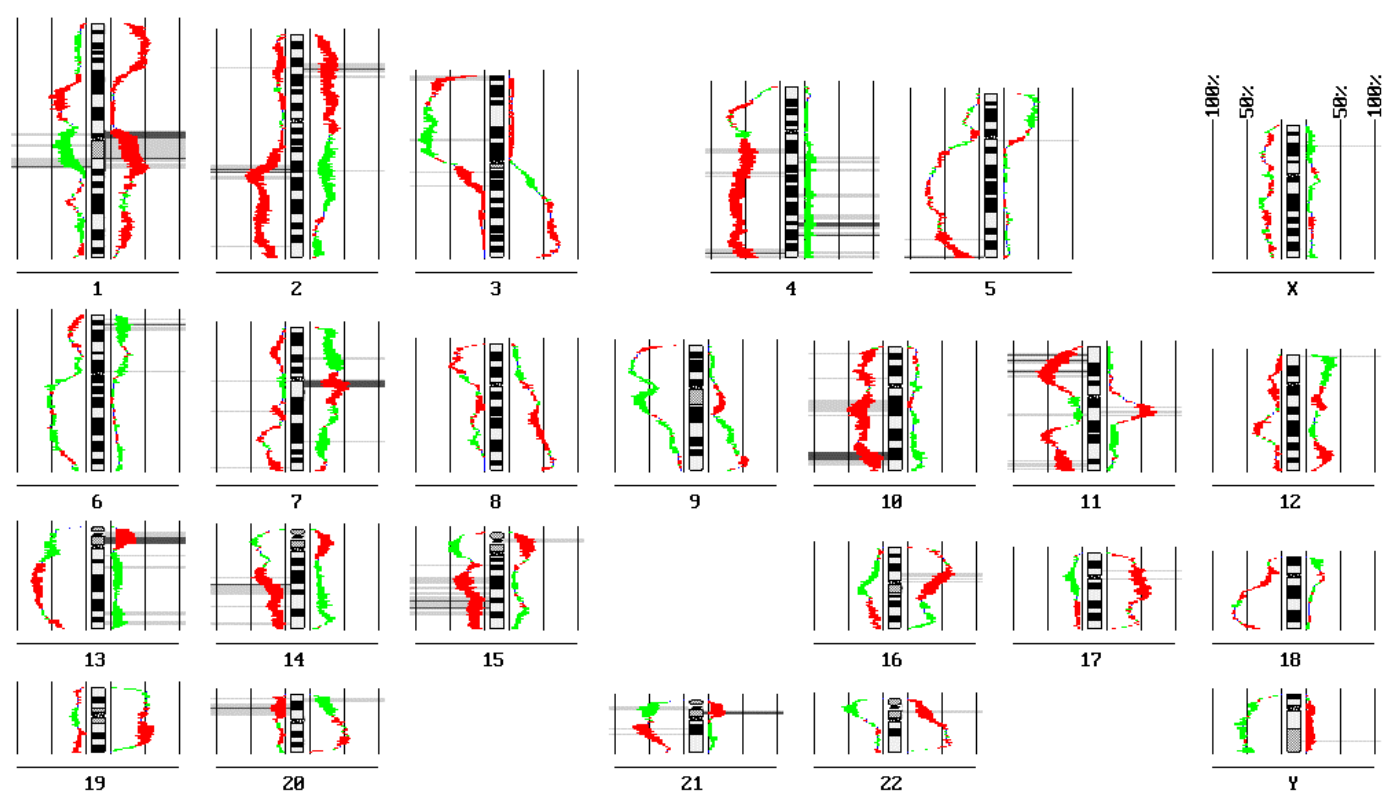

Abbildung 14: Differenzhistogramm zwischen 37 nicht metastasierenden (pN0) und 63 metastasierenden $(\mathrm{pN}+)$ Karzinomen.

Die roten Bereiche verdeutlichen ein Überwiegen der Alterationen in der $\mathrm{pN}+$ Gruppe. Die grünen Bereiche zeigen Veränderungen, die häufiger bei den pN0 Karzinomen auftreten. Die grau markierten Areale kennzeichnen wiederum statistisch signifikante Unterschiede zwischen beiden Gruppen im ChiQuadrattest (dunkelgrau $=99 \%, \quad$ hellgrau $=95 \% \quad$ Signifikanz). Die nicht metastasierenden Karzinome zeigen insgesamt mehr Überrepräsentierungen. Speziell betrifft das die Chromosomenarme 4q, 6p, 7p, 12p, 13q und 20p. Dabei sind die Überrepräsentierungen der Regionen 4q31.2-q32 und 6p23-p24 99\% signifikant für die pN0 Tumoren. Demgegenüber weisen die metastasierenden 
Karzinome mehr Deletionen im Bereich der Chromosomen 2q, 4q, 5q, 10q, 11p, $11 \mathrm{q}, 14 \mathrm{q}, 15 \mathrm{q}, 20 \mathrm{p}$ sowie $21 \mathrm{q}$ und Überrepräsentierungen bei 2p sowie 11q13 auf. Im einzelnen zeigte die statistische Analyse, daß die Banden 2q22-q23, 10q25q26 und 11p13-p15 hoch signifikant sind für den metastatischen Phänotyp. Regionen mit vorwiegend 95\% Signifikanz projezieren sich auf 2p21-p22, 4q13, 4q34-q35, 10q21, 11q13, 11q24-q25, 14q21-q23, 15q21-q24, 20p12 und 21q21.

Ausgehend davon, daß die Lymphknotenmetastasen die charakteristischen genetischen Veränderungen des metastasierenden Klons eines Primärtumors repräsentieren, wurden sie, ebenfalls über die Berechnung eines Differenzhistogramms, den pN0 Karzinomen gegenübergestellt. Die deutlichsten Unterschiede zeigten sich für die Chromosomen 10, 11, 14 und 19 (Abbildung $15)$.

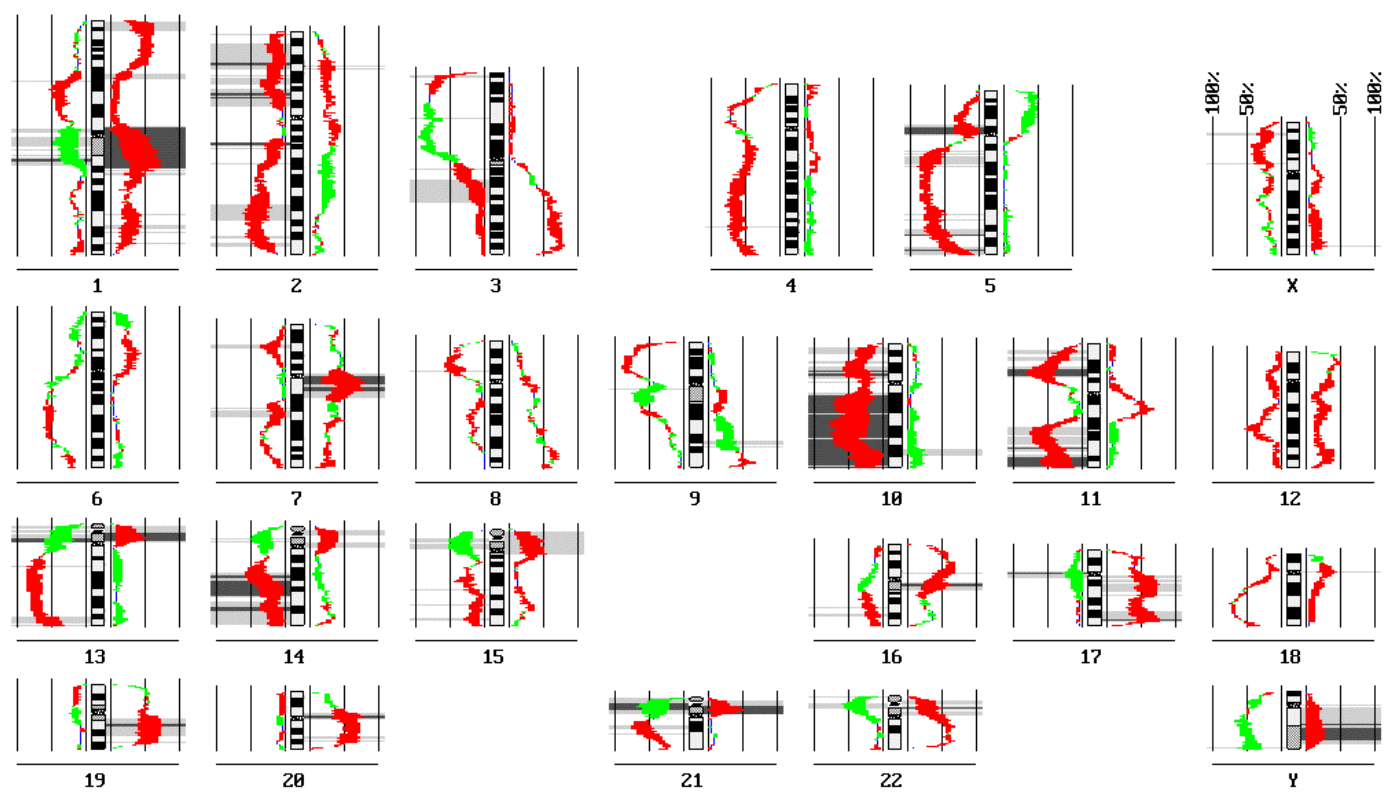

Abbildung 15: Differenzhistogramm zwischen 37 nicht metastasierenden KopfHals-Karzinomen und 25 Lymphknotenmetastasen.

Für die Interpretation der Abbildung 15 gelten die selben Prinzipien wie für die anderen Differenzhistogramme, wobei die roten Bereiche ein Überwiegen der Alterationen in den Lymphknotenmetastasen und die grünen Bereiche ein solches für die pN0 Karzinome markieren. Die bereits bei den metastasierenden KopfHals-Tumoren signifikanten Deletionen auf 10q, 11p/q und 14q bestätigen sich 
und sind in den Metastasen sehr viel deutlicher ausgeprägt. Das gilt wiederum besonders für das Chromosom 10q, dessen Verlust statistisch hoch signifikant mit der Metastasierung assoziiert ist. Daneben zeigen sich in den Metastasen zusätzlich signifikant häufiger Deletionen auf 10p und Überrepräsentierungen auf dem Chromosom 19q.

\subsection{Vergleich von Karzinomen unterschiedlicher Differenzierung}

Plattenepithelkarzinome des Kopf-Hals-Bereiches werden entsprechend ihrer Differenzierung in die Grad 1 - 3 eingeteilt. Der Grad 1 bezeichnet gut differenzierte Tumoren wie in Abbildung 16A dargestellt. Typische Charakteristika sind die gut nachvollziehbare plattenepitheliale Differenzierung mit Verhornung, klaren Zellgrenzen und Zellkernstrukturen und nur wenigen Mitosen. Demgegenüber kennzeichnet der Grad 3 die schlecht differenzierten Malignome (Abbildung 16B), die architektonisch sowohl wie zytoplasmatisch nur noch sehr wenig an Plattenepithel erinnern. Ihre Zellgrenzen sind unscharf, die Zellkerne sehr polymorph mit Ausbildung großer Nukleoli, und es zeigen sich häufig Mitosen einschließlich atypischer Teilungsfiguren. Die Mehrzahl der Kopf-Hals-Karzinome ist mäßig differenziert, d.h. entspricht dem Grad 2, bei dem die morphologischen Malignitätscharakteristika zwischen denen der Grad 1- und 3-Karzinome liegen.

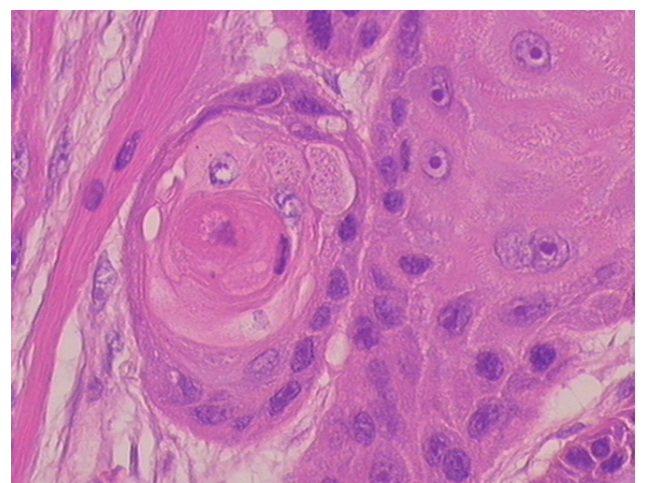

A

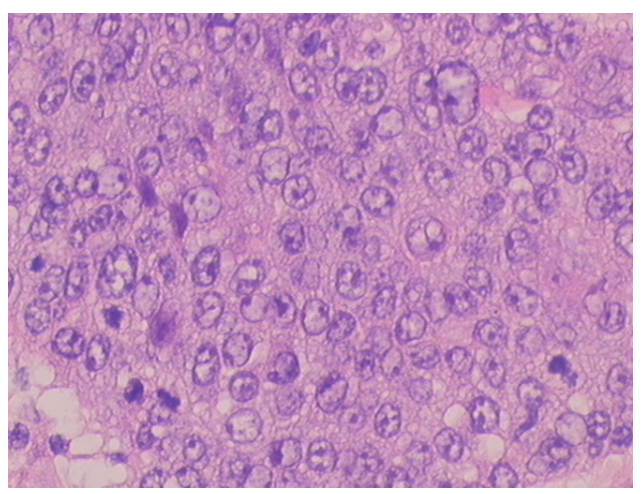

B

Abbildung 16: Histologischer Vergleich eines gut differenzierten (A) und eines schlecht differenzierten (B) Plattenepithelkarzinoms. Vergrößerung x 100 . 
Für den genetischen Vergleich zwischen Karzinomen unterschiedlicher Differenzierung wurden die Summen-Karyogramme aller Tumoren einer Gruppe jeweils zu einem Super-Karyogramm summiert. Dabei zeigten sich für die gut (G1) bzw. schlecht differenzierten (G3) Karzinome jeweils charakteristische chromosomale Veränderungen. Sie sind anhand der Super-Karyogramme in der Abbildung 17 dargestellt.
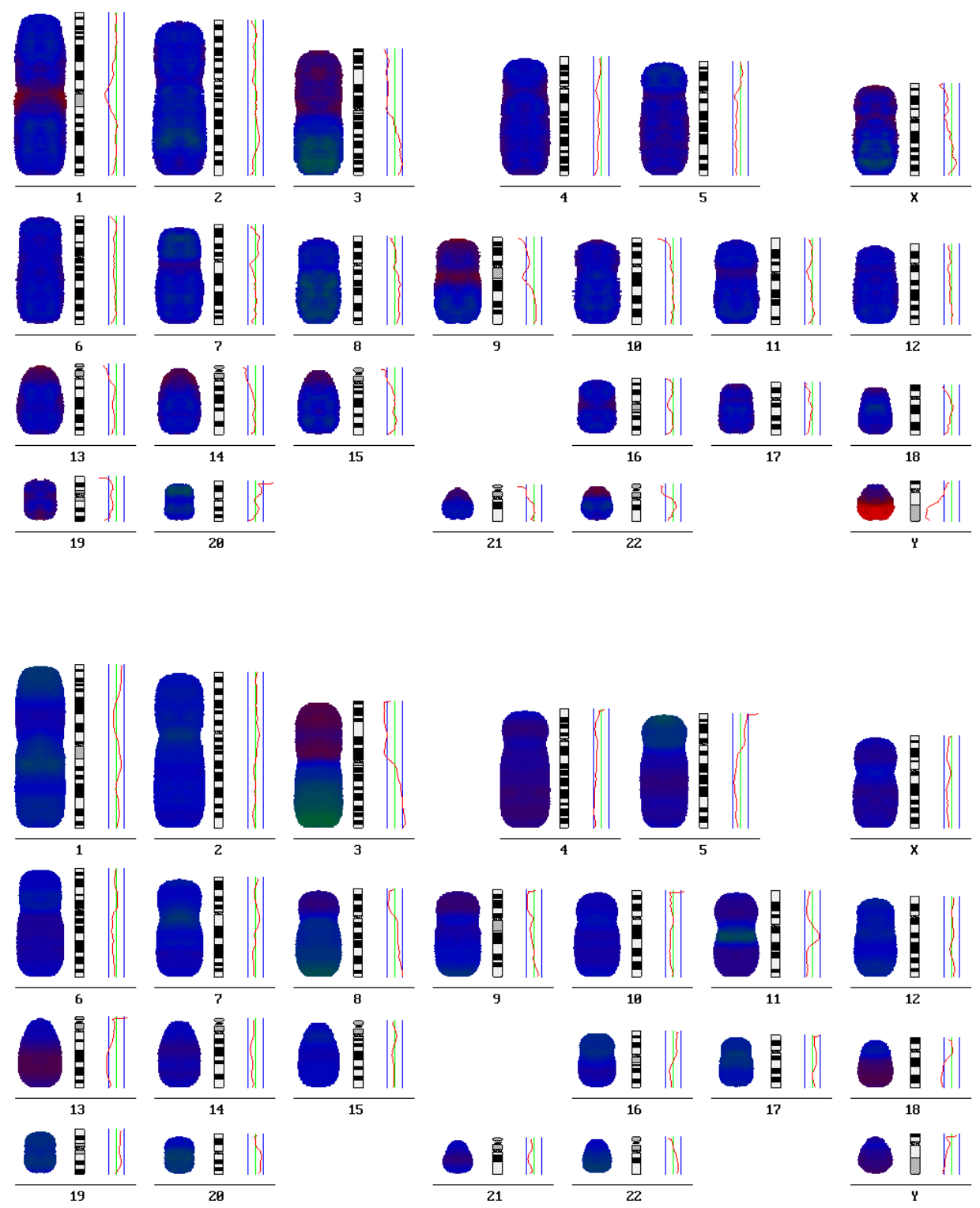

Abbildung 17: Vergleich der Super-Karyogramme von 4 G1-Tumoren (oben) und 19 G3-Karzinomen (unten). 
Die G1-Tumoren (A) sind durch die Deletionen auf 3p und 9p kombiniert mit der Überrepräsentierung auf $3 q$ gekennzeichnet. Im Vergleich dazu weisen die schlecht differenzierten Malignome (B) zusätzlich die Deletionen der Chromosomen 4, 5q, 8p, 11, 13q, 18q sowie 21q und die Überrepräsentierungen von 8q, 11q13 sowie 20q auf. Diese Unterschiede verdeutlichen den Zusammenhang der genetischen Instabilität und der Entdifferenzierung der Karzinome als ein Merkmal der Malignität.

\subsection{Vergleich Primärtumor und Zweitkarzinom}

Von 10 Patienten wurden jeweils der Primärtumor und das Zweitkarzinom mit Hilfe der $\mathrm{CGH}$ hinsichtlich der Frage der Klonalität und Suszeptibilität untersucht. In 3 Fällen handelte es sich um metachrone, in 7 Fällen um synchrone Zweitkarzinome, wobei unter letzteren in 3 Fällen Ösophaguskarzinome die zweite Tumormanifestation waren.

Der Vergleich des Gesamtkollektivs der Zweitkarzinome mit 15 sporadischen Karzinomen (Patienten mit einer unauffälligen Familienanamnese und einer hohen sowie langjährigen Nikotin-/Alkoholexposition) zeigte keine Einzelveränderung, die konstant mit einer Tumorsuszeptibilität assoziiert werden könnte.

Für den Vergleich der Mehrfachtumoren untereinander wurden jeweils die übereinstimmenden bzw. differierenden Einzelveränderungen ausgezählt und prozentual gegenübergestellt. Dabei wurde zwischen Alterationen, die für die Tumorentität der Plattenepithelkarzinome des Kopf-Hals-Bereiches charakteristisch sind (siehe 4.1.), und solchen, die sporadisch auftreten, unterschieden. Diese Auswertung zeigte, daß die klonale Zuordnung aufgrund der Heterogenität sowie der genetischen Instabilität der Tumoren sehr schwierig ist. Von einer Klonalität der Mehrfachkarzinome wurde ausgegangen, wenn die Malignome in möglichst mehr als 50\%, aber wenigstens $>40 \%$ der charakteristischen Alterationen übereinstimmten und/oder gleiche spezifische Amplifikationen aufwiesen. Die beiden nachfolgenden Beispiele sollen dieses verdeutlichen. 
Die Abbildung 18 zeigt die Summen-Karyogramme und -Profile der synchronen Tumoren des Falles 203. Das Hypopharynxkarzinom und das supraglottische Larynxkarzinom weisen in Bezug auf alle Alterationen nur in 50\% eine Übereinstimmung auf. Betrachtet man die charakteristischen genetischen Veränderungen, so besteht eine Identität in 58\%. Darüberhinaus zeigen beide Tumoren eine spezifische Amplifikation im Bereich von 10p11-p12 und der vollständige Verlust des Y-Chromosoms, sodaß ein gemeinsamer klonaler Ursprung angenommen werden kann.
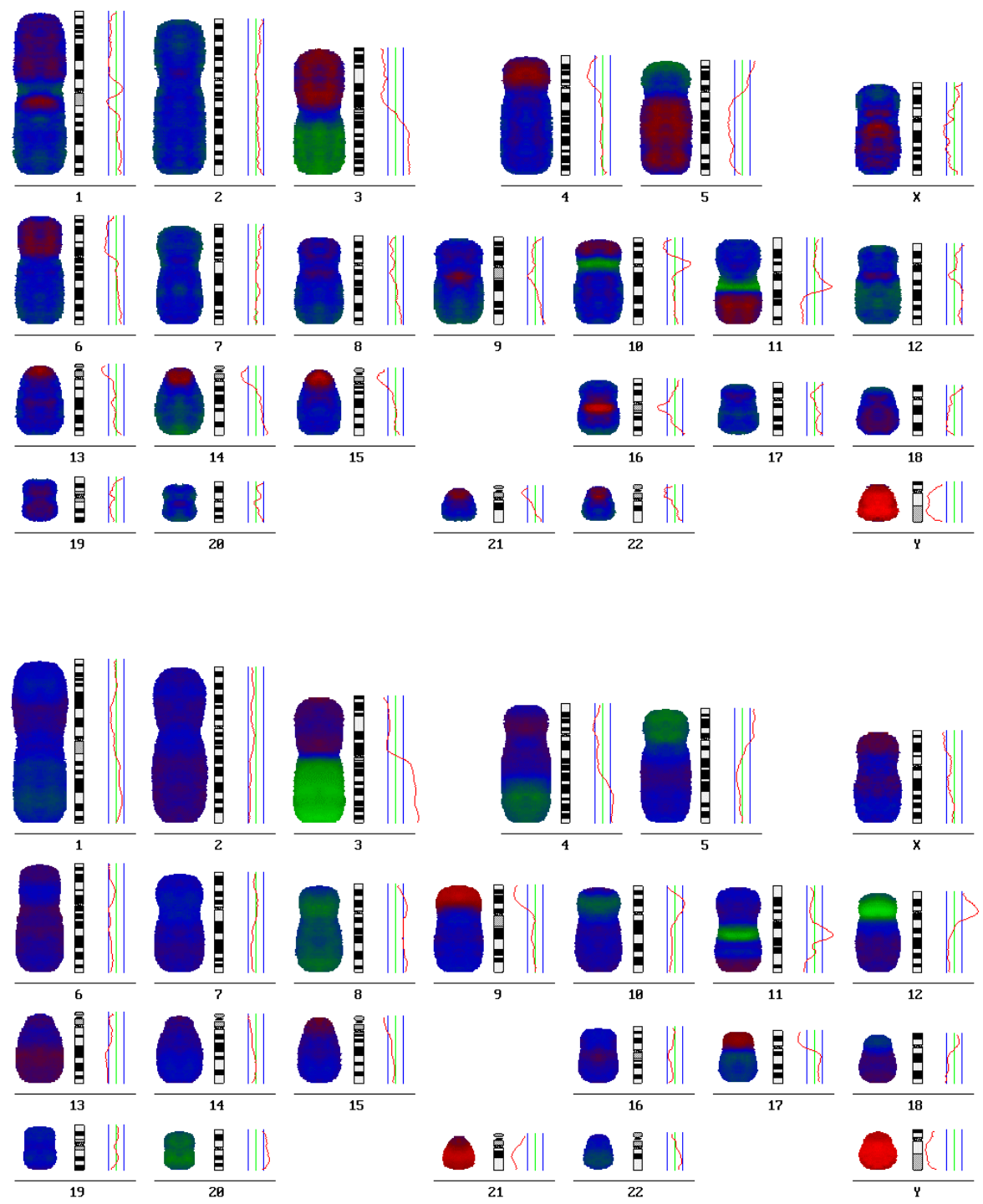

Abbildung 18: Summen-Karyogramme des Falles 203, eines Hypopharynxkarzinoms (oben) und eines synchronen supraglottischen Larynxkarzinoms (unten). 

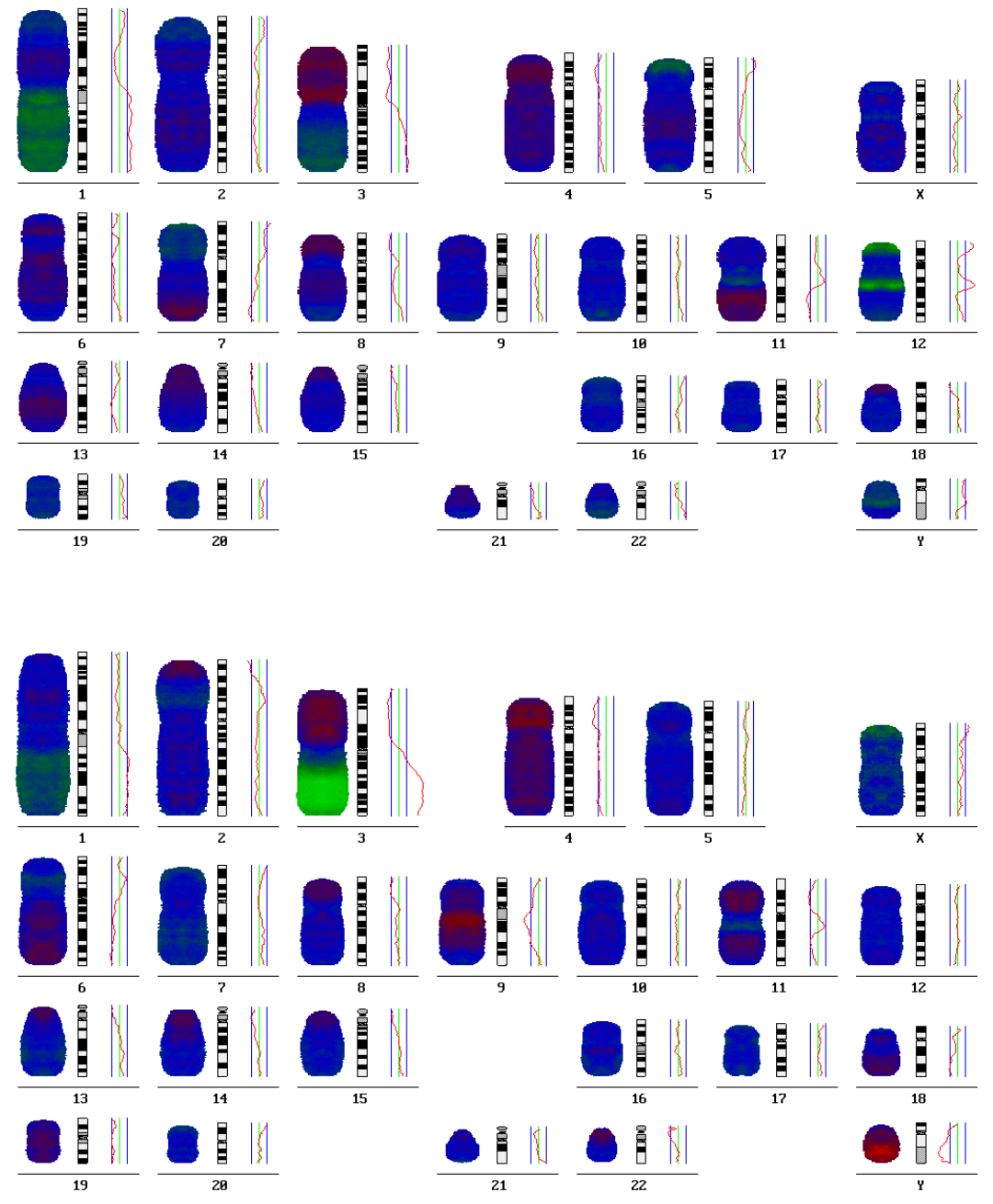

Abbildung 19: Summen-Karyogramme des Falles 192, eines Oropharynxkarzinoms (oben) und einer synchronen Lymphknotenmetastase (Mitte) sowie eines synchronen Ösophaguskarzinoms (unten).

Die Abbildung 19 zeigt die Summen-Karyogramme und -Profile der synchronen Tumoren des Falles 192 sowie eine synchrone Lymphknotenmetastase des Oropharynxkarzinoms. In Bezug auf alle Alterationen stimmen das Oropharynxund das Ösophaguskarzinom nur in 30\%, in Bezug auf die charakteristischen Veränderungen nur in 34\% überein. Als wesentlicher Unterschied ist das YChromosom beim ersteren überrepräsentiert und beim zweiten verloren gegangen. Ein klonaler Zusammenhang wird damit als eher unwahrscheinlich angesehen. Vergleicht man das Oropharynxkarzinom und dessen synchrone zervikale 
Lymphknotenmetastase, so besteht zwar auch nur eine genetische Übereinstimmung in $45 \%$ bzw. $50 \%$, aber beide zeigen spezifische Amplifikationen auf Chromosom 12, und in beiden ist das Y-Chromosom überrepräsentiert, worin sich die Klonalität manifestiert. Als Nebenbefund wird auch hier wieder deutlich, daß der 10q-Verlust erst in der Lymphknotenmetastase auftritt und damit, wie unter 4.3. beschrieben, mit der Metastasierung assoziiert zu sein scheint.

Anhand dieser Auswertung wurden für die Fälle 75, 200, und 203 der synchronen sowie den Fall 198 der metachronen Zweitkarzinome ein gemeinsamer klonaler Ursprung angenommen, während die genetischen Alterationen der anderen Malignome auf eine polyklonale Enstehung hinwiesen.

\section{7. $\quad$ Überlebensstatistik}

Der postoperative Beobachtungszeitraum der 100 Tumorpatienten erstreckte sich zwischen August 1994 und Juni 1998; er betrug somit längstens 4 mindestens aber 2 Jahre. 29 Patienten waren innerhalb dieser Zeit am Tumor verstorben, 15 davon am Lokalrezidiv und 14 an einer Metastasierung. Die statistische Auswertung erfolgte a) nach der Zeit bis zum Auftreten eines Rezidivs, b) der Zeit bis zur Entwicklung von Metastasen, c) dem rezidiv- und metastasenfreien Zeitintervall sowie d) dem Gesamtüberleben. Es wurden zunächst die kumulierten Überlebensraten nach der Kaplan-Meier-Methode unter dem Einfluß der einzelnen klinisch-pathologischen Parameter (Tumorgröße, Lymphknotenstatus, Grading, UICC-Stadium, Tumorlokalisation) und der einzelnen genetischen Daten (Auszählung von DNA-Verlust oder -Überrepräsentierung für jeden Chromosomarm, Anzahl der genetischen Veränderungen, LOH-Ergebnisse) auf die Überlebenkurven bestimmt. Die Überlebenraten wurden dann mit dem LogRank-Test (LR) und dem Breslow-Test (B) auf statistische Signifikanz überprüft, d.h. auf Abhängigkeit von den Einzelparametern. Mit dem Breslow-Test kann dabei der Einfluß einer Variablen innerhalb eines kurzen Zeitintervalls, mit dem Log-Rank-Test die Abhängigkeit bezogen auf lange Überlebenszeiten nachgewiesen werden. 


\section{Kaplan-Meier-Methode}

Für die Einschätzung der Überlebenszeit bis zum Auftreten von Nah- oder Fernmetastasen (metastasenfreies Überleben) erwies sich der Lymphknotenstatus als statistisch signifikantester Parameter mit $\mathrm{p}=0,0128$ (LR) und $\mathrm{p}=0,0224$ (B). Die Analyse der 37 pN0- und der 63 pN+ Tumoren zeigte, daß die metastasenfreie 4-Jahresüberlebensrate bei Patienten mit lymphknotennegativen Primärtumoren 94\% gegenüber $68 \%$ bei Patienten mit pN+ Karzinomen war. Als weiterer signifikanter Parameter für die metastasenfreie Überlebenszeit stellten sich der Nachweis von Heterozygotieverlusten bei 8 p23 mit p=0,0312 (LR) bzw. 0,0114 (B) heraus. Demgegenüber waren die Tumorgröße, das UICC-Stadium, das Grading oder auch die DNA-Verluste auf dem Chromosomenarm 10q für die Einschätzung der metastasenfreien Überlebensrate ohne Bedeutung.

Die Amplifikation der chromosomalen Region 11q13 sowie Heterozygotieverluste auf Chromosom 13q zeigten sich als die statistisch signifikanten Parameter für die Einschätzung der Überlebenszeit bis zum Auftreten eines Lokalrezidivs (rezidivfreies Überleben). Für 11q13 ergab sich eine Signifikanz von $p=0,0310(L R)$ und von $p=0,0427(B)$; für LOH auf $13 q$ waren $p=0,0454$ (LR) bzw. $p=0,0457$ (B). Die klinisch-pathologischen Parameter zeigten wiederum keine signifikante Korrelation mit der Prognose.

Für die Einschätzung der rezidiv- und metastasenfreien Überlebenszeit erwiesen sich die genetischen Marker 11q13-Amplifikation mit $p=0,0021$ (LR) bzw. $p=$ 0,0046 (B) und Amplifikationen von 3q mit $p=0,0314$ (LR) sowie von den pathologischen Parametern das Grading mit $\mathrm{p}=0,0447$ (LR) bzw. $\mathrm{p}=0,0350$ (B) als statistisch signifikant. Die rezidiv- und metastasenfreie 4-Jahresüberlebensrate war bei Patienten mit schlecht differenzierten Primärtumoren ( $n=19) \quad 38 \%$ gegenüber $63 \%$ bei G2-Karzinomen $(n=78)$, während die 4 Patienten mit gut differenzierten Karzinomen alle überlebten. Die Kaplan-Meier-Kurven für verschiedene Tumorgrößen ( $\mathrm{pT})$ und Lymphknotenmanifestationen $(\mathrm{pN})$ ergaben ebenfalls unterschiedliche Verläufe, jedoch keine Signifikanz.

Bezogen auf das Gesamtüberleben waren die genetischen Marker 11q13Amplifikation und Amplifikationen von 3q die einzigen statistisch signifikanten Parameter. Dabei erwies sich die statistische Signifikanz für die 11q13- 
Amplifikation als sehr hoch mit $\mathrm{p}=0,0008$ (LR) bzw. $\mathrm{p}=0,0024$ (B) gegenüber $3 \mathrm{q}$ mit $\mathrm{p}=0,0299$ (LR) und $\mathrm{p}=0,0546(\mathrm{~B})$.

Die Abbildung 20 zeigt die Kaplan-Meier-Kurven bei einer Klassifikation der Gesamtüberlebensrate der Patienten in Abhängigkeit von der 11q13Amplifikation. Von den 63 Patienten, deren Karzinome eine 11q13-Amplifikation aufwiesen, verstarben 26 gegenüber 3 verstorbenen Patienten von 37, in deren Tumoren keine 11q13-Amplifikation nachweisbar war, so daß die 4-JahresGesamtüberlebensrate $44 \%$ bzw. $92 \%$ betrug.

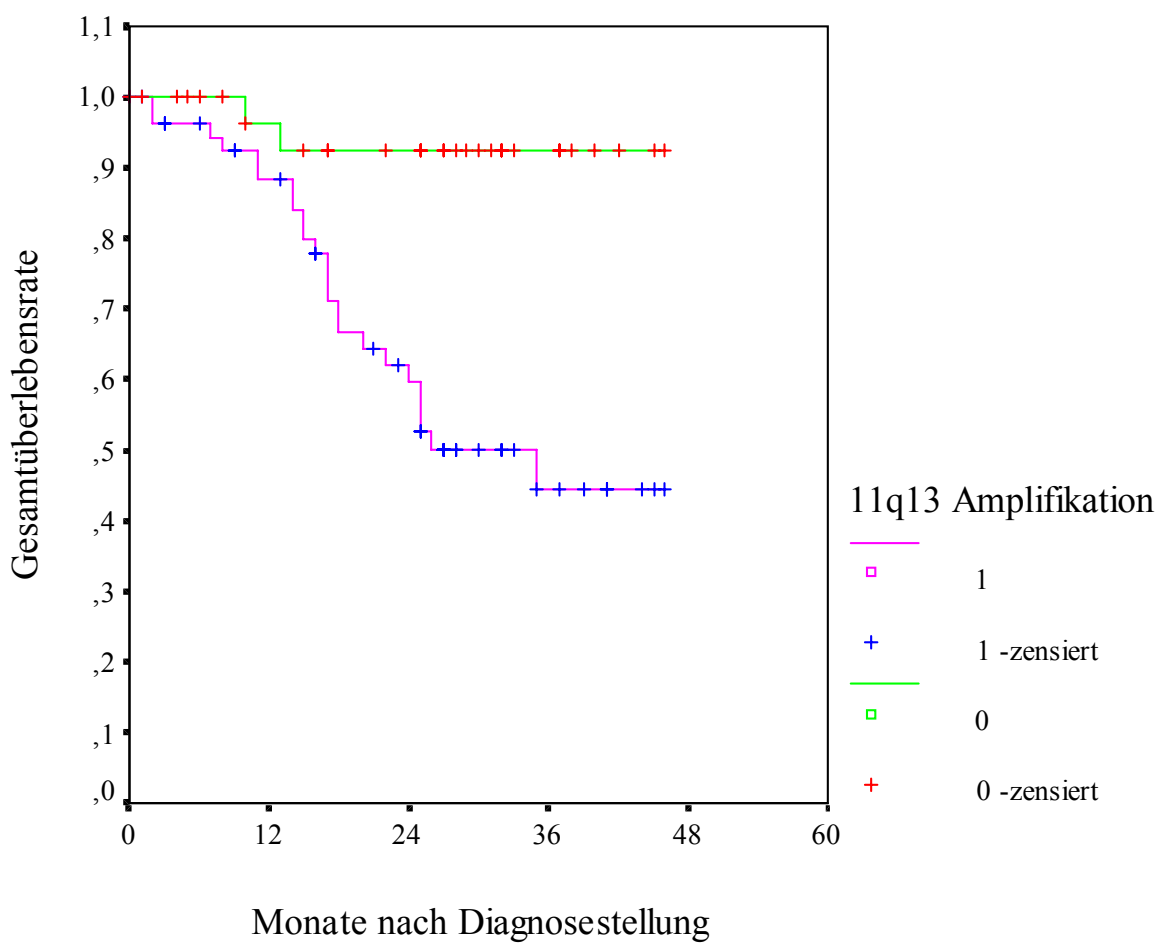

Abbildung 20: Kaplan-Meier-Kurve der Klassifikation der Gesamtüberlebenrate in Abhängigkeit von der 11q13-Amplifikation (1=11q13Amplifikation, $0=$ keine Veränderung).

Die Abbildung 21 zeigt die Überlebenskurven in Abhängigkeit von einer Amplifikation auf Chromosom 3q. Die 4-Jahres-Gesamtüberlebensrate betrug bei Patienten mit 3q-Amplifikation der Tumoren, 50\% gegenüber 83\% ohne diese genetische Veränderung. 


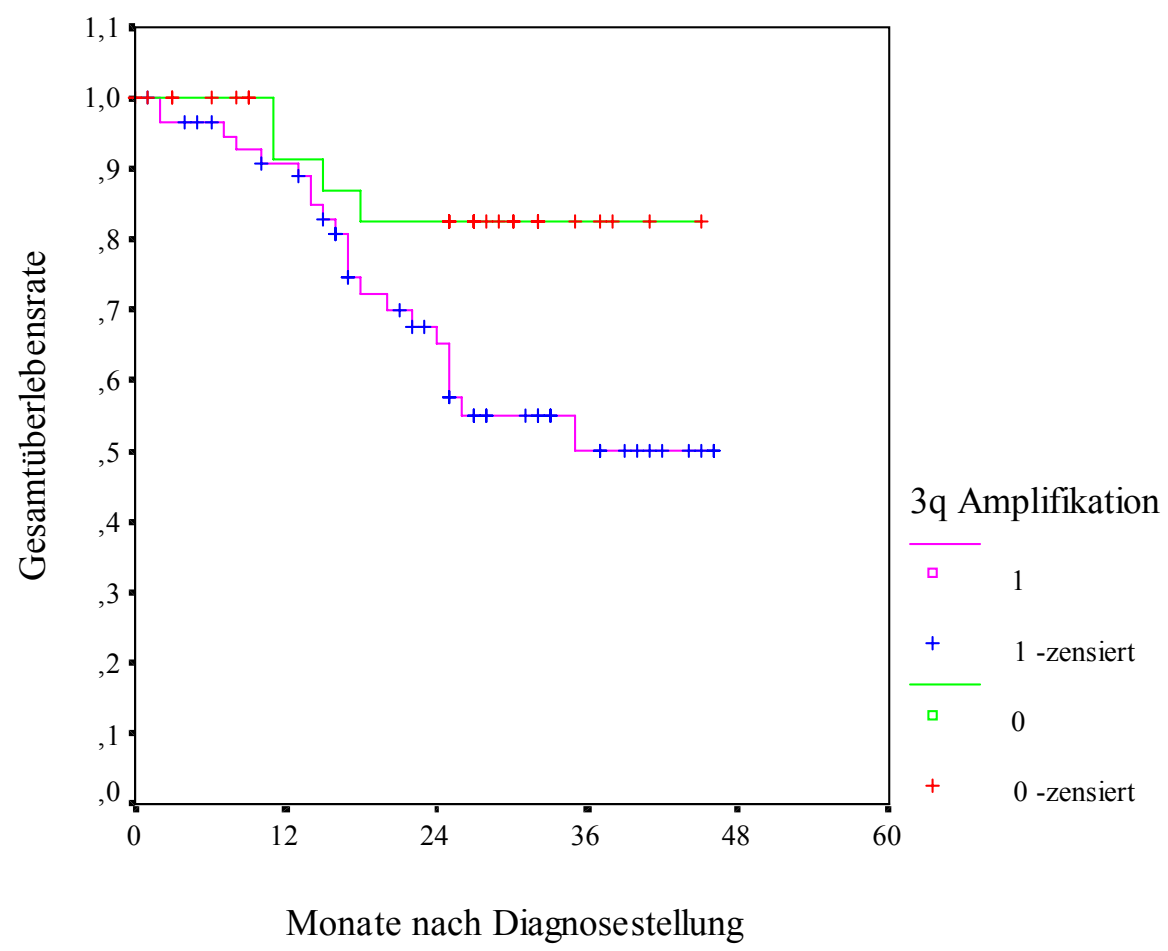

Abbildung 21:Kaplan-Meier-Kurve der Klassifikation der Gesamtüberlebenrate in Abhängigkeit von der 3q-Amplifikation (1=3q-Amplifikation, $0=$ keine Veränderung).

Die Kaplan-Meier-Kurven für das vom UICC-Stadium, von der Tumorgröße (pT), dem Lymphknotenstatus ( $\mathrm{pN}$ ) und dem Grading abhängige Gesamtüberleben ergaben unterschiedliche Verläufe, ohne daß diese jedoch signifikant waren. Für das UICC-Stadium z.B. überlebten alle Patienten bei einem Stadium I $(n=2)$, während die 4-Jahres-Gesamtüberlebensraten im Stadium II 87\% (n=9), im Stadium III 71\% $(n=34)$ und im Stadium IV 47\% $(n=55)$ betrugen. Im Vergleich dazu waren die 4-Jahres-Gesamtüberlebensraten für pT1 ebenfalls 100\% $(n=6)$, für pT2 70\% (n=28), für pT3 55\% (n=38) und für pT4 42\% (n=28). Abhängig von der Lymphknotenmetastasierung überlebten bei pN0 79\% $(n=37)$ gegenüber 51\% der Patienten bei $\mathrm{pN}+(\mathrm{n}=63)$.

\section{Multivariate Cox-Regression}

Um mehrere Parameter gleichzeitig hinsichtlich ihres Einflusses auf das Zielereignis (Überleben) analysieren zu können, müssen die simultanen Effekte 
der einzelnen Parameter bündig zusammengefaßt werden. Das geschieht am besten mit dem Cox-Modell. Es basiert darauf, daß aus der zeitabhängigen Überlebensfunktion die Häufigkeit des momentanen Ereignisrisikos zu jedem Zeitpunkt des Kurvenverlaufes, d.h. die Hazardfunktion, berechnet wird. Der Einfluß verschiedener prognostischer Faktoren wird jeweils als Vielfaches einer Referenzhazardkurve erfaßt, und der Effekt der einzelnen prognostischen Variablen wird durch einen zugehörigen Regressionskoeffizienten (ExpB) angegeben.

Die multivariate Cox-Regression wurde für das rezidiv- und metastasenfreie Überleben und für das Gesamtüberleben jeweils mit den klinisch-pathologischen Parametern pT-, pN-Status, UICC-Stadium, Grading und genetischen Markern 11q13- und 3q-Amplifikation durchgeführt. In beiden Fällen zeigte die Analyse die Amplifikationen von $11 \mathrm{q} 13$ und $3 \mathrm{q}$ als die wichtigsten Faktoren für Einschätzung des Überlebens und damit der Prognose, während alle klinischpathologischen Tumorklassifikationen ohne prognostischen Einfluß waren. Diese Ergebnisse sind in den nachfolgenden beiden Tabellen 8 und 9 aufgeführt.

Tabelle 8: Ergebnisse der Cox-Regression für das rezidiv- und metastasenfreie Überleben.

\begin{tabular}{lllll}
\hline Variable & \multirow{2}{*}{$\operatorname{Exp}(\mathbf{B})$} & \multicolumn{2}{c}{$\mathbf{9 5 \%}$ Konfidenzintervall Exp (B) } & p \\
& & nach unten & nach oben & \\
\hline 3q-Ampl. & 2,8832 & 0,9915 & 8,3836 & 0,0519 \\
11q13-Ampl. & 7,6647 & 1,8091 & 32,4731 & 0,0057 \\
\hline
\end{tabular}


Tabelle 9: Ergebnisse der Cox-Regression für das Gesamtüberleben.

\begin{tabular}{lllll}
\hline Variable & \multirow{2}{*}{ Exp (B) } & \multicolumn{2}{c}{$\mathbf{9 5 \%}$ Konfidenzintervall Exp (B) } & p \\
& & nach unten & nach oben & \\
\hline 3q-Ampl. & 2,7827 & 1,0567 & 7,3281 & 0,0383 \\
11q13-Ampl. & 4,5794 & 1,5886 & 13,2008 & 0,0048 \\
\hline
\end{tabular}

Die 11q13-Amplifikation erwies sich als der am stärksten signifikante Marker mit $p=0,0057$ für das rezidiv- und metastasenfreie Überleben und $p=0,0048$ für das Gesamtübereleben der Patienten. Daraus resultiert, daß Patienten, in deren Tumoren 11q13 amplifiziert ist, ein 7,6-fach erhöhtes Risiko haben, ein Rezidiv oder Metastasen zu bekommen. Das Risiko, am Tumor zu sterben, ist mit dieser einzigen genetischen Veränderung 4,6-fach erhöht. Die Amplifikationen auf 3q waren mit $p=0,0519$ für das rezidiv- und metastasenfreie Überleben und $p=0,0383$ für das Gesamtübereleben statistisch signifikant. Das ergibt jeweils ein 2,8-fach höheres Risiko kürzerer Überlebenszeiten. Sind bei einem Tumor sowohl 11q13 als auch $3 \mathrm{q}$ amplifiziert, so multipliziert sich das Risiko, d.h. die rezidiv- und metastasenfreie Überlebenszeit des Patienten ist 22-fach und die Gesamtüberlebenszeit 12,7-fach kürzer im Vergleich zu einem Patienten, dessen Karzinom keine dieser Veränderungen hat. 


\section{DISKUSSION}

Das therapeutische Konzept von Kopf-Hals-Karzinomen basiert bisher auf der TNM-Klassifikation der Malignome. Aber obwohl Tumorgröße, Lymphknotenstatus und Grading gut dokumentierte prognostische Marker sind, ist ihr Vorhersagewert im Einzelfall nur ungenügend (Glanz et al., 1993; Werner 1997). Die phänotypische Variabilität der Malignome, die sich z.B. im Wachstumsverhalten, der Metastasierung oder dem Auftreten typischer klinischer Symptome manifestiert, ist genetisch bedingt. Aufgabe ist es deshalb, molekulare Marker zu finden, die ein "genetisches Tumorgrading" ermöglichen, das besser mit der Tumorbiologie korreliert als die morphologischen Parameter und das zur Verbesserung von Therapieprotokollen beiträgt. Bei der Etablierung solcher Marker ist $\mathrm{zu}$ beachten, daß weniger das Vorhandensein einzelner Läsionen als vielmehr der multiplikative Effekt mehrerer Mutationen bzw. chromosomaler Aberrationen die Malignität eines Tumors und damit die Prognose bestimmt.

Mit der Vergleichenden Genomischen Hybridisierung (CGH) steht seit 1992 eine molekularzytogenetische Methode zur Verfügung, die die umfassende Genomanalyse eines Tumors erlaubt (du Manoir et al., 1993; Kallioniemi et al., 1992). Basierend auf dem Vergleich von Tumor-DNA und normaler genomischer DNA läßt sich mit einem Experiment das genetische bzw. chromosomale Muster des entsprechenden Tumors erfassen. Neben der Darstellung spezifischer DNAVerluste oder -Gewinne eines Einzeltumors ergibt die Summation der Ergebnisse mehrerer Fälle eines Tumortyps ein spezifisches Aberrationsmuster dieser Entität. Bisher wurden die meisten CGH-Studien zur Charakterisierung der Entitäten von Bronchialkarzinomen (Levin et al., 1995; Petersen et al., 1997a; Petersen et al., 1997b; Ried et al., 1994; Schwendel et al., 1997), Mammakarzinomen (Kallioniemi et al., 1994a; Isola et al., 1995) und Hirntumoren (Schröck et al., 1994; Weber et al., 1996) durchgeführt. Neben unseren eigenen vorläufigen Veröffentlichungen wurde nur in 2 Publikationen über die Untersuchung von Kopf-Hals-Karzinomen berichtet, wobei mit der CGH lediglich 10 bzw. 13 Tumoren analysiert wurden (Broszka et al., 1995; Speicher et al., 1995).

Die vorliegende Arbeit ist die erste umfassende CGH-Studie an Kopf-HalsMalignomen, in der 100 primäre Plattenepithelkarzinome sowie deren 
Lymphknotenmetastasen und Zweitkarzinome vor allem im Hinblick auf die genetische Charakterisierung von biologischen Tumorsubgruppen untersucht wurden.

\subsection{Charakteristische genetische Alterationen der Tumorentität}

\section{Deletionen}

In mehr als der Hälfte der Fälle zeigten die Kopf-Hals-Karzinome Deletionen der Chromosomen 3p, 4p/q, 5q, 6q, 8p, 9p, 11p/q, 13q, 18q und 21q. Die häufigsten DNA-Überrepräsentierungen fanden sich im Bereich von 1p, 3q, 5p, 8q, 9q, 11q13, 16p, 17q, 19, 20q und 22q. Das Spektrum der Alterationen wurde teilweise auch in zytogenetischen Untersuchungen (Carey et al., 1993; Jin et al., 1993; Jin et al., 1995; van Dyke et al., 1994) und Allelotype-Studien (Ah-See et al., 1994; Bockmühl et al., 1996a; Field et al., 1995a; Nawroz et al., 1994; Scully \& Field 1997) beschrieben. Die Häufigkeit der angegebenen Allelverluste lag für bestimmte chromosomale Regionen jedoch unter den von uns gefundenen entsprechenden Deletionen. Das weist auf die größere Bedeutung chromosomaler Aberrationen im Vergleich zu Mikrosatelliteninstabilitäten bei der Manifestation der genetischen Instabilität eines Tumors hin (Ishwad et al., 1995).

Unter den genannten Alterationen traten Deletionen von $3 p, 5 q, 8 p$ und $9 p$ häufig mit gleichzeitigen DNA-Überrepräsentierungen auf dem komplementären Chromosomenarm auf. Das entspricht der zytogenetischen Beobachtung, daß Plattenpeithelkarzinome zur Ausbildung von sog. 3q, 5p und 8q Isochromosomen neigen (Mertens et al., 1997; Mitelman 1995).

Als häufigste Alteration konnten bei 91 Tumoren Deletionen auf Chromosom 3p festgestellt werden. Diese Läsion ist jedoch für die Diagnose eines Plattenepithelkarzinoms des Kopf-Hals-Bereiches nicht ausreichend, da Deletionen auf $3 p$ auch bei anderen Tumorentitäten wie z.B. Bronchialkarzinomen (Petersen et al., 1997a; Petersen et al., 1997b) oder Nierenzellkarzinomen (Moch et al., 1996) auftreten. In der vorliegenden Studie war bei 55 Fällen der gesamte p-Arm des Chromosoms 3 deletiert, während 36 Tumoren nur partielle Deletionen aufwiesen. Gipfel der Inzidenzkurve zeigten sich bei 3p12-p14 und bei 3p21-p23. Neben diesen beiden wurde von Maestro et 
al. (1993) noch die Region 3p24-pter als häufig von Allelverlusten betroffen angegeben. Während Field et al. (1995) und Li et al. (1994) die hohe LOHFrequenz bei 3p24-p26 bestätigten, fanden andere Autoren (Califano et al., 1996; Mao et al., 1996), daß die Allelverluste am häufigsten bei 3p21 auftreten und eine sehr frühe Veränderung in der Karzinogenese von Kopf-Hals-Malignomen darstellen. Interessanterweise wurde das FHIT-Gen als potentielles TSG bei 3p14.2 identifiziert und bei Kopf-Hals-Karzinomen als häufig alteriert gefunden (Virgilio et al., 1996). Dieses Gen liegt in einer sog. fragile site des Genoms, d.h. an einer Stelle, wo sehr leicht, z.B. durch die Karzinogene aus Nikotin und Alkohol, Chromosomenbrüche auftreten. Matthias et al. (1998) stellten in diesem Zusammenhang fest, daß Tumoren von Patienten mit Risikogenotypen des detoxifizierenden Enzyms Glutathion-S-Transferase häufiger Allelverluste, besonders auf $3 p$, zeigen.

Die zweithäufigste Deletion betraf in 79 der 100 untersuchten Tumoren das Chromosom 9p, gefolgt von 5q-, 13q- und 18q-Verlusten in 77\% bzw. jeweils $72 \%$ der Fälle. Gipfel der Inzidenzkurve markierten die Regionen 5q15-q22 und 9p21-p22. In beiden Regionen sind bereits TSG identifiziert worden. Bei 5q21q22 sind das APC- sowie das MCC-Gen lokalisiert, die eine wichtige Rolle bei der Entstehung von gastrointestinalen Tumoren spielen. Der APC/MCC-Locus ist auch bei Kopf-Hals-Karzinomen (Bockmühl et al., 1996b; Bockmühl et al., 1998) und Lungenkarzinomen (Petersen et al., 1997a; Petersen et al., 1997b) regelmäßig deletiert. 9p-Verluste wurden als frühe Veränderungen in der Karzinogenese von Kopf-Hals-Malignomen beschrieben (Califano et al., 1996; van der Riet et al., 1994). Bei 9p21 befindet sich das p16-TSG, das in über $80 \%$ der Kopf-HalsKarzinome alteriert ist (Reed et al., 1996). Neben den in der vorliegenden Studie häufig festgestellten Deletionen des 9p21-Locus sprach das Fehlen des immunhistochemischen Nachweises des p16-Proteins in $87 \%$ unserer Tumoren für die Inaktivierung des p16-TSG.

Im Gegensatz zu p16 scheint das Rb-TSG in unserem Tumorkollektiv trotz häufig nachgewiesener DNA- sowie Allelverluste auf 13q, speziell auch 13q14, nicht funktionslos zu sein. Das resultiert aus dem Ergebnis der Immunhistochemie, wonach 36 von 38 Tumoren eine positive nukleäre Reaktion auf den spezifischen pRb-Antikörper zeigten. Bis auf einen Fall, bei dem gleichzeitig pRb und das 
p16-Protein negativ waren, ergab der immunhistochemische Nachweis eine inverse Proteinexpression ( $\mathrm{pRb}=$ positiv, p16-Protein=negativ). Sowohl p16 als auch $\mathrm{Rb}$ spielen eine wichtige Rolle bei der Zellzyklusregulation; die Phosphorylierung von $\mathrm{Rb}$, d.h. seine Inaktivierung, und damit der Übertritt der Zellen von der G1- in die S-Phase des Zellzyklus, wird u.a. durch p16 unterdrückt (Hartwell \& Kastan 1994). Unsere immunhistochemischen Ergebnisse stimmen mit den von Sakaguchi et al. (1996) publizierten Daten für nicht kleinzellige Lungenkarzinome überein und stützen die Hypothese, daß das funktionstüchtige $\mathrm{pRb}$ die Expression des p16-Proteins supprimieren kann. In diesem Zusammenhang konnten Loughran et al. (1996) zeigen, daß in Anwesenheit von pRb der Verlust von p16 eine notwendige Kondition für das Überleben humaner epithelialer Zellen in vitro ist.

\section{Amplifikationen}

Die häufigsten DNA-Gewinne fanden wir im Bereich von 1p, 3q, 5p, 8q, 9q, 11q13, 16p, 17q, 19, 20q und 22q mit Inzidenzpeaks bei 5p15, 8q24, 9q34, 11q13, 17q21 und 20q12-q13.1. Amplifikationen auf den Chromosomen 3q und $5 p$ waren wie o.b. häufig mit dem Verlust der korrespondierenden Arme kombiniert - Veränderungen, die auch bei Bronchialkarzinomen beschrieben wurden (Petersen et al., 1997a, Petersen et al., 1997b). High-copyAmplifikationen zeigten sich in einer hohen Frequenz bei 3q26-qter, 11q13, 8q24 und 9q34. Interessanterweise sind auf 11q13 das Proto-Oncogen Cyclin D1 und auf 8q24 das C-myc-Gen kodiert; im Bereich der anderen beiden Regionen konnten bisher keine potenten Oncogene lokalisiert werden. Von Field et al. (1989) wurde angegeben, daß die C-myc-Amplifikation bei Kopf-HalsKarzinomen mit einer schlechten Prognose der Patienten assoziiert ist. Die Amplifikation von Cyclin D1 wurde zum einen mit einer kürzeren Überlebenszeit korreliert gefunden (Åkervall et al., 1997), während andere Autoren diesen Zusammenhang nicht feststellen konnten (Muller et al., 1997). Unsere Ergebnisse zeigen eine hoch signifikante Korrelation der 11q13-Amplifikation mit einer schlechten Prognose der Tumorpatienten (siehe unten). Immunhistochemisch fanden wir jedoch keine signifikant unterschiedliche Cyclin D1-Expression.

In einem Drittel der Fälle zeigten sich bei einer Überrepräsentierung von 11q13 simultane Deletionen von 9p21 und 13q14. Zwar waren alle immunhistochemisch 
untersuchten Karzinome Cyclin D1 positiv, aber es ließ sich keine Abhängigkeit der Intensität der Färbung vom p16- bzw. Rb-Proteinstatus nachweisen. Dieser Fakt unterstützt die Angaben von Bartkova et al. (1995), wonach die Rbgesteuerte Regulation des Zellzyklus auch bei Kopf-Hals-Karzinomen gestört ist und die Progression der G1- zur S-Phase unabhängig entweder durch die Wechselwirkung von p16 und Cyclin D1 oder durch die Inaktivierung von Rb hervorgerufen wird. Die weitere funktionelle Aufklärung bedarf jedoch molekularbiologischer Untersuchungen.

Obwohl die Vielzahl chromosomaler Alterationen der Tumoren oftmals diffus erscheint, ist das beschriebene genetische Muster zum einen charakteristisch für Plattenepithelkarzinome des Kopf-Hals-Bereiches und zum anderen auch für den plattenepithelialen Zelltyp an sich, da Plattenepithelkarzinome der Lunge und des Genitaltraktes durch ein sehr ähnliches Muster gekennzeichnet sind (Heselmeyer et al., 1996; Petersen et al., 1997a).

\subsection{Genetische Unterschiede zwischen Tumorsubgruppen}

\section{Unterschiede in Abhängigkeit vom Differenzierungsgrad der Karzinome}

Die wichtigsten Ergebnisse dieser vorliegenden Studie basieren auf den in unserer Arbeitsgruppe etablierten neuen CGH-Auswertungsprogrammen, durch die erstmals der Vergleich genetischer Muster von Tumorsubgruppen möglich wurde.

Für die Gegenüberstellung von Plattenepithelkarzinomen unterschiedlicher Differenzierung benutzten wir die Summation der Karyogramme mehrerer Fälle zu einem Super-Karyogramm. Durch die Superposition werden dabei die Veränderungen, die nur in Einzelfällen auftreten, unterdrückt, während diejenigen, die häufiger vorkommen, sichtbar bleiben. Mit Hilfe dieser Analyseform konnten wir zeigen, daß gut differenzierte Tumoren (G1) lediglich Deletionen der Chromosomenarme 9p und 3p kombiniert mit einer Amplifikation von $3 q$ aufweisen. Demgegenüber sind schlecht differenzierte Karzinome (G3) durch zusätzliche DNA-Verluste von Chromosom 4, 5q, 8p, 11, 13q, 18q und 21q sowie Überrepräsentierungen auf 8q, 11q13 und 20q gekennzeichnet (Bockmühl et al., 1996). Diese genetischen Muster lassen sich gut mit dem 
Progressionsmodell für Kopf-Hals-Karzinome assoziieren, wonach bestimmte genetische Veränderungen einzelnen Stadien der Karzinogenese von Kopf-HalsMalignomen zugeordnet werden können (Califano et al., 1996). So ist der DNAVerlust auf 9p, d.h. wahrscheinlich die Inaktivierung des TSG p16, eine Alteration, die bereits bei Plattenepithelhyperplasien feststellbar ist. Mao et al. (1996) und van der Riet et al. (1994) stellten in epithelialen Präkanzerosen der Kopf-Hals-Region 9p-Allelverluste ebenfalls als erste genetische Veränderung fest. Heselmeyer et al. (1996) berichteten, daß in schweren plattenepithelialen Dysplasien der Zervix bereits 3q-Amplifikationen nachweisbar sind. Entsprechend dem Progressionsmodell treten in Dysplasien dann zusätzliche DNA-Verluste auf $3 p$ und $17 p$, in Carcinomata in situ weiterhin 11q-, 13q- und 14q-Deletionen, gefolgt von 6p-, 4q- und 8p-Verlusten bei invasiven Plattenepithelkarzinomen auf. Dieses Modell ist ein Ansatzpunkt für ein genetisches Tumorgrading. Im Vergleich $\mathrm{zu}$ den von uns gefundenen differenzierungsabhängigen genetischen Mustern wird deutlich, daß die biologische Bedeutung vieler Alterationen noch unklar ist. Außerdem fällt auf, daß sich die Tumorsubgruppen besser durch Deletionen als durch Amplifikationen voneinander unterscheiden, was darauf zurückzuführen ist, daß in der Tumorentität Plattenepithelkarzinom die Frequenz an DNA-Verlusten überwiegt. Demgegenüber konnte die Progression von Hirntumoren mit einer Akkumulation bestimmter Amplifikationen korreliert werden (Weber et al., 1996).

\section{Unterschiede in Abhängigkeit vom Lymphknotenstatus der Karzinome}

Für die Einschätzung der Prognose von Plattenepithelkarzinomen des Kopf-HalsBereiches ist der Lymphknotenstatus des Tumors derzeit der wichtigste Parameter. Der metastatische Phänotyp dieser Malignome kann jedoch sehr unterschiedlich ausgeprägt sein. So können kleine Tumoren zum Zeitpunkt der Diagnosestellung bereits ausgedehnt metastasiert sein, während andere Tumoren zu einer enormen Größe wachsen, ohne Lymphknotenmetastasen zu bilden. Selbst kleine Tumoren setzen oft klinisch nicht erfaßbare Metastasen und umgekehrt können Lymphknotenmetastasen ohne faßbaren Primärtumor auftreten.

Auf der Suche nach Parametern, die dieses biologische Tumorverhalten besser charakterisieren, analysierten wir 37 nicht metastasierende und 63 
metastasierende Kopf-Hals-Karzinome. Der statistische Vergleich der chromosomalen Aberrationsmuster beider Tumorsubgruppen war durch die Etablierung einer weiteren neuen Auswertungsmethode möglich. Dazu wurden die genetischen Imbalancen beider Gruppen jeweils in Histogrammform als Inzidenzen erfaßt und dann aus beiden Histogrammen ein Differenzhistogramm gebildet. Die daraus ersichtlichen Unterschiede wurden mit dem Chi-Quadrat-Test auf Signifikanz geprüft. Die statistische Analyse ergab, daß die pN0 Tumoren häufiger Amplifikationen der Chromosomenarme 4q, 6p, 7p, 12p, 13q und 20p aufwiesen. Demgegenüber zeigten die pN+ Karzinome mehr Deletionen im Bereich der Chromosomen 2q, 4q, 5q, 10q, 11p, 11q, 14q, 15q, 20p sowie 21q und DNA-Überrepräsentierungen nur bei $2 \mathrm{p}$ sowie 11q13 (Bockmühl et al., 1997a). Die metastasierenden Tumoren waren weiter durch eine größere Anzahl genetischer Imbalancen und speziell durch häufigere DNA-Verluste gekennzeichnet. In diesem Zusammenhang fanden Li et al. (1994), daß multiple Allelverluste bei Kopf-Hals-Karzinomen mit einer schlechten Prognose assoziiert sind. Das läßt den Schluß zu, daß die Akkumulation von Deletionen wie schon für kleinzellige Bronchialkarzinome (Petersen et al., 1997b), Mammakarzinome (Isola et al., 1995) und Nierenzellkarzinome (Moch et al., 1996) gezeigt, auch für die Progression der Kopf-Hals-Karzinome von Bedeutung ist. In Übereinstimmung damit fanden Soder et al. (1995) in einer zytogenetischen Studie, daß Kopf-Hals-Karzinome mit komplexen Karyotypen häufiger metastasieren.

Als statistisch signifikant für den metastatischen Phänotyp konnten in der vorliegenden Studie einige umschriebene Regionen lokalisiert werden, worunter die Projektion auf die Banden 10q21, 10q25-q26, 11p13-p15, 11q13 und 15q21q24 herausgehoben werden soll. Im Bereich von 11p13 ist das CD44 Gen kodiert, das bei Prostatakarzinomen als Suppressor der Metastasierung nachgewiesen wurde (Gao et al., 1997). Bei 11q13 ist das Proto-Onkogen Cyclin D1 lokalisiert und Deletionen auf $15 \mathrm{q}$ wurden bei Mammakarzinomen mit der Tumordisseminierung in Verbindung gebracht (Wick et al., 1996).

Im Rahmen der Tumorprogression scheinen 10q-Deletionen besondere Bedeutung zu haben. Verluste von Chromosom 10q wurden als die zweithäufigste Alteration bei kleinzelligen Bronchialkarzinomen beschrieben, also einer hochmalignen 
Tumorentität, die durch eine frühzeitige und ausgedehnte Metastasierung gekennzeichnet ist (Petersen et al., 1997b). Ausgehend von der Tatsache, daß invasive Subpopulationen des Primärtumors den zellulären Hauptanteil der Metastasen ausmachen können und damit den metastasierenden Klon charakterisieren, haben wir in 25 Fällen das genetische Muster von primären Plattenepithelkarzinomen mit dem ihrer Metastasen verglichen. Beide Gruppen unterschieden sich signifikant durch die Deletionen von 10q, die in den Lymphknotenmetastasen sehr viel häufiger auftraten. Die LOH-Analyse bestätigte dieses Ergebnis. Einzelfälle betrachtend zeigte sich in der Lymphknotenmetastase oft der gesamte 10q-Arm deletiert, während die Deletion im Primärtumor subtiler war. Daß 10q-Verluste die typische Aberration des metastasierenden Klons sein könnten, unterstrich letztlich auch der Vergleich zwischen den nicht metastasierenden Karzinomen und der Gruppe der Lymphknotenmetastasen.

Bei Plattenepithelkarzinomen der Lunge konnte ebenfalls eine Korrelation von Deletionen des Chromosomarms 10q mit der Metastasierung festgestellt werden (Petersen et al., 1998b). Darüberhinaus wurden durch Allelotypisierung dieser Tumoren 2 klar getrennte Regionen mit häufigen Allelverlusten bei 10q23 und eine bei 10q26 lokalisiert (Petersen et al., 1998a). Die telomerisch gelegene Region stimmt mit dem Ergebnis unserer CGH-Analyse überein. Interessanterweise konnten erst kürzlich bei 10q23 das TSG PTEN/MMAC1 (Steck et al., 1997; Li et al., 1997) und bei 10q25.3-q26.1 das TSG DMBT1 (Mollenhauer et al., 1997) identifiziert werden. Beide TSG wurden als mutiert in späten Tumorstadien bei Glioblastomen sowie Mamma- und Prostatakarzinomen beschrieben. In Mutationsanalysen, an Plattenepithelkarzinomen der Lunge und in 13 Fällen der Kopf-Hals-Region, zeigte das PTEN/MMAC1 Gen jedoch keine Veränderungen (Petersen et al., 1998a), und Mutationen des DMBT1 Gens konnten bei Kopf-Hals-Tumoren bisher auch noch nicht gefunden werden. Das legt den Schluß nahe, daß auf 10q noch andere, mit der Progression und dem metastatischen Phänotyp von Karzinomen des oberen Aerodigestivtraktes assoziierte TSG lokalisiert sein könnten.

\section{Genetische Prognoseparameter}

Um die direkte Relevanz genetischer Alterationen für die Einschätzung der Prognose von Patienten mit Kopf-Hals-Karzinomen zu ermitteln, wurden die 
Einzelveränderungen pro Chromosomarm nach Art aufgeschlüsselt und statistisch zusammen mit den klinisch-pathologischen Daten ausgewertet. In dem längstens 4-jährigen Beobachtungszeitraum waren von den 100 Tumorpatienten 29 am Tumor verstorben, 15 am Lokalrezidiv und 14 an einer Metastasierung.

Sowohl für die Einschätzung des rezidiv- und metastasenfreien als auch des Gesamtüberlebens erwiesen sich die Amplifikationen der Region 11q13 und des Chromsomarmes $3 \mathrm{q}$ als die statistisch signifikantesten Parameter. Die multivariate Auswertung zeigte erstmals sogar, daß der unabhängige Einfluß beider Alterationen als Einzelparameter und mehr noch in ihrem Zusammenhang auf das Überleben größer ist als der des Stagings. Danach haben Patienten, in deren Tumoren 11q13 bzw. 3q amplifiziert ist, ein 7,6-fach bzw. 2,8-fach erhöhtes Risiko, ein Rezidiv oder Metastasen zu bekommen. Das Risiko, am Tumor zu sterben, ist mit einer 11q13-Amplifikation als einziger genetischer Veränderung 4,6-fach erhöht, bei einer alleinigen 3q-Amplifikation 2,8-fach. Sind bei einem Tumor sowohl 11q13 als auch 3q amplifiziert, so ist die rezidiv- und metastasenfreie Überlebenszeit des Patienten 22-fach und die Gesamtüberlebenszeit 12,7-fach kürzer im Vergleich zu einem Patienten, dessen Karzinom keine dieser Veränderungen aufweist.

In einer zytogenetischen Studie konnte bisher gezeigt werden, daß Kopf-HalsKarzinome mit komplexen Karyotypen eine schlechtere Prognose haben als Tumoren mit rein numerischen oder einfachen strukturellen Aberrationen (Åkervall et al., 1995). Dabei wurde auch die prognostische Bedeutung von 11q13 Rearrangements beschrieben. Im Gegensatz zu unseren Ergebnissen hatten die Veränderungen bei 11q13 jedoch keine bessere Aussagefähigkeit hinsichtlich des Überlebens als Grading, pT- und pN-Status der Tumoren. Das mag vielleicht darauf zurückzuführen sein, daß die primäre Therapie der untersuchten Malignome in einer Radiatio und/oder Chemotherapie bestand. In einer nachfolgenden Studie fanden Åkervall et al. (1997), daß die Amplifikation von Cyclin D1, das bei 11q13 kodiert ist, unabhängig von der zytogenetischen 11q13Alteration auch mit einer schlechten Prognose assoziiert ist. Eine Korrelation zwischen der Expression der ebenfalls bei 11q13 lokalisierten Gene HST-1, INT2 sowie BCL-1 und dem Überleben wurde bei Kopf-Hals-Karzinomen nicht feststellt (Muller et al., 1997; Lese et al., 1995). 
Die Korrelation der 3q-Amplifikation mit der Prognose wurde bisher überhaupt noch nicht beschrieben. DNA-Überrepräsentierungen dieses Chromosomarmes galten lediglich als charakteristisch für die plattenepitheliale Differenzierung von Tumoren des oberen Aerodigestivtraktes sowie des Genitaltraktes (Bockmühl et al., 1996; Heselmeyer et al., 1996; Petersen et al., 1997a). Der Fakt, daß wir in der Hälfte der verstorbenen Patienten high-copy-Amplifikationen bei 3q26-qter fanden, und daß auch bei Plattenpeithelkarzinomen der Lunge häufige Amplifikationen von 3q26 festgestellt wurden (Brass et al., 1996), läßt die Lokalisation mindestens eines Proto-Onkogens auf $3 q$ vermuten.

Obwohl wir die 10q-Deletionen signifikant mit dem metastatischen Phänotyp assoziiert fanden, konnte ihre direkte prognostische Relevanz nicht nachgewiesen werden. Sie scheinen eine indirekte Bedeutung für die Prognose zu haben, indem sich für die Einschätzung der reinen metastasenfreien Überlebenszeit der Lymphknotenstatus als der signifikanteste Parameter zeigte. Darin wird deutlich, daß die Eigenschaften der Tumorzellen des metastasierenden Subklones nicht zwangsläufig an die Tumoreigenschaften gekoppelt sein müssen, die für die Aggressivität bzw. Malignität und damit die Prognose ausschlaggebend sind. Ebenfalls nur für die Einschätzung der Zeit bis zum Auftreten von Metastasen signifikant erwiesen sich die 8p23-Allelverluste. Scholnick et al. (1996) berichteten, daß das Auftreten von LOH bei $8 \mathrm{p} 23$ bei supraglottischen Larynxkarzinomen auch mit dem Gesamtüberleben korreliert ist.

Interessant ist, daß die beiden von uns gefundenen genetischen Prognoseparameter jeweils Amplifikationen sind. Dies läßt den Schluß zu, daß mit der Tumorprogression von Kopf-Hals-Karzinomen die Relevanz der Aktivierung von Proto-Onkogenen die Bedeutung der Inaktivierung von TSG übersteigt.

\subsection{Klonalitätsbestimmung}

\section{Vergleich Primärtumor - Zellinie}

In der vorliegenden Studie konnte gezeigt werden, daß die genetischen Muster von Primärtumor und Zellinie wesentlich, d.h. zumindest in den für die Tumorentität der Plattenepithelkarzinome charakteristischen Alterationen, 
übereinstimmten. Das traf sowohl für den Vergleich der CGH-Befunde als auch für die Gegenüberstellung mit den klassischen Karyotypen zu. Beide Methoden ergänzten sich, z.B. ließen bestimmte Amplifikationen in der CGH auf die Zusammensetzung der Markerchromosomen schließen, und umgekehrt konnten mit der Zytogenetik Translokationen und Inversionen erfaßt werden. Anhand der Zellinien D36 wurde aber auch deutlich, daß im Rahmen der Zellkultur Subklone des Primärtumors mit unterschiedlichen Eigenschaften selektiert werden können. In unserem Fall waren beide Zellinien morphologisch verschieden und die Kongruenz der genetischen Veränderungen zum Primärtumor bestand in der CGH nur in $50 \%$ (gegenüber $80 \%$ bei der Zellinie D40). Ursache dafür ist die Heterogenität der Plattenepithelkarzinome, die eine klonale Zuordnung erschweren kann. Die Zellkultur spiegelt prinzipiell die Situation im Primärtumor wieder und ist deshalb ein wertvolles Modell für in-vitro-Analysen. Für Untersuchungen im Hinblick auf die Etablierung klinisch relevanter genetischer Marker, die auch diagnostisch leicht zugänglich sein sollten, scheint jedoch die CGH methodisch besser geeignet.

\section{Vergleich Primärtumor - Lymphknotenmetastase}

Das CGH-Muster der chromosomalen Veränderungen erlaubte bis auf einen Fall die klonale Zuordnung von Primärtumor und Metastase. Dabei ergab der Vergleich zwischen den Primärtumoren und ihren Metastasen, daß die Alterationen im Mittel in $62,5 \%$ vollständig übereinstimmten. Die Klonalität wurde angenommen, wenn möglichst mehr als 50\%, aber wenigstens $>40 \%$ der charakteristischen Alterationen identisch und/oder gleiche spezifische Amplifikationen nachweisbar waren. Es zeigte sich, daß das klonale Verhältnis sehr eng sein konnte (z.B. 85\% Übereinstimmung). Andererseits wiesen 3 Fälle nur in $45-49 \%$ und in einem Fall sogar nur in 27\% Identität auf. Das kann durch eine starke Heterogenität im Primärtumor oder aber auch durch eine unabhängige klonale Entwicklung von Primärtumor und Metastase bedingt sein.

Ein enger klonaler Zusammenhang wurde mit Hilfe der CGH auch zwischen kleinzelligen Bronchialkarzinomen und deren Metastasen sowie zwischen Primärtumor und Metastase bei Nierenzellkarzinomen beschrieben (Gronwald et al., 1997; Petersen et al., 1997b). Bei Mammakarzinomen hingegen konnte in einem Drittel der Metastasen keine Klonalität aufgezeigt werden (Kuukasjärvi et 
al., 1997). Das unterstützt die oben genannte Hypothese einer unabhängigen klonalen Entwicklung nach Tumoraussaat, denn es wurden ausschließlich asynchrone Metastasen untersucht.

In der vorliegenden Arbeit wiesen die Metastasen im Vergleich zum Primärtumor insgesamt mehr Alterationen auf. Darin können sich mögliche Mechanismen der klonalen Entwicklung wiederspiegeln, z.B. gilt die Ausdehnung interstitieller Deletionen auf Verluste des gesamten Chromosomenarmes als Auslöser der Entwicklung großer chromosomaler Imbalancen.

Innerhalb der Lymphknotenmetastasen traten vermehrt 10q-Deletionen auf, so daß diese Einzelveränderung charakteristisch für den metastasierenden Klon zu sein scheint. In Metastasen von primären Nierenzellkarzinomen wurden mit der CGH ebenfalls einzelne Alterationen, speziell 1q-Amplifikationen und 3p-Deletionen, häufiger gefunden (Gronwald et al., 1997).

\section{Vergleich Primärtumor - Zweitkarzinom}

Slaughter et al. (1953) postulierten, daß die Entwicklung von Zweittumoren bei Patienten mit Karzinomen des oberen Aerodigestivtraktes auf eine sog. "Feldkanzerisierung" durch die fortgesetzte Exposition mit Karzinogenen (z.B. aus Zigarettenrauch) zurückzuführen ist. Danach entstehen Primär- und Zweitkarzinom unabhängig voneinander (polyklonal). Da Zweitkarzinome häufig, syn- oder metachron, in unmittelbarer Nähe des primären Malignoms auftreten, wurde vermutet, daß sie auch einen gemeinsamen Ursprung haben, d.h. monoklonal sein könnten. In diesem Falle wird angenommen, daß ein Zweitkarzinom durch die Migration einzelner transformierter Tumorzellen andernorts entsteht.

Bisher gibt es 3 Studien, in denen die Klonalität von Mehrfachtumoren im KopfHals-Bereich untersucht wurde. An 2 Fällen mit synchronen Karzinomen der Mundhöhle und des Hypopharynx wiesen Worsham et al. (1995) durch Karyotypisierung und Y-Markierung einen monoklonalen Ursprung der Tumoren nach. Bedi et al. (1996) konnten an 8 Patientinnen mit multiplen Kopf-HalsKarzinomen durch den Nachweis der X-Chromosom-Inaktivierung ebenfalls die Monoklonalität der Malignome feststellen. In der dritten Studie zeigten Scholes et al. (1998) durch die Analyse von Heterozygotieverlusten an den Tumoren von 5 
Patienten, daß die synchronen Mundhöhlenkarzinome sowohl mono- als auch polyklonalen Ursprungs waren.

Von 10 Patienten wurden jeweils der Primärtumor und das Zweitkarzinom untersucht. In 3 Fällen handelte es sich um metachrone, in 7 Fällen um synchrone Zweitkarzinome, wobei unter letzteren in 3 Fällen Ösophaguskarzinome die zweite Tumormanifestation waren.

Die Gegenüberstellung des Gesamtkollektivs der Zweitkarzinome mit 15 sporadischen Karzinomen ließ keine Einzelveränderung erkennen, die konstant mit einer Tumorsuszeptibilität assoziiert werden könnte. Ein Grund dafür liegt wahrscheinlich in der bisher zu geringen Patientenzahl.

Für den Vergleich der Tumorpaare wurden dieselben Auswertungskriterien zugrunde gelegt wie bei der Untersuchung von Primärtumor und Lymphknotenmetastase. Im Ergebnis zeigten die drei synchronen Ösophaguskarzinome sowie das metachrone Mundhöhlen- und ein metachrones Oropharynxkarzinom andere genetische Muster als die jeweiligen Primärtumoren, so daß ein polyklonaler Ursprung angenommen werden kann. Die anderen 5 Tumorpaare wiesen in über $50 \%$ identische Veränderungen auf, die somit auf eine monoklonale Entstehung hindeuten. In einem Fall konnte neben dem polyklonalen Ursprung des Ösophaguskarzinoms anhand der chromosomalen Alterationen die Abstammung einer Lymphknotenmetastase von dem synchronen Oropharynxkarzinom aufgedeckt werden.

Diese Ansätze machen deutlich, daß die bisher klinische bzw. histologische Entscheidung Primärtumor versus Zweitkarzinom oder Metastase durch eine genetische Klassifikation ergänzt und dadurch das Therapiekonzept optimiert werden könnte.

"Nicht das Leben unter abnormen Bedingungen erzeugt eine Krankheit, sondern die Insuffizienz der regulatorischen Apparate" (Rudolf Virchow, 1869). Die Aufdeckung der genetischen Alterationen, die zur Störung normaler Regulationsund Stoffwechselabläufe führen, wird langfristig dazu beitragen, die Prävention $\mathrm{zu}$ verbessern, das biologische Tumorverhalten exakter einzuschätzen und neue therapeutische Wege zu erschließen. Ansätze dazu sind auch die Ergebnisse der vorliegenden Arbeit. 


\section{ZUSAMMENFASSUNG}

Die Aufgabe der vorliegenden Arbeit bestand in der molekularzytogenetischen Charakterisierung von Plattenepithelkarzinomen des Kopf-Hals-Bereiches und darauf aufbauend in der Identifizierung von Tumorsubgruppen mit prognostisch relevanten genetischen Alterationen.

Es wurden 100 primäre Plattenepithelkarzinome des Kopf-Hals-Bereiches, in 27 Fällen syn- oder metachrone Metastasen und in 10 Fällen Zweitkarzinome untersucht. Alle Patienten wurden primär im Zeitraum zwischen 1994 und 1998 in der HNO-Klinik der Charité operiert.

Die Karzinome wurden alle mit Hilfe der Vergleichenden Genomischen Hybridisierung $(\mathrm{CGH})$ analysiert. Darüberhinaus wurden mehrere Tumorgruppen auf Heterozygotieverluste (LOH) im Bereich der Chromosomenarme 8p, 10q, 13q und 21q untersucht, immunhistochemisch die Proteinexpression der Tumorsuppressorgene p16 und Rb sowie des Proto-Onkogens Cyclin D1 dargestellt, und es wurden von den Primärtumoren Zellkulturen angelegt.

Für die Überlebensanalyse lag ein postoperativer Beobachtungszeitraum von längstens 4 , aber mindestens 2 Jahren zugrunde.

Die Auswertung der vorliegenden Studie erbrachte folgende Resultate:

- Plattenepithelkarzinome des Kopf-Hals-Bereiches sind durch ein typisches genetisches Muster charakterisiert. Dazu gehören Deletionen der Chromosomen 3p, 4p/q, 5q, 6q, 8p, 9p, 11p/q, 13q, 18q und 21q sowie Amplifikationen im Bereich von 1p, 3q, 5p, 8q, 9q, 11q13, 16p, 17q, 19, 20q und 22q. Es zeigen sich keine signifikanten Unterschiede dieses Musters hinsichtlich der Lokalisation des Primärtumors.

- Im genetischen Muster von Kopf-Hals-Karzinomen zeigen sich mehr Deletionen als Amplifikationen.

- Die Deletionen des Chromosomarmes 9p und der in 87\% der Fälle immunhistochemisch fehlende Nachweis der Proteinexpression des Tumorsuppressorgens p16 deutet darauf hin, daß es bei Kopf-HalsKarzinomen inaktiviert ist. 
- Die in 95\% der Fälle immunhistochemisch nachweisbare pRb-Expression spricht trotz häufiger Deletionen und Allelverluste auf Chromosom 13q dafür, daß das Rb-Tumorsuppressorgen bei Kopf-Hals-Karzinomen nicht inaktiviert ist.

- Gut (G1) und schlecht (G3) differenzierte Plattenepithelkarzinome unterscheiden sich durch ihr genetisches Muster. Während die G1-Tumoren durch die Deletionen auf $3 p$ und $9 p$ kombiniert mit der Überrepräsentierung auf $3 q$ gekennzeichnet sind, weisen die schlecht differenzierten Malignome zusätzlich die Deletionen von Chromosom 4, 5q, 8p, 11, 13q, 18q sowie 21q und die Überrepräsentierungen von 8q, 11q13 sowie 20q auf.

- Metastasierende ( $\mathrm{pN}+$ ) und nicht metastasierende (pN0) Kopf-Hals-Karzinome lassen sich ebenfalls durch bestimmte genetische Muster unterscheiden. Die pN0 Tumoren zeigen mehr Überrepräsentierungen der Chromosomenarme 4q, $6 p, 7 p, 12 p, 13 q$ und 20p. Demgegenüber weisen die pN+ Karzinome mehr Deletionen im Bereich der Chromosomen 2q, 4q, 5q, 10q, 11p, 11q, 14q, 15q, $20 p$ sowie $21 q$ und Überrepräsentierungen bei $2 p$ sowie $11 q 13$ auf.

- Metastasierende Kopf-Hals-Karzinome weisen mehr genetische Alterationen auf als nicht metastasierende Tumoren.

- Der genetische Vergleich von Primärtumoren mit ihren korrespondierenden Lymphknotenmetastasen zeigt, daß der metastasierende Klon durch 10qDeletionen charakterisiert ist.

- Die 11q13- und 3q-Amplifikation sind unabhängige genetische Prognosemarker bei Kopf-Hals-Karzinomen. Die multivariate Cox-Regression zeigt, daß ihr Einfluß und besonders die 11q13-Amplifikation für die Einschätzung des rezidiv- und metastasenfreien sowie des Gesamtüberlebens größer ist als der aller klinisch-pathologischen Parameter.

- Mit Hilfe der CGH ist eine klonale Zuordnung von Primärtumor und Lymphknotenmetastasen sowohl als auch von Primärtumor und Zweitkarzinom möglich. 
- Primärtumor und Zweitkarzinom können sowohl einen gemeinsamen klonalen Ursprung haben als auch polyklonal entstanden sein.

- Es kann mittels der CGH genetisch auch das Vorliegen einer Metastase oder eines Zweitkarzinoms, so es polyklonal entstanden ist, unterschieden werden.

Die CGH ist eine geeignete Methode, um bei soliden Malignomen genetische Muster zu finden, die das biologische Tumorverhalten genauer charakterisieren. Als Ergänzung der histologischen Diagnose könnte somit eine genetische Tumorklassifikation möglich werden, aus der sich langfristig auch neue Wege für die Therapie ergeben. 


\section{LITERATURVERZEICHNIS}

Ah-See, K.W., Cooke, T.G., Pickford, I.R., Soutar, D., Balmain, A.: An allelotype of squamous carcinoma of the head and neck. Cancer Res., 54, 1617-1621, 1994.

Åkervall, J.A., Jin, Y., Wennerberg, J.P., Zätterström, U.K., Kjellén, E., Mertens, F., Willén, R., Mandahl, N., Heim, S., Mitelman, F.: Chromosomal abnormalities involving $11 \mathrm{q} 13$ are associated with poor prognosis in patients with squamous cell carcinoma of the head and neck. Cancer, 76, 853-859, 1995.

Åkervall, J.A., Michaelides, R.J.A.M., Mineta, H., Balm, A., Borg, A., Dictor, M.R., Jin, Y., Loftus, B., Mertens, F., Wennerberg, J.P.: Amplification of cyclin D1 in squamous cell carcinoma of the head and neck and the prognostic value of chromosomal abnormalities and cyclin D1 overexpression. Cancer, 79, 380-389, 1997.

Anneroth, G., Batsakis, J., Kyba, N.: Review of the literature and recommended system of malignancy grading in oral squamous cell carcinomas. Scand. J. Dent. Res., 95, 229249, 1987.

Bartek, J., Vojtesek, B., Grand, R.J.A., Gallimore, P.H., Lane, D.P.: Cellular localization and $\mathrm{T}$ antigen binding of the retinoblastoma protein. Oncogene, 7, 101-108, 1992.

Bartkova, J., Lukas, J., Müller, H., Strauss, M., Gusterson, B., Bartek, J.: Abnormal patterns of D-type cyclin expression and G1 regulation in human head and neck cancer. Cancer Res., 55, 949-956, 1995.

Batsakis, J.: Tumors of the head and neck - clinical and pathological considerations. 1. Auflage, Williams and Wilkins, Baltimore, 1979.

Bedi, G., Westra, W., Gabrielson, E., Koch, W., Sidransky, D.: Multiple head and neck tumors: Evidence for a common clonal origin. Cancer Res., 56, 2484-2487, 1996.

Black, R.J., Bray, F., Ferlay, J., Parkin, D.M.: Cancer incidence and mortality in the European Union: cancer registry data and estimates of national incidence for 1990. Eur. J. Cancer, 33, 1075-1107, 1997.

Bockmühl, U., Petersen, I., Dietel, M.: Allelverluste bei Plattenepithelkarzinomen des Larynx. Laryngol. Rhinol. Otol., 75, 48-52, 1996a.

Bockmühl, U., Petersen, I., Schwendel, A., Dietel, M.: Genetisches Screening von KopfHals-Karzinomen mittels der Komparativen Genomischen Hybridisierung (CGH). Laryngol. Rhinol. Otol., 75, 408-414, 1996 b.

Bockmühl, U., Petersen, S., Schmidt, S., Wolf, G., Jahnke, V., Dietel, M., Petersen, I.: Patterns of chromosomal imbalances in metastasizing and non metastasizing head and neck cancer. Cancer Res., 57, 5213-5216, 1997a.

Bockmühl, U., Schwendel, A., Dietel, M., Petersen, I.: Distinct patterns of chromosomal alterations in high and low grade head and neck squamous cell carcinomas. Cancer Res., $56,5325-5329,1996 \mathrm{c}$.

Bockmühl, U., Wolf, G., Schmidt, S., Schwendel, A., Jahnke, V., Dietel, M., Petersen, I.: Genomic alterations associated with malignancy in head and neck cancer. Head Neck, 20, 145-151, 1997b. 
Boveri, T.: Zur Frage der Entstehung maligner Tumoren. Gustav-Fischer-Verlag Jena, $164,1914$.

Brass, N., Ukena, I., Remberger, K., Mack, U., Sybrecht, G.W., Meese, E.U.: DNA amplification on chromosom 3q26.1-q26.3 in squamous cell carcinoma of the lung detected by reverse chromosome painting. Eur. J. Cancer, 32A, 1205-1208, 1996.

Brennan, J.A., Boyle, J.O., Koch W.M., Goodman, S.N., Hruban, R.H., Eby, Y.J., Couch, M.J., Forastiere, A.A., Sidransky, D.: Association between cigarette smoking and mutation of the p53 gene in head and neck squamous cell carcinoma. N. Engl. J. Med., 332, 712-717, 1995.

Brennan, J.A., Mao, L., Hruban, R.H., Boyle, J.O., Eby, Y.J., Koch, W.M., Goodman, S.N., Sidransky, D.: Molecular assessment of histopathological staging in squamous-cell carcinoma of the head and neck. N. Engl. J. Med., 332, 429-435, 1995.

Brzoska, P.M., Levin, N.A., Fu, K.K., Kaplan, M.J., Singer, M.I., Gray, J.W., Christman, M.F.: Frequent novel DNA copy number increases in squamous cell head and neck tumors. Cancer Res., 55, 3055-3059, 1995.

Califano, J., van der Riet, P., Westra, W., Nawroz, H., Clayman, G., Piantadosi, S., Corio, R., Lee, D., Greenberg, B., Koch, W., Sidransky D.: Genetic progression model for head and neck cancer: Implications for field cancerization. Cancer Res., 56, 24882492, 1996.

Carey, T.E., van Dyke, D., Worsham, M.J.: Nonrandom chromosome aberrations and clonal populations in head and neck cancer. Anticancer Res., 13, 2561-2567, 1993.

Dib, C., Fizames, C., Samson, D., Drouot, N., Vignal, A., Millasseau, P., Marc, S., Hazan, J., Seboun, E., Lathrop, M., Gyapay, G., Morisette, J., Weissenbach, J.: A comprehensive genetic map of the human genome based on 5,264 microsattelites. Nature, 380, 152-154, 1996.

du Manoir, S., Speicher, M.R., Joos, S., Schröck, E., Popp, S., Döhner, H., Kovacs, G., Robert-Nicoud, M., Lichter, P., Cremer, T.: Detection of complete and partial chromosome gain and losses by comparative genomic hybridization. Hum. Genet., 90, 590-610, 1993.

Fearon, E.R., Vogelstein, B.: A genetic model for colorectal tumorigenesis. Cell, 61, 759-767, 1990.

Field, J.K., Kiaris, H., Howard, P., Vaughan, E., Spandidos, D., Jones, A.: Microsatellite instability in squamous cell carcinoma of the head and neck. Br. J. Cancer, 71, 10651069, 1995.

Field, J.K., Spandidos, D.A., Steel, P.M., Vaughan, E.D., Evan, G.I., Moore, J.P.: Elevated expression of the c-myc oncoprotein correlates with poor prognosis in head and neck squamous cell carcinoma. Oncogene, 4, 1463-1468, 1989.

Frommhold, H.: Strahlentherapie der Kopf-Hals-Tumoren. In: Naumann, H.H., Helms, J., Herberhold, C., Kastenbauer, E. (Hrsg). Oto-Rhino-Laryngologie in Klinik und Praxis. Bd. 2., 1. Auflage, Thieme-Verlag, Stuttgart, 460-467, 1995. 
Gao, A.C., Lou, W., Dong, J.T., Isaacs, J.T.: CD44 is a metastasis suppressor gene for prostatic cancer located on human chromosome 11p13. Cancer Res., 57, 846-849, 1997.

Glanz, H., Hermanek, P., Kleinsasser, O., Popella, C.: Weiterentwicklung der TNMKlassifikation der Larynxkarzinome. Laryngol. Rhinol. Otol., 72, 568-573, 1993.

Gluckman, J., Crissman, J., Donegan, J.: Multicentric squamous cell carcinoma of the upper aerodigestive tract. Head Neck, 3, 90-96, 1980.

Gronwald, J., Störkel, S., Holtgreve-Grez, H., Hadaczek, P., Brinkschmidt, C., Jauch, A., Lubinski, J., Cremer, T.: Comparison of DNA gains and losses in primary renal clear cell carcinomas and metastatic sites: Importance of $1 \mathrm{q}$ and $3 \mathrm{p}$ copy number changes in metastatic events. Cancer Res., 57, 481-487, 1997.

Hartwell, L.H., Kastan, M.B.: Cell cycle control and cancer. Science, 266, 1821-1828, 1994.

Heselmeyer, K., Schröck, E., du Manoir, S., Blegen, H., Shah, K., Steinbeck, R., Auer, G., Ried, T.: Gain of chromosome $3 \mathrm{q}$ defines the transition from severe dysplasia to invasive carcinoma of the uterine cervix. Proc. Natl. Acad. Sci. USA, 93, 479-484, 1996.

Huebner, R., Todaro, G.: Oncogenes of RNA tumor viruses as determinants of cancer. Proc. Natl. Acad. Sci. USA, 77, 1087-1094, 1969.

Ishwad, C.S., Ferrell, R.E., Rossie, K.M., Appel, B.N., Johnson, J.T., Myers, E.N., Law, J.C., Srivastava, S., Gollin, S.M.: Microsatellite instability in oral cancer. Int. J. Cancer, 64, 332-335, 1995.

Isola, J.I., Kallioniemi, O.P., Chu, L.W., Fuqua, S.A.W., Hilsenbeck, S.G., Osborne, C.K., Waldman, F.M.: Genetic aberrations detected by Comparative Genomic Hybridization predict outcome in node-negative breast cancer. Am. J. Pathol., 147, 905911, 1995.

Jahnke, V.: Bösartige Tumoren des Larynx. In: Naumann, H.H., Helms, J., Herberhold, C., Kastenbauer, E. (Hrsg.). Oto-Rhino-Laryngologie in Klinik und Praxis., Bd. 3., 1. Auflage, Thieme-Verlag, Stuttgart, 388-421, 1995.

Jin, Y., Mertens, F., Mandahl, N., Heim, S., Olegard, C., Wennerberg, J., Björklund, A., Mitelman, F.: Chromosome abnormalities in eigthy-three head and neck squamous cell carcinomas: Influence of culture conditions on karyotypic pattern. Cancer Res., 53, 2140-2146, 1993.

Jin, Y., Mertens, F., Jin, C., Akervall, J., Wennerberg, J., Gorunova, L., Mandahl, N., Heim, S., Mitelman, F.: Nonrandom chromosome abnormalities in short-term cultured primary squamous cell carcinomas of the head and neck. Cancer Res., 55, 3204-3210, 1995.

Kallioniemi, A., Kallioniemi, O.P., Sudar, D., Rutovitz, D., Gray, J.W., Waldman, F., Pinkel, D.: Comparative genomic hybridization for molecular cytogenetic analysis of solid tumors. Science, 258, 818-821, 1992.

Kallioniemi, A., Kallioniemi, O.P., Piper, J., Tanner, M., Stokke, T., Chen, L., Smith, H.S., Pinkel, D., Gray, J.W., Waldman, F.M.: Detection and mapping of amplified DNA sequences in breast cancer by comparative genomic hybridization. Proc. Natl. Acad. Sci. USA, 91, 2156-2160, 1994a. 
Kallioniemi, A., Kallioniemi, O.P., Sudar, D., Rutovitz, D., Gray, J.W., Waldman, F., Pinkel, D.: Optimizing comparative genomic hybridization for analysis of DNA sequence copy number changes in solid tumors. Genes Chromosom. Cancer, 10, 231243, 1994b.

Koch, W., Brennan, J., Zahurak, M., Goodman, S., Westra W., Schwab, D., Yoo, G., Lee, D., Forastiere, A., Sidransky, D.: p53 mutation and locoregional treatment failure in head and neck squamous cell carcinoma. J. Natl. Cancer Inst., 88, 1580-1586, 1996.

Kuukasjärvi, T., Karhu, R., Tanner, M., Kähkönen, M., Schäffer, A., Nupponen, N., Pennanen, S., Kallioniemi, A., Kallioniemi, O.P., Isola, J.: Genetic heterogeneity and clonal evolution underlying development of asynchronous metastasis in human breast cancer. Cancer Res., 57, 1597-1604, 1997.

Lese, C., Rossie,K., Appel, B., Reddy, J., Johnson, J., Myers, E., Gollin, S.: Visualization of INT2 and HST1 amplification in oral squamous cell carcinomas. Genes Chromosom. Cancer, 12, 288-295, 1995.

Levin, N.A., Broszka, P., Warnock, M.L., Gray, J.W., Christman, M.F.: Identifikation of novel regions of altered DNA copy number in small cell lung tumors. Genes Chromosom. Cancer, 13, 175-185, 1995.

Li, J., Yen, C., Liaw, D., Podsypania, K., Bose, S., Wang, S.I., Puc, J., Miliaresis, C., Rodgers, L., McCombie, R., Bigner, S.H., Giovanella, B.C., Ittmann, M., Tycko, B., Hibshoosh, H., Wigler, M.H., Parsons, R.: PTEN, a putative protein tyrosine phosphatase gene mutated in human brain, breast, and prostate cancer. Science, 275, 1943-1947, 1997.

Li, X., Lee, N.K., Ye, Y.-W., Waber, P.G., Schweitzer, C., Cheng, Q.-C., Nisen, P.D.: Allelic loss at chromosomes $3 \mathrm{p}, 8 \mathrm{p}, 13 \mathrm{p}$, and $17 \mathrm{p}$ associated with poor prognosis in head and neck cancer. J. Natl. Cancer Inst., 86, 1524-1529, 1994.

Loughran, O., Mallri, A., Owens, D., Gallimore, P.H., Stanley, M.A., Ozanne, B., Frame, M.C., Parkinson, E.K.: Association of CDKN2A/p16INK4A with human head and neck keratinocyte replicative senescence: relationship of dysfunction to immortality and neoplasia. Oncogene, 13, 561-568, 1996.

Lukas, J., Pagano, M., Staskova, Z., Draetta, G., Bartek, J.: Cyclin D1 protein oscillates and is essential for sell cycle progression in human tumor cell lines. Oncogene, 9, 707$718,1994$.

Lukas, J., Parry, D., Aagaard, L., Mann, D.J., Bartkova, J., Strauss, M., Peters, G., Bartek, J.: Retinoblastoma-protein-dependent cell-cycle inhibition by the tumor suppressor p16. Nature, 375, 503-506, 1995.

Maestro, R., Gasparotto, D., Vukosavljevic, T., Barzan, L., Sulfaro, S., Boiocchi, M.: Three discrete regions of deletion at $3 \mathrm{p}$ in head and neck cancers. Cancer Res., 53, 57755779, 1993.

Mao, L., Lee, J.S., Fan, Y.H., Ro, J.Y., Batsakis, J.G., Lippman, S., Hittelman, W., Hong, W.K.: Frequent microsatellite alterations at chromosomes 9p21 and 3q14 in oral premalignant lesions and their value in cancer risk assessment. Nature Med., 2, 682-685, 1996. 
Matthias, C., Bockmühl, U., Jahnke, V., Petersen, I., Dietel, M., Fryer, A., Strange, R.C.: Einfluß von Genpolymorphismen in den entgiftenden Enzymen der Glutathion-STransferasen auf die chromosomale Stabilität von Plattenepithelkarzinomen im KopfHals-Bereich. Laryngol. Rhinol. Otol., 77, 201-206, 1998.

Mertens, F., Johansson, B., Höglund, M., Mitelman, F.: Chromosomal imbalance maps of malignant solid tumors: a cytogenetic survey of 3185 neoplasms. Cancer Res., 57, 2765-2780, 1997.

Mitelman, F.: Catalog of chromosome aberations in cancer. 5. Auflage, Liss, New York, 1995.

Moch, H., Presti, Jr. J.C., Sauter, G., Buchholz, N., Jordan, P., Mihatsch, M.J., Waldman, F.M.: Genetic aberrations detected by comparative genomic hybridization are associated with clinical outcome in renal cell carcinoma. Cancer Res., 56, 27-30, 1996.

Mollenhauer, J., Wiemann, S., Scheurlen, W., Korn, B., Hayashi, Y., Wigenbus, K.K., von Deimling, A., Poustka, A.: DMBT1, a new member of the SRCR superfamily, on chromosome 10q25.3-26.1 is deleted in malignant brain tumors. Nat. Genet., 17, 32-39, 1997.

Muller, D., Millon, R., Velten, M., Bronner, G., Jung, G., Engelmann, A., Flesch, H., Eber, M., Methlin, G., Abecassis, J.; Amplification of 11q13 DNA markers in head and neck squamous cell carcinomas: correlation with clinical outcome. Eur. J. Cancer, 33, 2203-2210, 1997.

Nawroz, H., van der Riet, P., Hruban, R.H., Koch, W., Ruppert, J.M., Sidransky, D.: Allelotype of head and neck squamous cell carcinoma. Cancer Res., 54, 1152-1155, 1994.

Nowell, P.C.: The clonal evolution of tumor cell populations. Science, 132, 23-28, 1976.

Nowell, P.C., Hungerford, D.A.: A minute chromosome in chronic granulocytic leukemia. Science, 132, 1497-1503, 1960.

Petersen, I., Bujard, M., Petersen, S., Wolf, G., Goeze, A., Schwendel, A., Langreck, H., Gellert, K., Reichel, M., Just, K., du Manoir, S., Cremer, T., Dietel, M., Ried, T.: Patterns of chromosomal imbalances in adenocarcinoma and squamous cell carcinoma of the lung. Cancer Res., 57, 2331-2335, 1997a.

Petersen, I., Langreck, H., Wolf, G., Schwendel, A., Psille, R., Vogt, P., Reichel, M., Ried, T., Dietel, M.: Small cell lung cancer is characterized by a high incidence of deletions on chromosomes 3p, 4q, 5q, 10q, 13q and 17p. Br. J. Cancer, 75, 79-86, $1997 \mathrm{~b}$.

Petersen, I., Schwendel, A., Bockmühl, U., Dietel, M.: Die komparative genomische Hybridisierung: Eine Screeningmethode in der genetischen Tumordiagnostik. Pathologe, 17, 333-341, 1996.

Petersen, S., Rudolf, J., Bockmühl, U., Gellert, K., Wolf, G., Dietel, M., Petersen, I.: Distinct regions of allelic imbalance on chromosome 10q22-26 in squamous cell carcinomas of the lung. Oncogene 16, 449-454, 1998a. 
Petersen, S., Wolf, G., Bockmühl, U., Gellert, M., Dietel, M., Petersen, I.: Allelic loss on chromosome $10 \mathrm{q}$ in human lung cancer: association with tumour progression and metastatic phenotype. Br. J. Cancer, 77, 270-276, 1998b.

Rabbitts, T.H.: Chromosomal translocations in human cancer. Nature, 372, 143-149, 1994.

Reed, A.L., Califano, J., Cairns, P., Westra, W.H., Jones, R.M., Koch, W., Ahrendt, S., Eby, Y., Sewell, D., Nawroz, H., Bartek, J., Sidransky, D.: High frequency of p16 (CDKN2/MTS-1/INK4A) inactivation in head and neck squamous cell carcinoma. Cancer Res., 56, 3630-3633, 1996.

Ried, T., Petersen, I., Holtgreve-Grez, H., Speicher, M.R., Schröck, E., du Manoir, S., Cremer, T.: Mapping of multiple DNA gains and losses in primary small cell lung carcinomas by comparative genomic hybridization. Cancer Res., 54, 1801-1806, 1994.

Roth, K., Wolf, G., Dietel, M., Petersen, I.: Image analysis for Comparative genomic Hybridization based on a karyotyping program for Windows. Anal. Quant. Cytol. Histol., 19, 461-474, 1997.

Rudert, H.: Maligne Tumoren der Lippen, der Mundhöhle und des Oropharynx. In: Naumann, H.H., Helms, J., Herberhold, C., Kastenbauer, E. (Hrsg.). Oto-RhinoLaryngologie in Klinik und Praxis. Bd. 2., 1. Auflage, Thieme-Verlag, Stuttgart, 648675, 1995.

Sakaguchi, M., Fujii, Y., Hirabayashi, H., Yoon, H.-E., Komoto, Y., Oue, T., Kusafuka, T., Okada, A., Matsuda, H.: Inversely correlated expression of p16 and Rb protein in non-small cell lung cancers: an immunohistochemical study. Int. J. Cancer, 65, 442-445, 1996.

Sambrook, J., Fritsch, E.F., Maniatis, T.: Molecular Cloning: A Laboratory Manual. 2.Auflage, Cold Spring Harbor Laboratory, New York, 1989.

Schalhorn, A., Wustrow, T.P.U.: Systemische Chemotherapie von Kopf-Hals-Tumoren. In: Naumann, H.H., Helms, J., Herberhold, C., Kastenbauer, E. (Hrsg.). Oto-RhinoLaryngologie in Klinik und Praxis. Bd. 2., 1. Auflage, Thieme-Verlag, Stuttgart, 451457, 1995.

Scholes, A.G.M., Woolgar, J.A., Boyle, M.A., Brown, J.S., Vaughan, E.D., Hart, C.A., Jones, A.S., Field, J.K.: Synchronous oral carcinomas: Independent or common clonal origin? Cancer Res., 58, 2003-2006, 1998.

Schröck, E., Thiel, G., Lozanova, T., du Manoir, S., Meffert, M.-C., Jauch, A., Speicher, M.R., Nürnberg, P., Vogel, S., Jänisch, W., Donis-Keller, H., Ried, T., Witkowski, R., Cremer, T.: Comparative genomic hybridization of human malignant gliomas reveals multiple amplification sites and nonrandom chromosomal gains and losses. Am. J. Pathol, 144, 1203-1218, 1994.

Schantz, S.P., Harrison, L.B., Forastiere, A.A.: Tumors of the nasal cavity and paranasal sinuses, nasopharynx, oral cavity, and oropharynx. In: DeVita, V.T., Hellman, S., Rosenberg, S.A. (Hrsg.) Cancer: Principles and practice of oncology. 5. Auflage, J.B. Lippincott Co., Philadelphia, 741-801, 1997. 
Scholnick, S.B., Haughey, B.H., Sunwoo, J.B., El-Mofty, S.K., Baty, J.D., Piccirillo, J.F., Zequeira, M.R.: Chromosome 8 allelic loss and the outcome of patients with squamous cell carcinoma of the supraglottic larynx. J. Natl. Cancer Inst., 88, 1676-1682, 1996.

Schwendel, A., Langreck, H., Reichel, M., Schröck, E., Ried, T., Dietel, M., Petersen, I.: Primary small cell lung carcinomas and their metastases are characterized by a recurrent pattern of genetic alterations. Int. J. Cancer, 74, 86-93, 1997.

Sessions, R.B., Harrision, L.B., Forastiere, A.A.: Tumors of the larynx and hypopharynx. In: DeVita, V.T., Hellman, S., Rosenberg, S.A. (Hrsg.) Cancer: Principles and practice of oncology. 5. Auflage, J.B. Lippincott Co., Philadelphia, 802-829, 1997.

Sidransky, D.: Molecular biology of head and neck tumors. In: DeVita, V.T., Hellman, S., Rosenberg, S.A. (Hrsg.) Cancer: Principles and practice of oncology. 5. Auflage, J.B. Lippincott Co., Philadelphia, 735-740, 1997.

Slaughter, D.P., Southwick, H.W., Smejkal, W.: "Field cancerization" in oral stratified squamous epithelium: Clinical implications of multicentric origin. Cancer, 6, 963-968, 1953.

Soder, A.I., Hopman, A.H.N., Ramaekers, F.C.S., Conradt, C., Bosch, F.X.: Distinct nonrandom patterns of chromsomal aberrations in the progression of squamous cell carcinomas of the head and neck. Cancer Res., 55, 5030-5037, 1995.

Speicher, M.R., Howe, C., Crotty, P., du Manoir, S., Costa, J., Ward, D.C.: Comparative genomic hybridization detects novel deletions and amplifications in head and neck squamous cell carcinomas. Cancer Res., 55, 1010-1013, 1995.

Steck, P.A., Pershouse, M.A., Jasser, S.A., Yung, W.K.A., Lin, H., Ligon, A. H., Langford, L.A., Baumgard, M.L., Hattier, T., Davis, T., Frye, C., Hu, R., Swedlund, B., Teng, D.H.F., Tavtigan, S.V.: Identification of a candidate tumour suppressor gene, MMAC1, at chromosome 10q23.3 that is mutated in multiple advanced cancers. Nature Genet., 15, 356-362, 1997.

Tjio, G., Levan, A.: The chromosome number of man. Hereditas, 42, 441-447, 1956.

van der Riet, R., Nawroz, H., Hruban, R.H., Corio, R., Tokino, K., Koch, W., Sidransky, D.: Frequent loss of chromosome 9p21-22 early in head and neck cancer progression. Cancer Res., 54, 1156-1158, 1994.

van Dyke, D., Worsham, M.J., Benninger, M.S., Krause, C.J., Baker, S.R., Wolf, G.T., Drumheller, T., Tilley, B.C., Carey, T.E.: Recurrent cytogenetic abnormalities in squamous cell carcinomas of the head and neck region. Genes Chromosom. Cancer, 9, 192-206, 1994.

Verma, R.S., Babu, A.: Human Chromosomes: Principles and Techniques. 2. Auflage, McGraw-Hill, New York, 1994.

Virgilio, L., Shuster, M., Gollin, S.M., Veronese, M.L., Ohta, M., Huebner, K., Croce, C.M.: FHIT gene alterations in head and neck squamous cell carcinomas. Proc. Natl. Acad. Sci., 93, 9770-9775, 1996.

von Hansemann, D.: Über asymmetrische Zellteilung in Epithelkrebsen und deren biologische Bedeutung. Virchows Arch. Pathol. Anat., 119, 299-326, 1890. 
Weber, R., Sabel, M., Reifenberger, J., Sommer, C., Oberstraß, J., Reifenberger, G., Kiessling, M., Cremer, T.: Charakterization of genomic alterations associated with glioma progression by comparative genomic hybridization. Oncogene, 12, 983-994, 1996.

Werner, J.A.: Aktueller Stand der Versorgung des Lymphabflusses maligner Kopf-HalsTumoren. Laryngol. Rhinol. Otol., 76, 643-644, 1997.

Worsham, M.J., Wolman, S.R., Carey, T.E., Zarbo, R.J., Benninger, M.S., van Dyke, D.L.: Common clonal origin of synchronous primary head and neck squamous cell carcinomas: Analysis by tumor karyotypes and fluorescence in situ hybridization. Hum. Pathol., 26, 251-261, 1995.

Wright, K., Manos, M.M.: PCR Protocols: A guide to methods and amplications. Academic Press Inc., 153-158, 1990.

Yoo, G.H., Xu, H.J., Brennan, J.A., Westra, W., Hruban, R.H., Koch, W., Benedict, W.F., Sidransky D.: Infrequent inactivation of the retinoblastoma gene despite frequent loss of chromosome 13q in head and neck squamous cell carcinoma. Cancer Res., 54, 4603-4606, 1994. 


\section{ABKÜRZUNGSVERZEICHNIS}

CCD - $\quad$ charge-coupled device

CGH - Comparative Genomic Hybridization

DAPI ～- 4,6-Diamino-2-Phenylindol-Dihydrochlorid

DMBT1 - $\quad$ deleted in malignant brain tumors 1

FISH - Fluoreszenz-in-situ-Hybridisierung

FITC - Fluorescein-Avidin

HST1 - fibroblast growth factor 4

INT2 - fibroblast growth factor 3

$\mathrm{LOH} \quad$ - Loss of Hetrozygosity

MMAC1 $\quad$ - $\quad$ mutated in multiple advanced cancers 1

PBS - $\quad$ phosphate buffered saline

$\mathrm{pN} \quad$ - Lymphknotenstatus (pathologische Klassifikation)

pN0 - nicht metastasierende Karzinome

$\mathrm{pN}+\quad-\quad$ metastasierende Karzinome

pT - $\quad$ Tumorgröße (pathologische Klassifikation)

PTEN - $\quad$ protein tyrosine phosphatase domain

p16 - multiple tumor suppressor 1

$\mathrm{Rb} \quad-\quad$ Retinoblastom-Tumorsuppressorgen

SDS - $\quad$ - sodium dodecylsulphate

SSC - $\quad$ - sodium chloride/sodium citrate buffer

TRITC - Anti-Digoxigenin-Rhodamin

TSG - - Tumorsuppressorgen 


\section{TABELLARISCHER ANHANG}

Tabelle 1 Klinisch-pathologische Daten des untersuchten Tumorkollektivs.

\begin{tabular}{|c|c|c|c|c|}
\hline & & total & $\mathrm{pN} 0$ & $\mathrm{pN}+$ \\
\hline \multicolumn{2}{|c|}{ Anzahl der Patienten } & 100 & 37 & 63 \\
\hline \multirow{2}{*}{\multicolumn{2}{|c|}{$\begin{array}{l}\text { weiblich } \\
\text { männlich }\end{array}$}} & 23 & 7 & 16 \\
\hline & & 77 & 30 & 47 \\
\hline \multicolumn{5}{|c|}{ Tumorlokalisation } \\
\hline \multicolumn{2}{|c|}{ Larynx } & 38 & 23 & 15 \\
\hline \multicolumn{2}{|c|}{ Supraglottis } & 15 & 6 & 9 \\
\hline \multicolumn{2}{|c|}{ Glottis } & 22 & 16 & 6 \\
\hline \multicolumn{2}{|c|}{ subglottisch } & 1 & 1 & - \\
\hline \multicolumn{2}{|c|}{ Hypopharynx } & 24 & 6 & 18 \\
\hline \multicolumn{2}{|c|}{ Oropharynx } & 25 & 5 & 20 \\
\hline \multicolumn{2}{|c|}{ Mundhöhle } & 13 & 3 & 10 \\
\hline \multirow[t]{4}{*}{ pT-Stadium } & pT1 & 6 & 2 & 4 \\
\hline & pT2 & 28 & 8 & 20 \\
\hline & pT3 & 38 & 19 & 19 \\
\hline & pT4 & 28 & 8 & 20 \\
\hline \multirow[t]{4}{*}{ pN-Stadium } & $\mathrm{pN} 0$ & 37 & 37 & - \\
\hline & $\mathrm{pN} 1$ & 16 & - & 16 \\
\hline & $\mathrm{pN} 2$ & 44 & - & 44 \\
\hline & $\mathrm{pN} 3$ & 3 & - & 3 \\
\hline \multirow[t]{4}{*}{ UICC-Stadium } & I & 2 & 2 & - \\
\hline & II & 8 & 8 & - \\
\hline & III & 35 & 19 & 16 \\
\hline & IV & 55 & 8 & 47 \\
\hline \multirow[t]{3}{*}{ Grading } & G1 & 3 & 2 & 1 \\
\hline & $\mathrm{G} 2$ & 78 & 33 & 45 \\
\hline & G3 & 19 & 2 & 17 \\
\hline
\end{tabular}


Tabelle 2: Klinisch-pathologische Daten der untersuchten Zweitkarzinome.

\begin{tabular}{|c|c|c|c|c|c|c|c|c|c|c|c|c|}
\hline \multirow{3}{*}{$\begin{array}{l}\mathbf{N}^{\circ} \\
75\end{array}$} & \multirow{3}{*}{$\begin{array}{l}\text { Primärtumor } \\
\text { Oropharynx }\end{array}$} & \multicolumn{3}{|c|}{ pT pN M } & \multirow{3}{*}{$\begin{array}{c}\text { Grading } \\
2\end{array}$} & \multicolumn{2}{|c|}{ Zweittumor } & \multicolumn{3}{|c|}{ pT pN M } & \multirow{3}{*}{$\begin{array}{c}\text { Grading } \\
2\end{array}$} & \multirow{2}{*}{$\begin{array}{l}\text { Intervall } \\
\text { (Monate) }\end{array}$} \\
\hline & & & & & & \multirow{2}{*}{$\begin{array}{c}\text { synchron } \\
\text { Larynx }\end{array}$} & \multirow{2}{*}{ metachron } & & & & & \\
\hline & & 3 & 1 & 0 & & & & 1 & $\overline{0}$ & 0 & & \\
\hline 161 & Larynx & 3 & 0 & 0 & 2 & Unterlippe & & 1 & 0 & 0 & 1 & \\
\hline 192 & Oropharynx & 3 & 1 & 0 & 3 & Ösophagus & & 1 & 0 & 0 & 2 & \\
\hline 200 & Oropharynx & 3 & 1 & 0 & 2 & Supraglottis & & 1 & 0 & 0 & 2 & \\
\hline 203 & Hypopharynx & 4 & 1 & 0 & 2 & Supraglottis & & 1 & 0 & 0 & 2 & \\
\hline 212 & Hypopharynx & 3 & 0 & 0 & 2 & Ösophagus & & 3 & $\mathrm{x}$ & $\mathrm{x}$ & 2 & \\
\hline 215 & Oropharynx & 3 & 0 & 0 & 2 & Ösophagus & & 3 & 1 & $1 b$ & 2 & \\
\hline 196 & Hypopharynx & 3 & 0 & 0 & 3 & & Mundhöhle & 2 & 0 & 0 & 1 & 17 \\
\hline 198 & Oropharynx rechts & 4 & 1 & 0 & 3 & & Oropharynx links & 3 & 0 & 0 & 2 & 19 \\
\hline 204 & Larynx & 2 & 0 & 0 & 2 & & Oropharnyx & 2 & 0 & 0 & 2 & 70 \\
\hline
\end{tabular}


Tabelle 3: $\quad$ Einzeldaten der LOH-Analyse für Chromosom 10q.

\begin{tabular}{|c|c|c|c|c|}
\hline Fall & $\begin{array}{l}\text { D10S569 } \\
10 q 21-22\end{array}$ & $\begin{array}{l}\text { D10S541 } \\
10 q 22\end{array}$ & D10S185 & $\begin{array}{l}\text { D10S169 } \\
10 q 25-26\end{array}$ \\
\hline $\mathbf{3 a}$ & het & ni & ni & ni \\
\hline $7 \mathbf{a}$ & het & het & het & het \\
\hline $\mathbf{8 a}$ & het & het & het & het \\
\hline $19 a$ & het & ni & het & het \\
\hline $20 a$ & $\mathrm{LOH}$ & het & het & ni \\
\hline $22 a$ & het & het & het & ni \\
\hline $23 \mathbf{a}$ & het & het & ni & het \\
\hline $24 a$ & het & ni & ni & ni \\
\hline $26 a$ & het & het & het & het \\
\hline $27 \mathbf{a}$ & het & $\mathrm{LOH}$ & $\mathrm{LOH}$ & $\mathrm{LOH}$ \\
\hline $27 b$ & het & $\mathrm{LOH}$ & LOH & $\mathrm{LOH}$ \\
\hline $28 a$ & het & het & het & het \\
\hline $29 a$ & het & ni & het & het \\
\hline 30a & het & het & het & het \\
\hline 33a & het & het & het & het \\
\hline $37 \mathbf{a}$ & het & ni & ni & $\mathrm{LOH}$ \\
\hline $37 b$ & het & ni & ni & $\mathrm{LOH}$ \\
\hline 38a & het & het & het & het \\
\hline $38 b$ & het & het & het & het \\
\hline $44 a$ & het & het & het & het \\
\hline $45 a$ & het & het & het & het \\
\hline $51 a$ & $\mathrm{LOH}$ & ni & ni & het \\
\hline $51 b$ & $\mathrm{LOH}$ & ni & ni & $\mathrm{LOH}$ \\
\hline $54 a$ & het & het & het & ni \\
\hline $55 a$ & het & het & het & ni \\
\hline $56 a$ & het & het & het & het \\
\hline $57 \mathbf{a}$ & het & ni & $\mathrm{LOH}$ & $\mathrm{LOH}$ \\
\hline $58 \mathbf{a}$ & ni & het & ni & ni \\
\hline $60 a$ & het & het & het & het \\
\hline $61 a$ & $\mathrm{LOH}$ & het & het & ni \\
\hline $62 a$ & het & ni & het & het \\
\hline $63 a$ & het & het & het & het \\
\hline $64 a$ & $\mathrm{LOH}$ & $\mathrm{LOH}$ & ni & $\mathrm{LOH}$ \\
\hline $65 a$ & het & $\mathrm{ni}$ & LOH & het \\
\hline $65 b$ & het & ni & $\mathrm{LOH}$ & $\mathrm{LOH}$ \\
\hline $66 a$ & ni & ni & ni & ni \\
\hline $67 a$ & het & het & ni & $\mathrm{LOH}$ \\
\hline $67 b$ & $\mathrm{LOH}$ & $\mathrm{LOH}$ & ni & $\mathrm{LOH}$ \\
\hline $68 a$ & $\mathrm{LOH}$ & het & het & het \\
\hline $68 b$ & ni & het & het & het \\
\hline
\end{tabular}




\begin{tabular}{ccccc} 
Fall & D10S569 & D10S541 & D10S185 & D10S169 \\
& 10q21-22 & 10q22 & & 10q25-26 \\
\hline 69a & het & het & het & het \\
69b & het & het & het & het \\
70a & het & het & het & ni \\
71a & het & LOH & ni & LOH \\
72a & het & het & het & het \\
72b & het & het & het & LOH \\
73a & het & LOH & het & het \\
73b & het & ni & het & het \\
74a & het & ni & ni & LOH \\
75a & het & het & het & het \\
76a & ni & het & het & het \\
78a & het & LOH & ni & ni \\
81a & het & LOH & ni & ni \\
89a & het & het & ni & het \\
92a & het & ni & het & het \\
94a & msi & het & msi & het \\
98a & het & het & het & ni \\
123a & het & LOH & het & LOH \\
\hline
\end{tabular}

LOH Verlust der Heterozygotie

het Heterozygotie

ni nicht informativ

msi Mikrosatelliteninstabilität 
Tabelle 4: Einzeldaten der immunhistochemischen Untersuchung auf die Proteinexpression der TSG p16, Rb und Cyclin D1 sowie der LOHAnalyse für Chromosom 13q.

\begin{tabular}{|c|c|c|c|c|c|c|c|c|}
\hline \multirow[t]{2}{*}{ Fall } & \multicolumn{3}{|c|}{ Immunhistochem. } & \multirow{2}{*}{$\begin{array}{l}\text { D13S232 } \\
\text { 13q11-q12 }\end{array}$} & \multirow{2}{*}{\multicolumn{2}{|c|}{$\begin{array}{c}\text { D13S788 D13S887 } \\
\text { 13q14.1-q14.3 }\end{array}$}} & \multirow{2}{*}{$\begin{array}{r}\text { D13S796 } \\
13 q 32-q 34\end{array}$} & \multirow{2}{*}{$\begin{array}{r}\text { D13S285 } \\
\text { 13q34-qter }\end{array}$} \\
\hline & p16 & CycD1 & pRb & & & & & \\
\hline 1a & - & + & ++ & ni & het & $\mathrm{ni}$ & $\mathrm{LOH}$ & LOH \\
\hline $\mathbf{2 a}$ & - & ++ & +++ & ni & het & $\mathrm{ni}$ & het & het \\
\hline $\mathbf{3 a}$ & - & + & ++ & het & het & $\mathrm{ni}$ & $\mathrm{ni}$ & $\mathrm{ni}$ \\
\hline $4 a$ & - & + & ++ & LOH & LOH & ni & LOH & ni \\
\hline $\mathbf{5 a}$ & - & + & ++ & het & het & ni & het & $\mathrm{LOH}$ \\
\hline $6 a$ & - & + & ++ & het & ni & ni & het & het \\
\hline $7 \mathbf{a}$ & - & + & +++ & ni & het & het & het & ni \\
\hline $\mathbf{8 a}$ & - & +++ & + & ni & $\mathrm{LOH}$ & ni & $\mathrm{LOH}$ & LOH \\
\hline 19a & - & + & +++ & het & het & $\mathrm{ni}$ & het & het \\
\hline 20a & - & + & + & het & het & ni & het & het \\
\hline $21 \mathrm{a}$ & - & + & ++ & $\mathrm{LOH}$ & het & ni & ni & ni \\
\hline $22 a$ & - & ++ & + & het & het & ni & $\mathrm{LOH}$ & het \\
\hline 23a & - & ++ & ++ & het & ni & het & het & het \\
\hline $24 a$ & - & + & +++ & het & het & ni & het & het \\
\hline $25 a$ & \# & + & - & het & het & ni & het & het \\
\hline $26 a$ & - & +++ & +++ & het & ni & ni & ni & ni \\
\hline $27 \mathbf{a}$ & - & +++ & ++ & ni & ni & het & het & ni \\
\hline $28 a$ & - & ++ & - & het & het & ni & LOH & het \\
\hline 29a & - & ++ & + & het & het & het & het & het \\
\hline $30 \mathrm{a}$ & \# & ++ & +++ & $\mathrm{ni}$ & het & $\mathrm{ni}$ & het & $\mathrm{ni}$ \\
\hline $31 \mathrm{a}$ & - & + & + & het & ni & het & ni & ni \\
\hline $51 \mathrm{a}$ & - & ++ & + & $\mathrm{ni}$ & LOH & ni & $\mathrm{LOH}$ & het \\
\hline $53 a$ & - & ++ & +++ & het & het & ni & LOH & het \\
\hline $54 a$ & - & ++ & ++ & ni & het & ni & het & ni \\
\hline $55 a$ & - & +++ & + & ni & ni & het & het & $\mathrm{LOH}$ \\
\hline $56 a$ & - & ++ & + & het & LOH & ni & ni & LOH \\
\hline $57 a$ & - & +++ & + & LOH & $\mathrm{LOH}$ & ni & LOH & ni \\
\hline $59 a$ & - & ++ & +++ & het & ni & ni & het & ni \\
\hline $60 a$ & \# & +++ & ++ & het & ni & ni & $\mathrm{ni}$ & het \\
\hline $61 \mathrm{a}$ & - & + & ++ & ni & ni & ni & het & het \\
\hline $62 a$ & - & +++ & +++ & ni & ni & ni & het & LOH \\
\hline $63 a$ & - & + & +++ & het & ni & het & het & het \\
\hline $64 a$ & - & + & ++ & het & LOH & ni & het & LOH \\
\hline $65 a$ & - & ++ & +++ & het & LOH & ni & het & het \\
\hline $66 a$ & \# & + & ++ & $\mathrm{LOH}$ & het & ni & $\mathrm{LOH}$ & $\mathrm{LOH}$ \\
\hline $67 a$ & - & + & ++ & het & ni & ni & het & ni \\
\hline $68 a$ & \# & + & + & het & het & ni & het & het \\
\hline $69 a$ & - & +++ & ++ & ni & het & $\mathrm{LOH}$ & ni & LOH \\
\hline
\end{tabular}

\# $\quad$ p16 positive Tumorzellen

$+\quad$ CycD1/pRb schwach positive Tumorzellen

++ $\quad$ CycD1/pRb mäßig positive Tumorzellen

$++\quad \mathrm{CycD} 1 / \mathrm{pRb}$ stark positive Tumorzellen

$\begin{array}{ll}- & \text { negative Immunhistologie } \\ \text { LOH } & \text { Loss of Heterozygosity } \\ \text { het } & \text { Heterozygotie } \\ \text { ni } & \text { nicht informativ }\end{array}$


Tabelle 5: Einzeldaten der LOH-Analyse für Chromosom 21q.

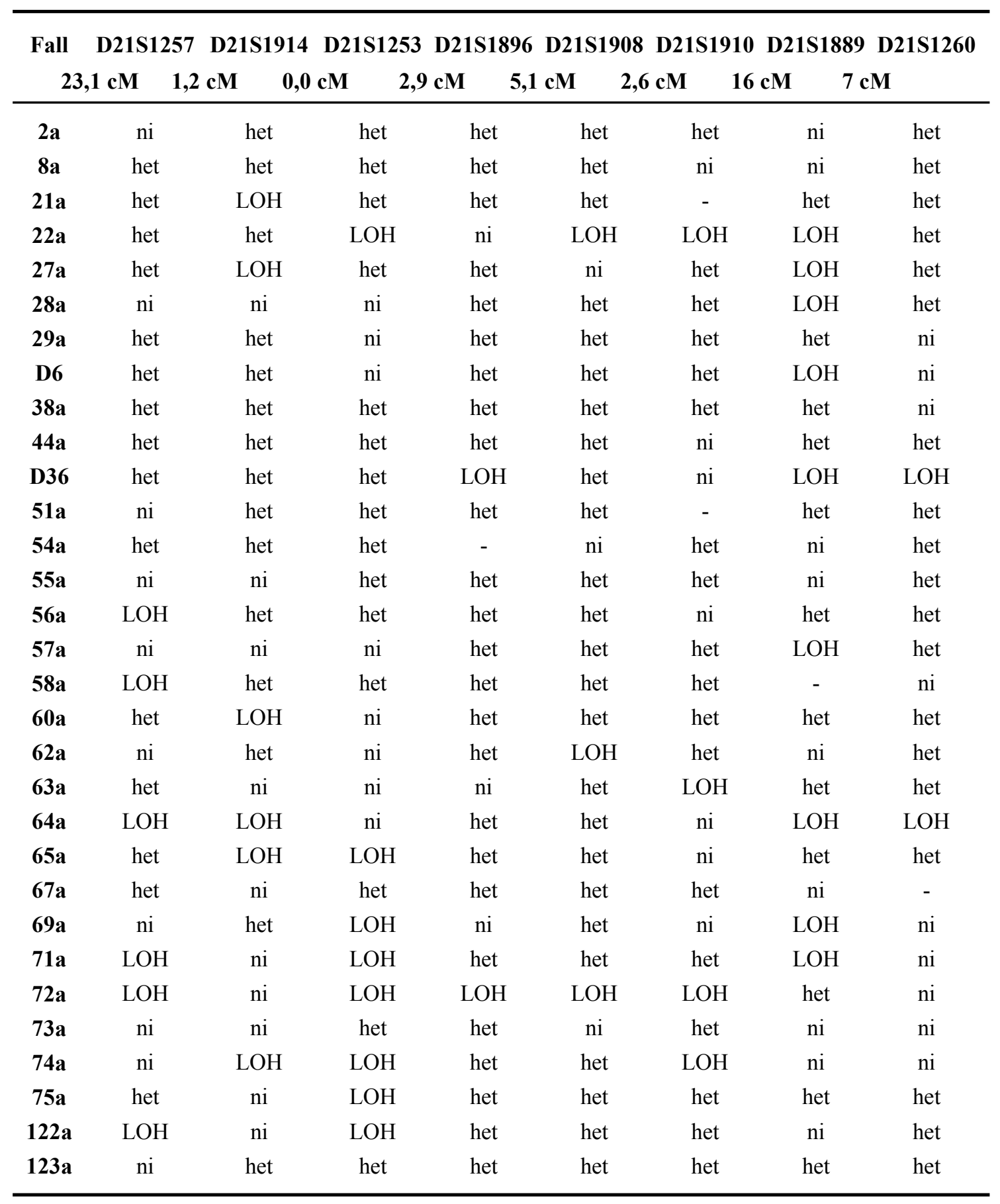

LOH Verlust der Heterozygotie

het Heterozygotie

ni nicht informativ

- $\quad$ nicht getestet 
Tabelle 6: Einzeldaten der LOH-Analyse für Chromsom 8q23.

\begin{tabular}{|c|c|c|c|c|c|c|c|}
\hline Fall & D8S264 & D8S1788 & D8S1824 & D8S1781 & D8S1806 & D8S1798 & D8S262 \\
\hline $1 \mathrm{a}$ & het & het & het & het & het & het & het \\
\hline $1 b$ & het & het & het & het & het & het & het \\
\hline $2 a$ & ni & ni & het & ni & ni & het & ni \\
\hline $2 b$ & ni & ni & het & ni & ni & het & ni \\
\hline $\mathbf{3 a}$ & het & - & ni & het & ni & het & het \\
\hline $4 a$ & het & - & het & - & het & het & het \\
\hline $6 a$ & het & het & het & het & het & ni & het \\
\hline $7 \mathbf{a}$ & het & het & het & het & ni & ni & het \\
\hline $7 \mathbf{b}$ & het & het & het & het & ni & ni & het \\
\hline $8 \mathbf{a}$ & het & ni & het & het & het & ni & het \\
\hline $19 a$ & het & ni & het & ni & het & het & het \\
\hline $20 a$ & het & het & het & het & het & het & ni \\
\hline $21 \mathrm{a}$ & ni & het & het & het & ni & ni & het \\
\hline $23 a$ & het & ni & het & ni & ni & het & ni \\
\hline $24 a$ & $\mathrm{LOH}$ & $\mathrm{LOH}$ & het & het & ni & $\mathrm{LOH}$ & $\mathrm{LOH}$ \\
\hline $25 a$ & het & ni & het & het & ni & het & ni \\
\hline $26 a$ & het & het & ni & het & het & het & het \\
\hline $27 a$ & $\mathrm{LOH}$ & ni & $\mathrm{LOH}$ & ni & het & het & ni \\
\hline $27 b$ & $\mathrm{LOH}$ & ni & $\mathrm{LOH}$ & ni & het & het & ni \\
\hline $28 a$ & het & het & het & het & het & het & ni \\
\hline 29a & het & het & ni & ni & het & het & het \\
\hline D6 & $\mathrm{LOH}$ & LOH & ni & ni & $\mathrm{LOH}$ & $\mathrm{LOH}$ & $\mathrm{LOH}$ \\
\hline 30a & $\mathrm{LOH}$ & ni & $\mathrm{LOH}$ & $\mathrm{LOH}$ & ni & $\mathrm{LOH}$ & ni \\
\hline $40 a$ & ni & $\mathrm{ni}$ & het & - & het & het & het \\
\hline $41 \mathrm{a}$ & ni & het & het & - & het & het & $\mathrm{LOH}$ \\
\hline $41 b$ & ni & het & het & - & het & het & het \\
\hline $42 a$ & het & het & het & - & ni & het & $\mathrm{LOH}$ \\
\hline $43 a$ & ni & het & het & het & het & $\mathrm{LOH}$ & ni \\
\hline $43 b$ & ni & het & het & het & het & - & ni \\
\hline $44 a$ & het & ni & het & het & het & ni & het \\
\hline $51 \mathrm{a}$ & $\mathrm{LOH}$ & LOH & $\mathrm{LOH}$ & het & ni & $\mathrm{LOH}$ & $\mathrm{LOH}$ \\
\hline $51 b$ & $\mathrm{LOH}$ & $\mathrm{LOH}$ & $\mathrm{LOH}$ & $\mathrm{LOH}$ & ni & $\mathrm{LOH}$ & $\mathrm{LOH}$ \\
\hline $53 a$ & het & het & $\mathrm{LOH}$ & het & het & het & $\mathrm{LOH}$ \\
\hline $54 a$ & het & het & het & het & ni & het & het \\
\hline 54b & het & het & het & het & ni & het & het \\
\hline $55 a$ & het & ni & $\mathrm{LOH}$ & het & ni & het & ni \\
\hline $56 a$ & het & het & ni & het & ni & het & ni \\
\hline $56 b$ & het & het & ni & het & ni & het & ni \\
\hline $57 \mathbf{a}$ & het & het & ni & $\mathrm{LOH}$ & $\mathrm{LOH}$ & ni & $\mathrm{LOH}$ \\
\hline $58 a$ & het & ni & het & het & het & ni & ni \\
\hline $59 a$ & ni & ni & $\mathrm{LOH}$ & $\mathrm{LOH}$ & ni & $\mathrm{LOH}$ & ni \\
\hline
\end{tabular}




\begin{tabular}{|c|c|c|c|c|c|c|c|}
\hline Fall & D8S264 & D8S1788 & D8S1824 & D8S1781 & D8S1806 & D8S1798 & D8S262 \\
\hline $60 a$ & ni & $\mathrm{LOH}$ & het & ni & $\mathrm{LOH}$ & $\mathrm{LOH}$ & $\mathrm{LOH}$ \\
\hline $61 \mathrm{a}$ & ni & ni & het & het & ni & ni & $\mathrm{LOH}$ \\
\hline $61 b$ & ni & ni & het & het & ni & ni & het \\
\hline $62 a$ & $\mathrm{LOH}$ & ni & $\mathrm{LOH}$ & het & ni & $\mathrm{LOH}$ & $\mathrm{LOH}$ \\
\hline $62 b$ & $\mathrm{LOH}$ & ni & $\mathrm{LOH}$ & het & ni & $\mathrm{LOH}$ & $\mathrm{LOH}$ \\
\hline $63 a$ & ni & het & $\mathrm{LOH}$ & het & het & het & het \\
\hline $64 a$ & ni & het & het & $\mathrm{LOH}$ & het & $\mathrm{LOH}$ & $\mathrm{LOH}$ \\
\hline $65 a$ & $\mathrm{LOH}$ & ni & het & $\mathrm{LOH}$ & het & het & het \\
\hline $65 b$ & $\mathrm{LOH}$ & ni & $\mathrm{LOH}$ & $\mathrm{LOH}$ & het & het & het \\
\hline $66 a$ & ni & ni & ni & $\mathrm{LOH}$ & $\mathrm{LOH}$ & $\mathrm{LOH}$ & ni \\
\hline $67 a$ & het & het & het & het & ni & het & het \\
\hline $67 b$ & $\mathrm{LOH}$ & $\mathrm{LOH}$ & $\mathrm{LOH}$ & $\mathrm{LOH}$ & ni & $\mathrm{LOH}$ & $\mathrm{LOH}$ \\
\hline $68 a$ & ni & het & het & ni & het & het & ni \\
\hline $68 b$ & ni & het & het & ni & het & het & ni \\
\hline $69 a$ & $\mathrm{LOH}$ & ni & het & het & ni & - & $\mathrm{LOH}$ \\
\hline $69 \mathrm{~b}$ & het & ni & het & het & ni & - & $\mathrm{LOH}$ \\
\hline $88 a$ & het & het & het & het & het & ni & het \\
\hline $90 a$ & het & het & het & het & het & het & het \\
\hline $91 \mathrm{a}$ & $\mathrm{LOH}$ & $\mathrm{LOH}$ & $\mathrm{LOH}$ & $\mathrm{LOH}$ & het & - & $\mathrm{LOH}$ \\
\hline $91 b$ & $\mathrm{LOH}$ & $\mathrm{LOH}$ & $\mathrm{LOH}$ & LOH & het & - & $\mathrm{LOH}$ \\
\hline $92 a$ & het & $\mathrm{LOH}$ & $\mathrm{LOH}$ & het & $\mathrm{LOH}$ & $\mathrm{LOH}$ & ni \\
\hline $93 a$ & het & het & $\mathrm{LOH}$ & $\mathrm{LOH}$ & ni & $\mathrm{LOH}$ & ni \\
\hline 93b & het & het & $\mathrm{LOH}$ & $\mathrm{LOH}$ & ni & $\mathrm{LOH}$ & ni \\
\hline $94 a$ & het & ni & het & het & het & het & het \\
\hline 95a & het & het & het & het & het & het & ni \\
\hline $96 a$ & het & het & het & het & het & het & ni \\
\hline $97 \mathbf{a}$ & ni & het & het & het & ni & ni & het \\
\hline $98 \mathbf{a}$ & $\mathrm{LOH}$ & ni & $\mathrm{LOH}$ & $\mathrm{LOH}$ & ni & $\mathrm{LOH}$ & $\mathrm{LOH}$ \\
\hline
\end{tabular}

LOH Verlust der Heterozygotie

het Heterozygotie

ni nicht informativ

- $\quad$ nicht getestet 


\section{EIDESSTATTLICHE ERKLÄRUNG}

Hiermit erkläre ich an Eides statt,

daß gegen mich keine staatsanwaltlichen Ermittlungsverfahren anhängig sind,

daß von mir weder früher noch gleichzeitig ein Habilitationsverfahren durchgeführt oder angemeldet wurde,

daß die vorliegende Habilitationsschrift von mir selbst ohne unzulässige Hilfe Dritter verfaßt und die beschriebenen Ergebnisse von mir selbst gewonnen wurden,

daß die Zusammenarbeit mit anderen Wissenschaftlern und technischen Hilfskräften sowie die Literatur vollständig angegeben sind,

daß mir die geltende Habilitationsordnung bekannt ist.

Berlin, den 20.10.1998 


\section{DANKSAGUNG}

Für die Überlassung des Themas sowie für die Unterstützung meiner klinischen und wissenschaftlichen Arbeit möchte ich Herrn Prof. Dr. V. Jahnke und Herrn Prof. Dr. M. Dietel danken.

Mein Dank gilt weiter Herrn Dr. I. Petersen und Herrn Dr. rer. nat. G. Wolf für die Betreuung der molekularzytogenetischen Arbeiten, die Auswertung der Ergebnisse und die anregenden Diskussionen.

Für die unermüdliche Unterstützung bei der Laborarbeit danke ich Frau Dr. rer. nat. A. Schwendel, Frau Dipl. Biochem. S. Petersen sowie Frau Deutschmann, Frau Schütze und Frau Gruber auf das herzlichste.

Danken möchte ich auch Frau Prof. S.M. Gollin (Institut für Humangenetik der Universität Pittsburgh) für die Möglichkeit, in ihrem Labor arbeiten zu können, Frau PD Dr. G. Thiel für die Erstellung der Karyotypen der etablierten Zellinien und Frau Dr. Küchler für die Hilfe bei der statistischen Auswertung.

Und nicht zuletzt bin ich meinen Eltern für die Unterstützung und das immerwährende Verständnis außerordentlich dankbar. 


\section{Curriculum vitae}

Priv.-Doz. Dr. med. Ulrike Bockmühl, Jahrgang 1963

\section{Ausbildung}

01.09.1970 - 31.08.1982 Schulzeit, Abschluß mit dem Abitur

01.09.1983 - 31.08.1985 Medizinstudium (vorklinische Semester) an der

Humboldt-Universität zu Berlin

01.09.1985 - 31.08.1989 Medizinstudium (klinische Semester) am Universitätsklinikum

Carl Gustav Carus in Dresden

31.08 .1989

Approbation

01.09.1989 - 30.09.1991 Assistenzärztin am Institut für Pathologie des

Universitätsklinikums Carl Gustav Carus in Dresden

01.10.1991 - 31.03.1993 Assistenzärztin an der Universitäts-HNO-Klinik der

Rheinischen Friedrich-Wilhelms-Universität Bonn

seit 01.04 .1993

Assistenzärztin an der Universitäts-HNO-Klinik des Virchow-

Klinikums der Freien Universität und nachfolgend der

Medizinischen Fakultät Charité der Humboldt-Universität zu

Berlin

seit 15.11 .1997

Fachärztin für Hals-Nasen-Ohrenheilkunde

seit 20.07.1999

Oberärztin an der HNO-Klinik der Charité, Humboldt-

Universität zu Berlin

\section{Wissenschaftlicher Werdegang}

1987 Diplomarbeit, Thema: “Analyse zytologischer Befunde der Portio vaginalis cervicis uteri bei Patientinnen unter dem 18. Lebensjahr"

1991 Dissertation, Thema: "Morphologische Untersuchungen zur prognostischen Bedeutung der Nucleolar Organizer Regions (NOR's) beim invasiven duktalen Mammakarzinom" 
seit 1994 Mitarbeit im molekularpathologischen Labor von Prof. Dr. M. Dietel am Institut für Pathologie der Charité

seit 1996 Forschungsförderung durch die DFG

1996 - 1997 Forschungsstipendium des Deutschen Akademischen Austauschdienstes (DAAD) für einen Forschungsaufenthalt am Pittsburgh Cancer Institut (USA) bei Herrn Prof. E. Myers und Frau Prof. S. M. Gollin

1999 Habilitation, Thema: "Molekularzytogenetische Charakterisierung von Kopf-HalsKarzinomen"

\section{Mitgliedschaften}

Deutsche Gesellschaft für Hals-Nasen-Ohrenheilkunde \& Kopf-Hals-Chirurgie American Association for Cancer Research (AACR)

Berlin-Brandenburgische Cochlear Implant Gesellschaft e.V. 